\title{
Advances in CNS PET: the state-of-the-art for new imaging targets for pathophysiology and drug development
}

\author{
Stuart P. McCluskey ${ }^{1,2} \cdot$ Christophe Plisson $^{1}$ • Eugenii A. Rabiner ${ }^{1} \cdot$ Oliver Howes $^{2}$
}

Received: 7 May 2019 / Accepted: 15 August 2019 / Published online: 21 September 2019

(C) The Author(s) 2019

\begin{abstract}
Purpose A limit on developing new treatments for a number of central nervous system (CNS) disorders has been the inadequate understanding of the in vivo pathophysiology underlying neurological and psychiatric disorders and the lack of in vivo tools to determine brain penetrance, target engagement, and relevant molecular activity of novel drugs. Molecular neuroimaging provides the tools to address this. This article aims to provide a state-of-the-art review of new PET tracers for CNS targets, focusing on developments in the last 5 years for targets recently available for in-human imaging.

Methods We provide an overview of the criteria used to evaluate PET tracers. We then used the National Institute of Mental Health Research Priorities list to identify the key CNS targets. We conducted a PubMed search (search period 1st of January 2013 to 31st of December 2018), which yielded 40 new PET tracers across 16 CNS targets which met our selectivity criteria. For each tracer, we summarised the evidence of its properties and potential for use in studies of CNS pathophysiology and drug evaluation, including its target selectivity and affinity, inter and intra-subject variability, and pharmacokinetic parameters. We also consider its potential limitations and missing characterisation data, but not specific applications in drug development. Where multiple tracers were present for a target, we provide a comparison of their properties.

Results and conclusions Our review shows that multiple new tracers have been developed for proteinopathy targets, particularly tau, as well as the purinoceptor P2X7, phosphodiesterase enzyme PDE10A, and synaptic vesicle glycoprotein 2A (SV2A), amongst others. Some of the most promising of these include ${ }^{18} \mathrm{~F}-\mathrm{MK}-6240$ for tau imaging, ${ }^{11} \mathrm{C}-\mathrm{UCB}-\mathrm{J}$ for imaging SV2A, ${ }^{11} \mathrm{C}$-CURB and ${ }^{11} \mathrm{C}-\mathrm{MK}-3168$ for characterisation of fatty acid amide hydrolase, ${ }^{18} \mathrm{~F}$-FIMX for metabotropic glutamate receptor 1 , and ${ }^{18} \mathrm{~F}-\mathrm{MNI}-444$ for imaging adenosine $2 \mathrm{~A}$. Our review also identifies recurrent issues within the field. Many of the tracers discussed lack in vivo blocking data, reducing confidence in selectivity. Additionally, late-stage identification of substantial off-target sites for multiple tracers highlights incomplete preclinical characterisation prior to translation, as well as human disease state studies carried out without confirmation of test-retest reproducibility.
\end{abstract}

Keywords PET $\cdot$ CNS $\cdot$ Brain $\cdot$ First-in-human

This article is part of the Topical Collection on Neurology

Stuart P. McCluskey

stuart.mccluskey@invicro.co.uk

1 Invicro LLC, A Konica Minolta Company, Burlington Danes Building, Imperial College London, Hammersmith Hospital, Du Cane Road, London W12 0NN, UK

2 Psychiatric Imaging Group, MRC London Institute of Medical Sciences, Imperial College London, Hammersmith Hospital, London, UK

\section{Introduction}

Neurological and neuropsychiatric disorders are a major contributor to global disease burden and economic costs $[1,2]$. This highlights the importance of identifying the molecular mechanisms underlying them and evaluating novel therapeutic strategies to combat them.

It is well known that drug development programmes are expensive and risky due to low success rates. For therapeutics targeting the central nervous system (CNS), these issues are amplified, with substantially longer average development 
times and reduced success rate over non-CNS targets, such as those for cardiac or gastrointestinal disorders [3]. One contributor to CNS drug failure is the additional pharmacokinetic challenge of crossing the blood-brain barrier (BBB) [3]. Peripheral measurement of drug concentration is often a poor representation of availability within the CNS; therefore, knowing if a drug has reached the brain in high enough concentrations for pharmacological effect is important [4].

Molecular imaging techniques such as positron emission tomography (PET) have the ability to quantitatively characterise molecular targets and target occupancy, within the CNS. PET utilises short-lived isotopes which decay to emit two gamma photons in approximately opposite directions. The molecular sensitivity of PET imaging, and the capacity to selectively image targetligand interactions in vivo at tracer doses, gives this technique the ability to probe CNS targets with high selectivity and sensitivity in humans [5]. This information can be utilised to further the understanding of pathologies and identify new targets for therapeutic intervention, allowing innovative strategies to be designed. Additionally, molecular imaging has the ability to characterise the pharmacokinetics and selectivity of CNStargeted drugs and is now a common strategy in drug development programmes. This allows greater characterisation of investigational drugs, potentially reducing the risk of costly late-stage failure and increasing overall efficiency of drug development programmes.

PET imaging has an advanced understanding of a number of neurological and psychiatric conditions. Some well-known examples include ${ }^{18}$ F-FDG for imaging alterations in glucose metabolism across disease states $[6,7],{ }^{18}$ F-FDOPA to index dopamine synthesis capacity in Parkinson's disease (PD) and schizophrenia [8], ${ }^{11} \mathrm{C}$-PIB for tracking the accumulation of amyloid $\beta$ plaques in Alzheimer's disease (AD) [9], and multiple tracers for imaging translocator protein in multiple disease states including AD, PD, and Creutzfeldt-Jakob disease [10].

The aim of this review is to provide an overview of recent developments in PET imaging probes for CNS targets in humans and to evaluate the potential of PET imaging tools available. A critical assessment of both the pre-clinical and in-human characterisation of the novel PET tracers is conducted. For each tracer, we summarise the evidence of its properties in terms of criteria for evaluating CNS tracers as tools for the investigation of pathophysiology or target engagement by a drug. Whilst these properties are important for the use of a tracer in drug evaluation, specific applications of tracers for drug development are beyond the scope of this review. Potential confounds of the tracers are discussed, and areas of in vivo characterisation currently lacking in the literature highlighted. Where sufficient data is available, comparisons between tracers are conducted and future potential of both tracer and target proposed.

The cut-off for 'recent' was defined as a first peerreviewed publication from the last 6 years (1st of January 2013 to 31 st of December 2018 inclusive). 'New' targets were defined as having no in-human PET tracers published for that target prior to this timeframe, or where the tracer(s) published within this timeframe were judged to represent a significant advance over tracers published prior to this period.

\section{Criteria for evaluating CNS PET tracers and outcome parameters}

This section gives an overview of what is required for a CNS PET tracer and highlights the challenges to overcome in the development of a successful tracer. For an in-depth comprehensive review on criteria for CNS PET tracers, refer to the review by Victor Pike (2016) [11].

\section{Ability to accumulate within the CNS}

An obvious requirement for a CNS PET tracer is the accumulation within the CNS; however, achieving this in tracer design is non-trivial. Multiple factors play a key role in determining the success or failure of a tracer in this facet. Some published 'rule of thumb' criteria for passive diffusion into the brain are highlighted in Box 1 $[11,12]$. High-molecular-weight compounds often struggle to cross the tight junction in the blood-brain barrier leading to no or very slow accumulation within the brain and rendering them unsuitable for PET imaging [11]. The lipophilicity of a compound is essential for accumulation and availability within the brain. This is often determined from the partition coefficient between octanol and aqueous phases at physiological $\mathrm{pH}$, quantified as the $\log \mathrm{D}_{7.4}$. If the $\log _{7.4}$ is too low, then the tracer will be unable to passively cross lipid membranes preventing accumulation in the brain, unless there is active transport. However, if it is too high, the compound will preferentially remain within lipid bilayers, increasing nonspecific binding and decreasing the availability and dynamic range. 


\title{
Box 1. Published 'rule of thumb' criteria for CNS PET radiotracers.
}

Molecular weight $<500 \mathrm{kDa}$

$\log \mathrm{D}_{7.4}$ between 1 and 5

$\mathrm{pK}_{\mathrm{a}}$ of most basic site $<9.5$

No. hydrogen bond donors $<3$

No. heteroatoms $(\mathrm{O}, \mathrm{N}, \mathrm{S}, \mathrm{P}$, or halogen $)<9$

Topological polar surface area $<90 \AA^{2}$

Other parameters such as charge and polarity play a part in the lipophilicity, but have also been linked to increasing susceptibility for being efflux transporter substrates [13, 14]. Efflux transporters are responsible for the inability of a large proportion of drugs and pharmaceuticals to accumulate in the brain, shuttling the compounds back into the bloodstream too fast to allow accumulation [11]. These efflux transporters, which include P-glycoprotein (P-gp), multidrug resistance-associated protein (MDR), and breast cancer-resistant protein (BCRP), vary considerably between species and often render substrates useless for CNS applications [15].

\section{Suitable pharmacokinetics and selectivity}

The ability to cross the BBB is an essential criterion for all CNS PET tracers, but the pharmacokinetics and selectivity ultimately determine a PET tracer's usefulness. Factors impeding or reducing its ability to accurately report on its target can severely limit its applicability or render it unusable. Some of these key parameters are listed in Box 2.

\author{
Box 2. Pharmacokinetic and selectivity criteria for a successful CNS PET tracer \\ High affinity for target: usually nanomolar- sub nanomolar affinity \\ High (or adequate) target selectivity \\ Kinetic profile suitable for mathematical modelling \\ High dynamic range \\ Suitable metabolic profile \\ Absence of brain penetrant metabolites \\ Low variability both inter- and inta-subject \\ Biologically relevant target
}


While an ideal PET tracer would be outstanding in all of the criteria listed in Box 2, in practice, this is often unachievable. Fully characterising the limitations of a tracer allows informed decisions on its applicability to answer the proposed question, and importantly when it is not. For example, consider a hypothetical tracer which has overall good properties, but shows additional high off-target binding within the brain. In brain areas where both target and off-target sites are present, this will often render the tracer unable to answer the desired question. However, in brain regions with low or no off-target site, it may be possible to accurately quantify the target and gain an accurate answer. Therefore, if the off-target site is known and well-characterised, then a tracer with offtarget binding in some brain regions may, nevertheless, be useful for studies where the focus is the regions with low off-target binding.

\section{Common outcome parameters}

To effectively interpret the results presented in this review, an understanding of the various outcome parameters used in these studies is necessary. Below is an overview of some of the most common outcome parameters used in PET studies, both pre-clinically and in-human, summarised in
(Table 1). For a comprehensive review, see reference [11] or refer to the Turku PET centre website (http://www. turkupetcentre.net).

$\mathrm{SUV}_{\text {target }}$ is the standardised uptake value of the target region, $\mathrm{SUV}_{\text {other }}$ is the standardised uptake value of other regions, $C_{\mathrm{T}}$ is the concentration of PET tracer in tissue, $C_{\mathrm{P}}$ is the concentration of PET tracer in plasma, $V_{\mathrm{T}}$ (tissue) is the tissue volume of distribution, $V_{\mathrm{T}}(\mathrm{ND})$ is the non-displaceable volume of distribution, $\mathrm{BP}_{\mathrm{ND}}$ (baseline) is the non-displaceable binding potential at baseline, $\mathrm{BP}_{\mathrm{ND}}$ (drug) is the nondisplaceable binding potential at after drug administration, $\mathrm{OP}_{\text {test }}$ is the outcome parameter measurement from an initial test scan, $\mathrm{OP}_{\text {retest }}$ is the outcome parameter measurement from a repeated scan, SD is standard deviation, BSMSS is between subject mean sum of squares, WSMSS is the within-subject mean sum squares, $K$, in this case, is the number of repeated observations.

The most simplistic outcome measures quote the proportion of radiotracer in the target region at a designated time, such as the percentage injected dose per gram of tissue (\%ID) or the injected dose corrected for subject weight, standardised uptake value (SUV). Ratios of uptake between areas (SUVr) provide easy to obtain and useful outcome parameters in early characterisation of a PET tracer and can be justified in human studies when assumptions

Table 1 Basic description of common outcome parameters used in PET imaging studies

\begin{tabular}{|c|c|c|c|}
\hline Outcome parameter & Full name & Equation & Description \\
\hline$\% \mathrm{ID}$ & Percentage injected dose & $\frac{\% \text { of injected dose }}{\mathrm{g} \text { of tissue }}$ & $\begin{array}{l}\text { Percentage of injected radiotracer per unit } \\
\text { volume (or weight) of tissue }\end{array}$ \\
\hline SUV & Standardised uptake value & $\frac{\% \text { ID } \times 100}{\text { subject weight }}$ & Weight corrected parameter of $\%$ ID \\
\hline SUVr & Relative SUV & $\frac{\mathrm{SUV}}{\mathrm{SUV}_{\text {target }}}$ & $\begin{array}{l}\text { Ratio between SUV values between target } \\
\text { and other regions }\end{array}$ \\
\hline$V_{\mathrm{T}}$ & Volume of distribution & $\frac{C_{\mathrm{T}}}{C_{\mathrm{P}}}$ & $\begin{array}{l}\text { Ratio of tracer concentration between tissue } \\
\text { and plasma at equilibrium }\end{array}$ \\
\hline DVR & Distribution volume ratio & $\frac{V_{\mathrm{T}} \text { (tissue) }}{V_{\mathrm{T}(\mathrm{ND})}}$ & $\begin{array}{l}\text { Ratio of } V_{\mathrm{T}} \text { between tissue and non-displaceable } \\
\text { tissue component (often given by reference } \\
\text { region when available) }\end{array}$ \\
\hline $\mathrm{BP}_{\mathrm{ND}}$ & $\begin{array}{l}\text { Binding potential } \\
\text { non-displaceable }\end{array}$ & $\frac{V_{\mathrm{T} \text { (tissue) }}}{V_{\mathrm{T}(\mathrm{ND})}}-1$ & $\begin{array}{l}\text { Normalised DVR; when } \\
\qquad V_{\mathrm{T}(\text { tissue })}=\underline{V}_{\mathrm{T}(\mathrm{ND})}, \mathrm{BP}_{\mathrm{ND}}=0\end{array}$ \\
\hline RO & Receptor occupancy & $\frac{\mathrm{BP}_{\mathrm{ND} \text { (baseline) }}-\mathrm{BP}_{\mathrm{ND}(\mathrm{dnug})}}{\mathrm{BP}_{\mathrm{ND} \text { (baseline) }}} \times 100 \%$ & $\begin{array}{l}\% \text { of receptors occupied, usually by drug } \\
\text { administration }\end{array}$ \\
\hline TRV & Test-retest value & $\left|\frac{\mathrm{OP}_{\text {test }}-\mathrm{OP}_{\text {retest }}}{\left(\mathrm{OP}_{\text {test }}+\mathrm{OP}_{\text {retest }}\right) / 2}\right| \times 100 \%$ & $\begin{array}{l}\text { Average variation of OP from two scans on } \\
\text { the same subject without intervention }\end{array}$ \\
\hline $\mathrm{COV}$ & Coefficient of variance & $\frac{\mathrm{SD}}{\text { Mean }} \times 100 \%$ & Average variation of $\mathrm{OP}$ within a group \\
\hline ICC & Intraclass correlation coefficient & $\frac{\text { BSMSS-WSMSS }}{\text { BSMSS }+(K-1) \times \text { WSMSS }}$ & $\begin{array}{l}\text { Comparison of reliability of within-subject } \\
\text { variability to between-subject variability }\end{array}$ \\
\hline
\end{tabular}


can be made regarding constant radiotracer delivery and brain non-displaceable binding. However, for many tracers and applications in humans, they do not provide sufficient characterisation of the target to be useful. A useful parameter is the ratio of tracer in a target region in comparison with the tracer in the blood plasma. For reversible tracers, this ratio becomes constant at equilibrium and is quoted as the volume of distribution, $V_{\mathrm{T}}$ [16]. $V_{\mathrm{T}}$ is commonly used as an outcome parameter in human studies of reversible tracers. As a parameter, $V_{\mathrm{T}}$ is a measure of both specific (displaceable) and non-specific (non-displaceable) signal and, as such, can be insensitive to change or differences, especially if background signal is relatively high (where a large change in target availability/density may only cause small changes in observed $V_{\mathrm{T}}$ ). Additionally, to calculate $V_{\mathrm{T}}$, blood sampling, and metabolite correction is required, increasing the time, effort, and invasiveness of PET procedures. Correcting for background non-specific binding (non-displaceable binding seen upon blocking the target, denoted ND) across the brain allows a more sensitive measure of target alterations.

Often for a given tracer, regions of the brain contain no or negligible quantities of the target protein and represent only non-specific binding. This region can thus serve as a reference region to account for non-specific binding in the region of interest. As non-displaceable binding is generally assumed to be constant across the brain, the very useful ratio of $V_{\mathrm{T}} / V_{\mathrm{ND}}$ (DVR) can be easily obtained when a reference region is present. The SUVr between the region of interest and the reference region at equilibrium gives DVR (and $\mathrm{BP}_{\mathrm{ND}}$ ) without the necessity of plasma input methods (as plasma component cancels out) [16]. However, this calculation should always be initially validated against full plasma input methods in humans to determine suitability and bias. DVR and $\mathrm{BP}_{\mathrm{ND}}$ are parameters which are more sensitive to alteration of target availability/density for reversible tracers than other outcomes, with a decrease of $100 \%$ $\mathrm{BP}_{\mathrm{ND}}$ representing full block of the target. As DVR or $\mathrm{BP}_{\mathrm{ND}}$ are intrabrain comparison outcomes, they give no information on the overall brain uptake of a tracer.

An important parameter to consider in the design of studies is the variability of the measurement, as this influences the sample size required to sufficiently power a study. Variability can be considered as within-subject (measured by test-retest value (TRV)) and between-subjects, which is often expressed as the coefficient of variation (COV). For tracers where these values are high, delineating small alterations in outcome parameters becomes increasingly more difficult as measurement variability obscures effects. As a rule of thumb, alterations in outcome parameters similar or less than inherent variability will not be accurately quantified on small-scale studies. The intraclass correlation coefficient (ICC) is a measure of reliability comparing intra- and inter-subject variability.
Lastly, it is important to remember that multiple factors may contribute to the alteration of an outcome parameter in vivo. Some of these include differences in target expression, alteration in target affinity (i.e. high or low-affinity states), internalisation of a target, and changes in endogenous occupancy [17].

Box 3 Abbreviations

\begin{tabular}{|c|c|}
\hline TRV & Test retest value \\
\hline $\mathrm{AD}$ & Alzheimer's disease \\
\hline ALS & Amyotrophic lateral sclerosis \\
\hline $\mathrm{A}_{2 \mathrm{~A}}$ & Adenosine $2 \mathrm{~A}$ \\
\hline$\alpha 7-n A C h R$ & $\alpha-7$ subtype of the nicotinic acetylcholine receptor \\
\hline BBB & Blood-brain barrier \\
\hline$B_{\max }$ & Target density \\
\hline $\mathrm{BP}_{\mathrm{ND}}$ & Binding potential (non-displaceable) \\
\hline cAMP & Cyclic adenosine monophosphate \\
\hline CBD & Corticobasal degeneration \\
\hline cGMP & Cyclic guanosine monophosphate \\
\hline $\mathrm{CN}$ & Cognitively normal \\
\hline CNS & Central nervous system \\
\hline $\mathrm{COV}$ & Coefficient of variance \\
\hline COX & Cyclooxygenase \\
\hline DLB & Dementia with Lewy bodies \\
\hline DVR & Distribution volume ratio \\
\hline FAAH & Fatty acid amide hydrolase \\
\hline FDA & Food and Drugs Administration \\
\hline GABA & $\gamma$-aminobutyric acid \\
\hline GBq & Gigabecquerel \\
\hline $\mathrm{HC}$ & Healthy controls \\
\hline HD & Huntington's disease \\
\hline ICC & Intraclass correlation coefficient \\
\hline I2BS & Imidazoline 2 subtype binding site \\
\hline $\mathrm{KO}$ & Knockout \\
\hline LBD & Lewy body disorders \\
\hline M & Molar \\
\hline MAO & Monoamine oxygenase \\
\hline MCI & Mild cognitive impairment \\
\hline mGluR & Metabotropic glutamate receptor \\
\hline MRI & Magnetic resonance imaging \\
\hline MS & Multiple sclerosis \\
\hline NFT & Neurofibrillary tangles \\
\hline NHP & Non-human primate \\
\hline OLR & Opioid-like receptor \\
\hline OR & Opioid receptor \\
\hline PD & Parkinson's disease \\
\hline PDE & Cyclic nucleotide phosphodiesterase \\
\hline PET & Positron emission tomography \\
\hline PSP & Progressive supranuclear palsy \\
\hline RO & Receptor occupancy \\
\hline SPECT & Single-photon emission computed tomography \\
\hline SRTM & Simplified reference tissue model \\
\hline SUV & Standardised uptake value \\
\hline SUVr & Relative standardised uptake value \\
\hline SV2A & Synaptic vesicle glycoprotein 2A \\
\hline TCM & Tissue compartment model \\
\hline TDP-43 & TAR DNA-binding protein \\
\hline TRPV1 & Vanilloid receptor \\
\hline TSPO & Translocator protein \\
\hline VAChT & Vesicular acetylcholine transporter \\
\hline $\mathrm{V}_{\mathrm{T}}$ & Volume of distribution \\
\hline $\mathrm{K}-\mathrm{OR}$ & Kappa opioid receptor \\
\hline 5-HT & Serotonin \\
\hline$\% \mathrm{ID}$ & Percentage injected dose \\
\hline
\end{tabular}




\section{Methods}

\section{Search strategy}

The list of tracer and target systems was based on the national institute of mental health research priorities list (https://www. nimh.nih.gov/research-priorities/therapeutics/cns-radiotracertable.shtml) and supplemented by hand-searching of references, including of recent review articles [18, 19]. PET tracers with the first-in-human peer-review publication between 2013 and 2018 were considered. This was refined with further inclusion criterion of PET tracers for targets that had not previously been imaged in man, or where the tracer(s) published within this timeframe represented a 'significant advancement' over those published prior to 2013. A significant advancement was defined as the potential of a tracer to answer questions about the targets that were previously unobtainable or with much greater accuracy. Additionally, PET tracers with firstin-human studies reported at conference between 2013 and 2018, but without associated first-in-human peer-review publication, were also included if other PET tracers for that target met the inclusion criterion of the article.

PubMed literature search terms including (CNS and PET), (brain and PET and first in human), ('target' and PET), and ('target' and imaging) were used to identify tracers translated into human. Tracers meeting selectivity criteria were systematically reviewed via PubMed literature search of all articles containing the ['tracer'] term, including previous names and isotopologues, including non-radioactive molecule. The published literature for each in-human tracer was collated and compared with other tracers using the evaluation criteria outlined below.

\section{Evaluation criteria}

In-human tracers were assessed via two categories of criteria: the selectivity of the tracer in vivo and its pharmacokinetic profile. Selectivity was primarily assessed from in vivo blocking and occupancy data. In vitro techniques were also considered, especially in cases where specific off-target sites were investigated. Where a known off-target specific binding site was found for a tracer, discussion of the potential impact on quantification of the desired target is also conducted.

In vitro studies were deemed insufficient to extrapolate to proof of in vivo selectivity. Self-blocking and structurally dissimilar heterologous blocking with selective agents in vivo allow assessment of total specific binding and total selective binding, respectively, at full occupancy. Tracers were deemed to have proven high specificity or high selectivity if the outcome parameter approached saturation value upon relevant blocking experiment. At full occupancy, theoretical alteration of $\mathrm{BP}_{\mathrm{ND}}=0, \mathrm{DVR}=1, \mathrm{SUVr}=1, \mathrm{RO}=100 \%$. For situations where full occupancy is unobtainable, i.e. due to toxicity, Lassen plots can provide a suitable alternative; however, they become less accurate at lower occupancies [20]. For parameters without correction for non-displaceable binding, such as $V_{\mathrm{T}}$ and SUV, the magnitude of decrease depends on the proportion of non-displaceable binding present and therefore is expected to show lower relative alterations than other outcome parameters.

Studies which specifically investigate off-target binding were also investigated and potential impact on tracer assessed. Compounds which bind to sites other than the target site can be used in blocking studies to determine if the tracer also binds to these off-target sites. Additionally, self-blocking experiments where a reduction in signal is observed in regions where no specific signal is expected (i.e. in brain regions where no target is present, in target knockout models, or in healthy controls (HC) tissues not expressing the target of interest) highlight areas of offtarget specific binding which can perturb target quantification.

The pharmacokinetic profile of a tracer encompasses multiple parameters essential for tracer performance in vivo. The ability to efficiently cross the BBB is fundamental to a CNS PET tracers' success. Outcome measures related specifically to brain signal, such as $\mathrm{SUV}$ or $V_{\mathrm{T}}$, were assessed for evidence of this. Further observation of a PET tracers' regional brain distribution provides circumstantial evidence of selectivity when correlating with known distribution of the target.

The accuracy and reliability of modelling techniques to produce outcome parameters depend partially on the kinetics of a tracer. Slow kinetics generally requires longer scan times and produces more variable outcome measures, reducing the usefulness of a tracer.

The dynamic range of a tracer is the proportion of signal alteration that can occur under a perturbed system (i.e. during an occupancy study or altered expression in disease state). A high dynamic range allows smaller alterations in a system to be accurately detected, thus increasing sensitivity. Tracers with low dynamic range (for example due to high nonspecific binding) may not be able to accurately determine even large alterations in target availability, rendering the tracer incapable of quantifying target accurately.

The presence of a reference region, an area of the brain with no or very low specific signal, allows simplified calculation of outcome parameters such as DVR and $\mathrm{BP}_{\mathrm{ND}}$ without invasive arterial input functions. This allows a simplified scanning procedure, reducing invasiveness and potentially improving the accuracy of outcome parameters. A reference region was deemed validated if there was evidence of a strong correlation between the outcome parameters calculated from full arterial input function and reference tissue methods. Any evidence of consistent bias of reference region models compared to plasma input methods was reported (Tables 2, 3, and 4).

The metabolism of a tracer can play a key role in the success or failure of a tracer. Rapid metabolism in vivo reduces the availability of tracer to bind to the target, reducing signal magnitude. Additionally, the presence of radiometabolites within the brain can have a huge impact on the quantification 
of the desired target. Evidence relating to rapid metabolism, radiometabolite formation within the brain, or peripheral formation of brain penetrant metabolites is discussed along with potential impact on tracer performance.

Intra- and inter-subject variability was assessed from published in human data quoting TRV and ICC or COV, respectively. Higher variability reduces the usefulness of a PET tracer, requiring larger sample size studies to delineate alterations between populations. Therefore, the clinical utility of tracers with moderate to high variability is more limited than those with low variability. TRV $<10 \%, \mathrm{COV}<10 \%$, and ICC $>0.8$ were deemed as low variability and a high intraclass correlation coefficient, respectively.

Lastly, the radiochemical parameters of the PET tracer can also have an impact on outcome parameters. For human studies, it is assumed that high radiochemical purity is a minimum requirement and is not discussed within. However, the ratio of radioactive tracer to non-radioactive isotopologue can vary substantially between tracers and individual syntheses. The common measurements of this are either specific activity, with units of $\mathrm{GBq} / \mu \mathrm{g}$ or molar activity $\mathrm{GBq} / \mu \mathrm{mol}$ [153]. As a directly comparable term between tracers and targets, molar activity is used throughout this article. Low molar activity can result in high injected mass of non-radioactive compound and can cause non-negligible self-blocking, with a magnitude dependant on tracer and target.

\section{Review format}

The CNS targets are discussed in three sections: proteinopathies, which focusses on imaging of misfolded protein aggregates; receptors and transporter proteins; and enzymatic targets. The evidence for tracer selectivity and pharmacokinetic parameters is summarised in tables at the beginning of each section along with a short summary of the current advantages and disadvantages of each tracer. Within this table blocking study, results are quoted from the region of highest alteration, at the largest target occupancy dose. Studies with highly structurally related blocking agents are included within homologous blocking studies due to the high likelihood of displacing the tracer from all specific binding sites. Reference regions listed have been validated in humans unless otherwise stated.

Each target is introduced and its relevance in human disease state is summarised. The in-human tracers for the target are discussed collectively, outlining the evidence for selectivity followed by pharmacokinetic suitability. Where tracer limitations or lacking evidence is apparent, this is also highlighted within these sections. When available, results from in-human disease states are also succinctly summarised. Overall evaluation of the target and the available tracers' applicability for imaging it is summarised in the final discussion section of each target.

\section{Targets for proteinopathies}

Proteinopathy is the abnormal accumulation of misfolded protein. These insoluble aggregates are commonplace in neurodegenerative diseases such as $\mathrm{AD}$ and $\mathrm{PD}$ and are thought to be the driving factors in pathology [154]. Three major forms of protein aggregates known to contribute to proteinopathy in the human brain are amyloid $\beta$ plaques, tau, and $\alpha$-synuclein $[154,155]$. There have been a number of well-established PET tracers used for detection of amyloid in humans for well over a decade [156], and as such, amyloid tracers fall out of the scope of this review. In contrast, to date, $\alpha$-synuclein has no promising in-human PET tracers. The field of tau imaging, however, has erupted in the last 5 years with the emergence of the first widely successful tau tracers and the highest number of tracers progressing into human studies of any CNS target within that time.

\section{Tau imaging}

The aggregation of tau proteins into neurofibrillary tangles (NFTs) is widely associated with AD as a pathologic hallmark [154]. Its accumulation has been shown to correlate with the disease progression and symptoms of the disease [154], with the 'Braak staging' of AD based on the spread of NFTs across the brain [157]. Therefore, there is a large dynamic alteration in NFT accumulation from cognitively normal, through to high risk asymptomatic, mild cognitive impairment, and demented patients. As an example, the first published PET study involving autosomal dominant AD showed cognition correlated strongly with tau imaging, while amyloid $\beta$ concentration increased significantly over cognitively normal controls approximately 15 years prior to the onset of disease, highlighting the importance of both proteinopathies in the AD pathology [158].

Multiple other neurodegenerative diseases besides AD show characteristic accumulation patterns of tau, often referred to collectively as tauopathies. For neuroimaging of $\mathrm{AD}$ and other tauopathies, tracers targeting tau are very attractive for diagnosis and staging. However, until recently, no tau imaging agents were available.

The first tracers investigated, including ${ }^{11} \mathrm{C}-\mathrm{PBB} 3$ and ${ }^{18} \mathrm{~F}$ FDDNP, showed an array of restricting issues including low brain uptake, brain-penetrating metabolites, and amyloid $\beta$ binding, respectively, hindering wide-scale use in humans [159-162]. Since then, from 2013 to 2018, we identified 7 tracers with first-in-human studies, and a further 5 have clinical trials initiated or initial in-human results presented at conferences (Table 2) Of these, ${ }^{18} \mathrm{~F}-\mathrm{AV}-1451$ and the ${ }^{18} \mathrm{~F}$-THK series are the most widely studied [163]. 


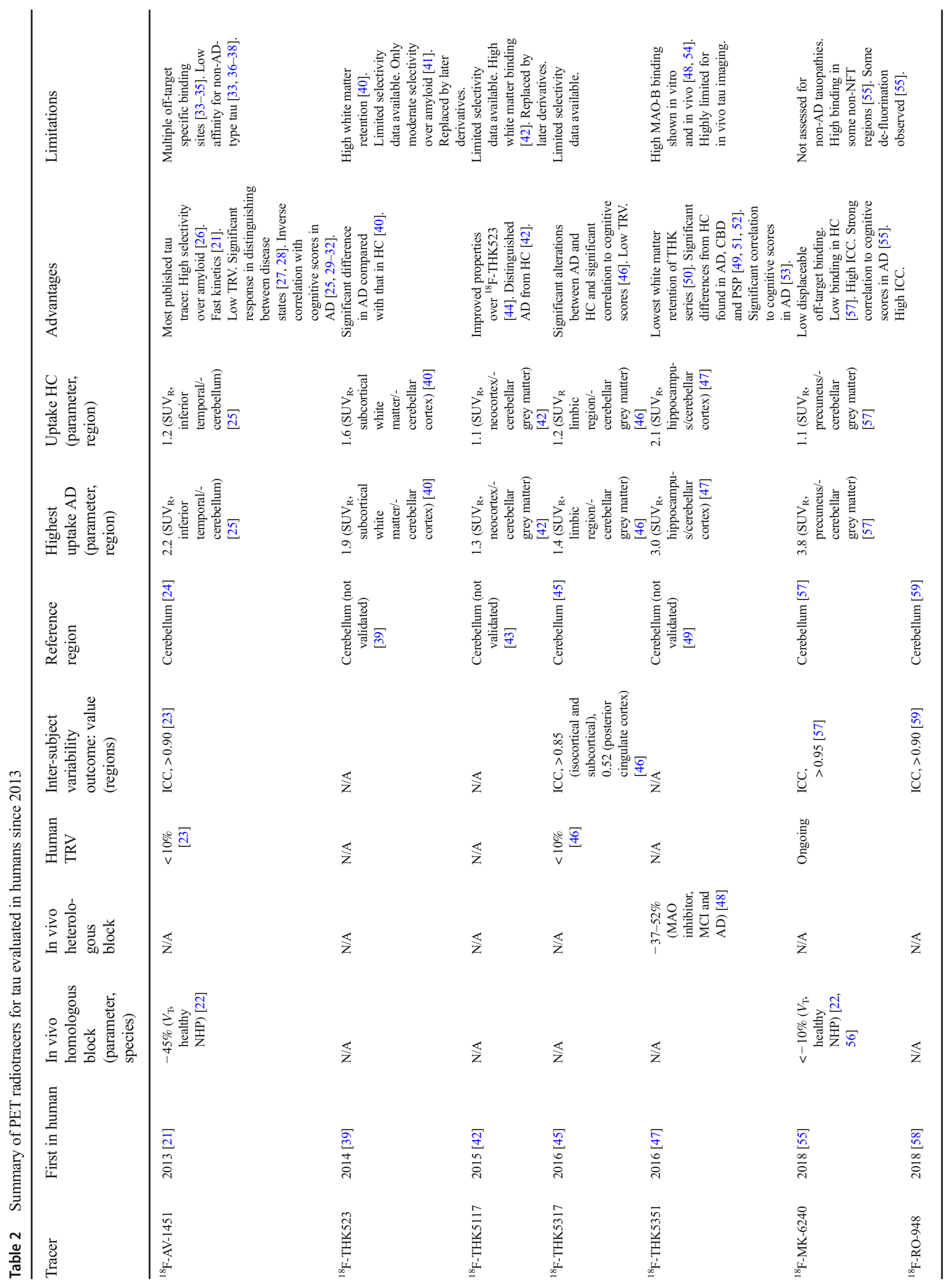




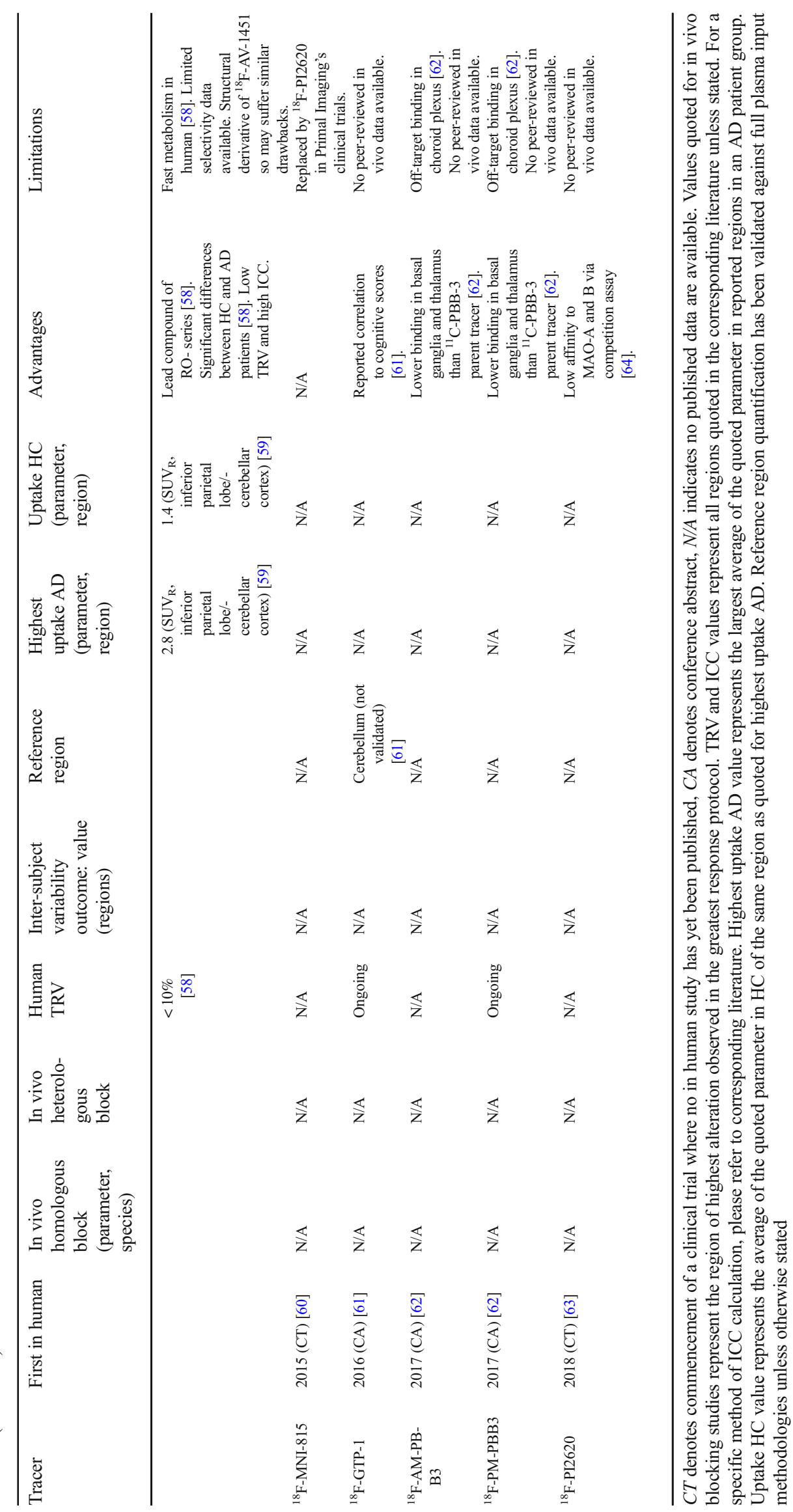


All tracers reported in peer-reviewed journals have shown significant differences between $\mathrm{AD}$ and non-AD controls in brain areas associated with tau aggregation (Table 2). Additionally, significant direct correlations with cognitive scores have been reported for ${ }^{18} \mathrm{~F}-\mathrm{AV}$-1451 (in multiple studies) $[25,29-32,158,164],{ }^{18} \mathrm{~F}-\mathrm{THK} 5351$ [53], and ${ }^{18} \mathrm{~F}-\mathrm{MK}$ 6240 [55] (Table 2), bringing these tracers to the forefront for disease staging purposes. Both ${ }^{18} \mathrm{~F}-\mathrm{AV}-1451$ and ${ }^{18} \mathrm{~F}$ THK5351 have been studied in disease states and tauopathies other than AD. Significant differences in ${ }^{18}$ F-AV-1451 distribution between patients with PD and progressive supranuclear palsy (PSP) [27] and AD and dementia with Lewy bodies (DLB) [28] have been shown.

${ }^{18} \mathrm{~F}$-THK5351 has shown significant response in both PSP and corticobasal syndrome in comparison with that in controls $[51,52]$. In PSP, the $\mathrm{SUV}_{\mathrm{R}}$ of the midbrain, with cerebellum as the reference region, showed the most pronounced difference from controls and was inversely correlated to cognitive scores [51].

\section{Selectivity studies for tau agents}

\section{In vivo}

Very limited in vivo blocking data are available for tau tracers (Table 2). Homologous block data has been presented for only two tracers, ${ }^{18} \mathrm{~F}-\mathrm{AV}-1451$ and ${ }^{18} \mathrm{~F}-\mathrm{MK}$ 6240 , and heterologous block only reported for ${ }^{18} \mathrm{~F}$ THK5317, with a non-tau agent (probing off-target binding). For ${ }^{18} \mathrm{~F}-\mathrm{AV}-1451$, self-block in healthy non-human primate (NHP), showed a large decrease in signal. Healthy NHPs are devoid of NFT. Therefore, all displaceable signal from a self-block experiment represents specific binding to off-target sites. The large decrease observed for ${ }^{18} \mathrm{~F}$-AV-1451 in healthy NHP suggests substantial off-target binding, which may perturb signal quantification in disease groups [22].

For ${ }^{18}$ F-MK-6240, the decrease upon self-block was minimal and showed the proportion of displaceable offtarget binding is small in healthy NHP [22]. ${ }^{18} \mathrm{~F}$ THK5351 has been pursued as the leading tracer of the THK series due to favourable pharmacokinetics [50]; however, recent in vivo evidence of off-target binding has emerged. In vivo imaging in mild cognitive impairment (MCI) and AD patients after $10 \mathrm{mg}$ of selegiline, used clinically as an irreversible monoamine oxidase (MAO) inhibitor, reduced brain uptake of ${ }^{18} \mathrm{~F}$-THK 1351 by $37-$ $52 \%$ compared with baseline. The greatest decrease was observed in regions expected to have high MAO-B concentrations, and signal loss was maintained during the third scans 9-28 days later [48]. A substantial portion of signal in $\mathrm{AD}$ and MCI patients therefore appears to be specific off-target binding to MAO.

\section{In vitro}

In vitro and ex vivo binding to tau has been reported in peerreviewed journals for all published tracers [40, 163, 165]. However, further in vitro blocking studies have also indicated potential off-target binding sites for many of the in-human tau tracers.

Multiple studies have found potential off-target binding sites for ${ }^{18} \mathrm{~F}$-AV-1451 including indications that off-target binding may be linked to iron accumulation [34], evidence for off-target binding of ${ }^{18} \mathrm{~F}-\mathrm{AV}-1451$ to neuromelaninand melanin-containing cells in the substantia nigra[33] and compelling evidence of high affinity and moderate affinity binding to MAO-A and MAO-B, respectively, using ${ }^{3} \mathrm{H}-\mathrm{AV}-1451$ [35]. The latter case is interesting as cold AV-1451 showed no inhibition of MAO-A or MAO$\mathrm{B}$ at a $1-\mu \mathrm{M}$ concentration during initial screening [166]. This example highlights an important subtlety in PET tracer development, where lack of inhibition or activation (i.e. high $\mathrm{IC}_{50}$ value) does not necessarily equate to a lack of binding (i.e. high $K_{\mathrm{D}}$ ).

For the leading compound of the THK series, ${ }^{18} \mathrm{~F}$ THK5351, a study was carried out on the brain tissue of patients who had received a ${ }^{18}$ F-THK5351 scan while alive. The post-mortem autoradiography study on these brains using ${ }^{3}$ H-THK5351 showed concordant uptake between PET scan and autoradiography data but also showed that the vast majority of ${ }^{3} \mathrm{H}$-THK5351 signal was blocked with MAO-B inhibitor lazabemide [54]. This study is consistent with the in vivo data discussed above and provides strong evidence of off-target binding to MAO-B. MAO-B is prevalent across the entire brain, increases with age, has been proposed as a biomarker for astrocytosis (frequently observed at sites of degenerative lesions), and can have variable availability, such as decreased availability due to tobacco inhalation $[167,168]$. Therefore, the prevalence of MAO-B in brain regions central to NFT formation coupled with the high degree of ${ }^{18} \mathrm{~F}$-THK5351 binding to it will limit the use and interpretation of this tracer for tau imaging in vivo. Results from other derivatives have yet to be published and may suffer similar MAO binding.

A very recent candidate for tau imaging in humans is ${ }^{18}$ F-RO-948 (also referred to as ${ }^{18}$ F-RO6958948). It was deemed to be the lead candidate of three potential tracers during initial translation into humans $\left({ }^{18} \mathrm{~F}-\mathrm{RO} 6958948\right.$, ${ }^{11} \mathrm{C}-\mathrm{RO6931643}$, and $\left.{ }^{11} \mathrm{C}-\mathrm{RO} 6924963\right)$ [58]. In vitro data showed a good indication of distribution in post-mortem $\mathrm{AD}$ brain regions expected to contain tau, with in vitro AV1451 blocking studies showing large displacement. However, RO-948 is structurally similar to AV-1451, which has evidence of multiple off-target binding sites. Therefore, ${ }^{18}$ F-RO-948 may display similar off-target binding. 


\section{Pharmacokinetic profiles of tau tracers}

${ }^{18} \mathrm{~F}-\mathrm{AV}-1451,{ }^{18} \mathrm{~F}-\mathrm{THK} 5351,{ }^{18} \mathrm{~F}-\mathrm{MK}-6240$, and ${ }^{18} \mathrm{~F}-\mathrm{RO}-$ 948 all showed rapid brain delivery and fast kinetics suitable for imaging, with ${ }^{18} \mathrm{~F}$-THK5351 having the fastest washout from the cerebellum of the THK series $[21,47,55,58]$. Where results have been published, inter- and intra-subject variability reported is low (Table 2), meaning the repeatability of the outcome parameter(s) of these tracers within patients is high, and the differences in uptake across HC subjects is low. Additionally, the cerebellum appears a suitable reference region for tau imaging and is validated as such for multiple tau tracers (Table 2).

Retention in areas of the brain not expected to contain tau or in $\mathrm{HC}$ can indicate off-target binding and perturb quantification of tau in vivo. ${ }^{18} \mathrm{~F}-\mathrm{AV}-1451$ shows sites of high uptake in $\mathrm{HC}$ with the most prominent being the basal ganglia, mid-brain, and choroid plexus [163]. Initial compounds of the THK series ${ }^{18} \mathrm{~F}$-THK523 and ${ }^{18} \mathrm{~F}$-THK5117 showed high white matter retention in HC [40, 42], but this was progressively improved over the series, through ${ }^{18} \mathrm{~F}$ THK5317 and finally ${ }^{18} \mathrm{~F}$-THK5351 [45, 47]. For ${ }^{18} \mathrm{~F}-\mathrm{MK}$ 6240 , the ethmoid sinus, clivus, meninges, and substantia nigra had increased uptake, outlining these as sites of offtarget binding, as well as some skull uptake, indicative of de-fluorination [55]. Sites with reported off-target binding of ${ }^{18} \mathrm{~F}-\mathrm{RO}-948$ include the substantia nigra, cerebellar vermis, meninges, and in the retina [58]. The presence of tracer retention in brain areas of $\mathrm{HC}$ raises issues of tracer quantification. A high off-target signal will reduce the relative dynamic range of the tracer in that area and may differ in magnitude between individuals or patient groups, making correction for off-target binding difficult. In extreme cases, signal from areas adjacent to sites of high off-target binding may be perturbed due to partial volume effect. Therefore, for example, white matter retention is a substantial barrier to quantification due to widespread distribution and variability between patients. However, for areas removed from expected distribution and spread of tau, such as the retina, or regions of uptake which remain constant across study groups may not present substantial quantification issues.

Several additional tau tracers have been translated into humans and presented at conference including ${ }^{18} \mathrm{~F}-\mathrm{GTP}-1$ [61], ${ }^{18} \mathrm{~F}-\mathrm{PI}-2620$ [169] (replacing weaker candidate ${ }^{18} \mathrm{~F}$ MNI-815, which has also been translated into humans $[60]$ ), ${ }^{18} \mathrm{~F}-\mathrm{AM}-\mathrm{PBB} 3$, and ${ }^{18} \mathrm{~F}-\mathrm{PM}-\mathrm{PBB} 3$ (also known as ${ }^{18}$ F-MNI-958) (Table 2) [62]. The initial presented data from these tracers appears promising. However, no in vivo data have been published in peer-reviewed journals, preventing objective comparison with the more established tracers. Therefore, the field eagerly awaits the emergence of clinical trial data and associated publications.

\section{Conclusions and outstanding issues for tau imaging}

The large number of recent tracers for tau highlights the impetus associated with the development and translation of tau PET probes within the medical imaging community. The ability to distinguish $\mathrm{AD}$ patients from $\mathrm{HC}$ and people with $\mathrm{MCI}$ on the basis of tau load has been shown in multiple studies. Expansion of tau imaging into other disease states and clinical populations is well underway. Over 60 'PET + tau' clinical studies are currently active or recruiting to investigate tau load in many disease states including dementias, motor neuron diseases, traumatic brain injury, and depression, amongst others (clinicaltrails.gov, data obtained 30 October 2018). There are currently no promising in-human tau-based therapeutics. The ability to track tau load within human subjects is of huge importance for tau-based drug development programmes. Assessment of an anti-tau drugs effect on tau load in vivo, and direct comparison to cognitive performance/disease progression, would provide invaluable information of a drug's efficacy and the merits of tau reduction as a therapy in humans.

Of all in-human tau tracers, ${ }^{18} \mathrm{~F}-\mathrm{MK}-6240$ is currently the most promising. The selectivity profile, to date, is the most robust, with minimal off-target specific binding apparent in NHP, and strong correlation to cognitive scores in AD reported. However, for this, and all tau tracers published, there are still many open questions to be addressed. In the following section, we discuss the issues that would be useful to address.

\section{Tau has multiple targets}

Pathologic accumulation of tau into paired helical filaments and subsequently NFTs initially provide distinct targets. However, intracellular NFTs can be varied in composition and form. Different isoforms of NFT tau are associated with different disease states, predominantly $3 \mathrm{R}$ tau in Pick's disease, 4R in PSP, corticobasal degeneration (CBD) and argyrophilic grain disease, and a $1: 1 \mathrm{mix}$ of $3 \mathrm{R}$ and $4 \mathrm{R}$ in $\mathrm{AD}$ [170]. Additionally, the morphology of the NFT is altered between disease states, with AD being characterised by flameshaped NFT and neuropil threads [170]. As such, different binding sites, and the affinities of tau tracers for them, may vary substantially between isoforms and morphologies of tau. For example, multiple studies have reported that the binding affinity for ${ }^{18} \mathrm{~F}$-AV-1451 may be substantially lower for non$\mathrm{AD}$ type tau, restricting its use in imaging other tauopathies [33, 36-38]. Therefore, categorisation of tracers as 'tau imaging agents' may be misleading. Screening across diverse tauopathies in vitro would allow assessment of tracers' affinity across different tau isoforms and the disease states they are 
most suited to image. For example, ${ }^{18} \mathrm{~F}-\mathrm{AV}-1451$ may be more aptly described as a '3R + 4R tau' imaging agent.

\section{In-depth characterisation of tracers pre-clinically}

The current leading tau tracers in terms of published research and inclusion in clinical trials are ${ }^{18} \mathrm{~F}-\mathrm{AV}-1451$ and ${ }^{18} \mathrm{~F}$-THK 5351. The rapid translation into clinical trials of these tracers appears to have left a vacuum of in vitro and in vivo data, which is only now catching up. As such, the selectivity profile for these tracers, and all tau tracers discussed, is far from complete. Critical selectivity data for ${ }^{18} \mathrm{~F}$-AV-1451 and ${ }^{18} \mathrm{~F}$-THK5351 has only emerged after the commencement of multiple large-scale trials. For ${ }^{18} \mathrm{~F}$ THK5351, MAO-B binding appears a major confound given the extent of in vivo binding and distribution of MAO and may severely restrict the use of ${ }^{18}$ F-THK5351 as a tau imaging agent. Off-target binding in ${ }^{18} \mathrm{~F}-\mathrm{AV}-1451$ appears to present issues also, however, appears less substantial than for ${ }^{18} \mathrm{~F}$-THK5351.

Conducting in vivo blocking studies in disease models and $\mathrm{HC}$ is standard practice for CNS PET tracer development as a measure of selectivity. For proteinopathies, preclinical models rely on a transgenic mouse to induce protein dysfunction. Unfortunately, many current models fail to replicate the type of tau observed in human diseases, with tracers showing much lower binding to murine models [40, 171]. The higher cost of transgenic strains and the caveats of these models may be contributors to the lack of published data available in this area.

Blocking studies in $\mathrm{HC}$, as well as in more representative tau-accumulating disease models, would be a substantial addition to the knowledge of tracer selectivity and dynamic range.

\section{Lack of selective compounds}

Currently, there are no well-characterised, highly selective compounds available for use in competitive binding studies, preventing the determination of a tracer's tau specific signal and dynamic range. Development of such agents would allow more robust characterisation of selective tau agents and allow determination of binding site(s) occupied by tracers.

Addressing these challenges is vital for the research effort into imaging of tau and to support research of AD and other tauopathies.

\section{Receptor, transporter, and synaptic targets}

Many neuropsychiatric conditions are thought to be due to or characterised by dysfunction in neuroreceptors, transporters, or synaptic proteins [172]. Additionally, multiple targets within this section are linked to degenerative neurological disorders. PET tracers for these targets are therefore of great importance for characterisation of a wide range of diseases, diagnosis, and drug development programmes [173]. Table 3 highlights the recent tracers for receptor, transporter, and synaptic targets that have been translated into humans from 2013 to 2018 .

\section{Cholinergic targets}

The cholinergic system has been widely related to cognitive decline in disorders including $\mathrm{AD}, \mathrm{PD}$ with dementia, and Lewy body disorders (LBD), often in tandem with dopaminergic dysfunction [174]. In AD, initial postmortem data lead to the cholinergic hypothesis which proposes a causal role of reduced acetylcholine synthesis in disease propagation. As a consequence, multiple cholinergic-based treatment strategies to reduce neuropsychiatry symptoms have been developed, with some, but limited, effects [175]. While this hypothesis has fallen in popularity, in place of the amyloid and tau hypotheses, imaging studies have shown a link between the cholinergic system and these pathologies in vivo [174, 176]. Recent MRI studies have provided evidence that basal forebrain pathology precedes and predicts both entorhinal pathology and memory impairment in AD, implicating cholinergic neuronal loss as an early indicator of the disease [177, 178].

As with many neurotransmitters, there are multiple potential targets for cholinergic imaging. Recently, PET tracers for the cholinergic targets of vesicular acetylcholine transporter (VAChT) and alpha-7 subtype of the nicotinic acetylcholine receptor $(\alpha 7-\mathrm{nAChR})$ have been reported and characterised.

VAChT activity has been seen as a purer indication of presynaptic cholinergic terminal density than other targets [179] and is distinct from the therapeutic site of cholinesterase inhibitors. [ $\left.{ }^{123} \mathrm{I}\right] \mathrm{IBVM}$ is well-established for imaging and has been utilised in humans for decades [180, 181]. The recently translated ${ }^{18} \mathrm{~F}$-FEOBV and ${ }^{18} \mathrm{~F}$-VAT potentially offer the inherent benefits of PET tracers over established SPECT tracers, such as higher resolution. For ${ }^{18}$ F-FEOBV, authors claim it allows quantification of VAChT in smaller brain regions, infeasible with ${ }^{123} \mathrm{I}$ IBVM [65].

The $\alpha 7-n A C h R$ is a cholinergic receptor of great interest across multiple fields. It has been associated with decreased expression in post-mortem schizophrenia tissue [182-184], in traumatic brain injury models [185, 186], and the hippocampus of post-mortem AD tissue [183], as well as increased expression in perirhinal cortex and 
hippocampus of bipolar post-mortem tissue [187]. Multiple PET tracers have been developed for this target but have failed to perform either pre-clinically or in human studies $[188,189]$. The recent translation of ${ }^{18} \mathrm{~F}$-ASEM into humans represents the first promising $\alpha 7$-nAChR imaging agent for this target with encouraging performance both pre-clinically and in clinical trials.

\section{Selectivity data for cholinergic tracers}

The lack of in vivo blocking data represents a major drawback for the confidence of selectivity for ${ }^{18} \mathrm{~F}$-FEOBV in vivo. In rodents, dose escalation of homologous blocking studies was deemed unethical due to adverse effects of blocking VAChT in vivo; therefore, only a partial self-block was achieved [66]. No heterologous blocking studies have been reported for ${ }^{18} \mathrm{~F}$ FEOBV in vivo.

In contrast, large displacement of ${ }^{18} \mathrm{~F}$-VAT was observed upon administration of vesamicol in NHP (Table 3) [69, 70]. Vesamicol is not selective for VAChT with wellknown binding to sigma receptors [71] and therefore represents a non-selective block. The in vitro characterisation of ${ }^{18}$ F-VAT determined high selectivity of VAT over sigma receptors [69], but this cannot be assumed to translate into in vivo selectivity of a radiotracer, as discussed with ${ }^{18} \mathrm{~F}$ AV-1451 above. Nevertheless, substantial binding to sigma seems unlikely as no decrease in SUV was observed in the cerebellum upon blockade, where sigma receptors are prevalent, as well as showing contradictory distribution [190].

For imaging $\alpha 7$-nAChR with ${ }^{18} \mathrm{~F}$-ASEM, substantial reduction in uptake upon heterologous $\alpha 7$-nAChR specific block, with DXMB-A and SSR180711 in rodent and NHP respectively has been shown [74, 191], and no response to multiple negative control blocking studies in rodents [74]. These studies imply high selectivity and dynamic range of ${ }^{18} \mathrm{~F}$-ASEM for $\alpha 7$-nAChR in vivo.

\section{Pharmacokinetic properties of cholinergic tracers}

${ }^{18} \mathrm{~F}$-FEOBV, ${ }^{18} \mathrm{~F}$-VAT, and ${ }^{18} \mathrm{~F}$-ASEM all show good peak brain activity, heterogeneous distribution in line with target distribution, and moderate to fast kinetics in most brain regions $[65,73]$. The exception is the slow kinetics of ${ }^{18} \mathrm{~F}-\mathrm{FEOBV}$ in basal ganglia structures requiring long scan durations or delayed scanning protocols for quantification in this region [65]. Outcome parameter variability interpatient was moderate for ${ }^{18} \mathrm{~F}$-FEOBV and ${ }^{18} \mathrm{~F}$ ASEM, as well as moderate intrapatient variability reported for ${ }^{18} \mathrm{~F}$-ASEM (Table 3). Peer-reviewed in-human, ${ }^{18} \mathrm{~F}$ VAT data is not yet available.

As $\alpha 7-n A C h$ is present across the entire brain, there is no available reference region for ${ }^{18} \mathrm{~F}$-ASEM, and therefore, full plasma input methods will be required for accurate quantification. For ${ }^{18} \mathrm{~F}$-FEOBV, the cerebellar grey matter has been validated as a suitable reference region and provided lower variability than arterial input measures, with high correlation, however, had a lower dynamic range [65]. In NHP, the cerebellum may also provide a reference region for ${ }^{18} \mathrm{~F}$-VAT quantification [70].

\section{Conclusions and outstanding issues for recent cholinergic tracers}

${ }^{18} \mathrm{~F}$-FEOBV and ${ }^{18} \mathrm{~F}$-ASEM both show pharmacokinetic profiles suitable for imaging and have been successfully utilised in disease state imaging. ${ }^{18} \mathrm{~F}$-FEOBV was shown to have the highest sensitivity compared with both ${ }^{18} \mathrm{~F}$ FDG (metabolism) and ${ }^{18} \mathrm{~F}-\mathrm{NAV} 4694$ (amyloid) for distinguishing between $\mathrm{HC}$ and $\mathrm{AD}$ patients in a smallscale study [67]. ${ }^{18} \mathrm{~F}$-ASEM $V_{\mathrm{T}}$ was found to be significantly decreased in schizophrenia patients in some brain regions, although an outlier was excluded in order to achieve this [75]. Additionally, an occupancy of up to $49 \%$ was determined when schizophrenic patients were treated with $\alpha 7$-nAChR selective agonist DXMB-A. The significant alteration observed with these tracers in disease state clinical trials shows the prospective applicability of these cholinergic targets in disease state imaging.

The lack of reference region available for $\alpha 7-\mathrm{nACh}$ increases the practical complexity of scanning with ${ }^{18} \mathrm{~F}$ ASEM as quantification will require full arterial input function. The slow kinetics of ${ }^{18} \mathrm{~F}-\mathrm{FEOBV}$ in the basal ganglia structures may result in higher demands on equipment for quantification in these regions, due to long scan duration. The in vivo selectivity data for ${ }^{18} \mathrm{~F}$-ASEM appears comprehensive and robust, whereas further work is required for ${ }^{18} \mathrm{~F}$-FEOBV.

\section{Adenosine $\mathrm{A}_{\mathbf{2 A}}$}

A large number of human CNS disease studies have implicated adenosine $2 \mathrm{~A}$ receptors $\left(\mathrm{A}_{2 \mathrm{~A}}\right)$, including schizophrenia [192], Pick's disease [193], MCI [194], bipolar disorder [195], and HD [196], and additionally in pre-clinical models of AD [197], addiction [198], aging [199], attention deficit hyperactivity disorder [200], epilepsy [201], hyperoxia [202], multiple sclerosis (MS) [203], PD [204], restless leg syndrome [205], and tauopathy [206], amongst others. For in-depth reviews, refer to Waarde et al. [207] and Cheffer et al. [208].

Multiple tracers have been developed for $\mathrm{A}_{2 \mathrm{~A}}$ within the $\mathrm{CNS}$, and until recently, the most suitable were ${ }^{11} \mathrm{C}$-TMSX and ${ }^{11} \mathrm{C}-\mathrm{SCH} 442416$ [209, 210]. Although these tracers are able to cross the $\mathrm{BBB}$ and bind to $\mathrm{A}_{2 \mathrm{~A}}$, both suffer 


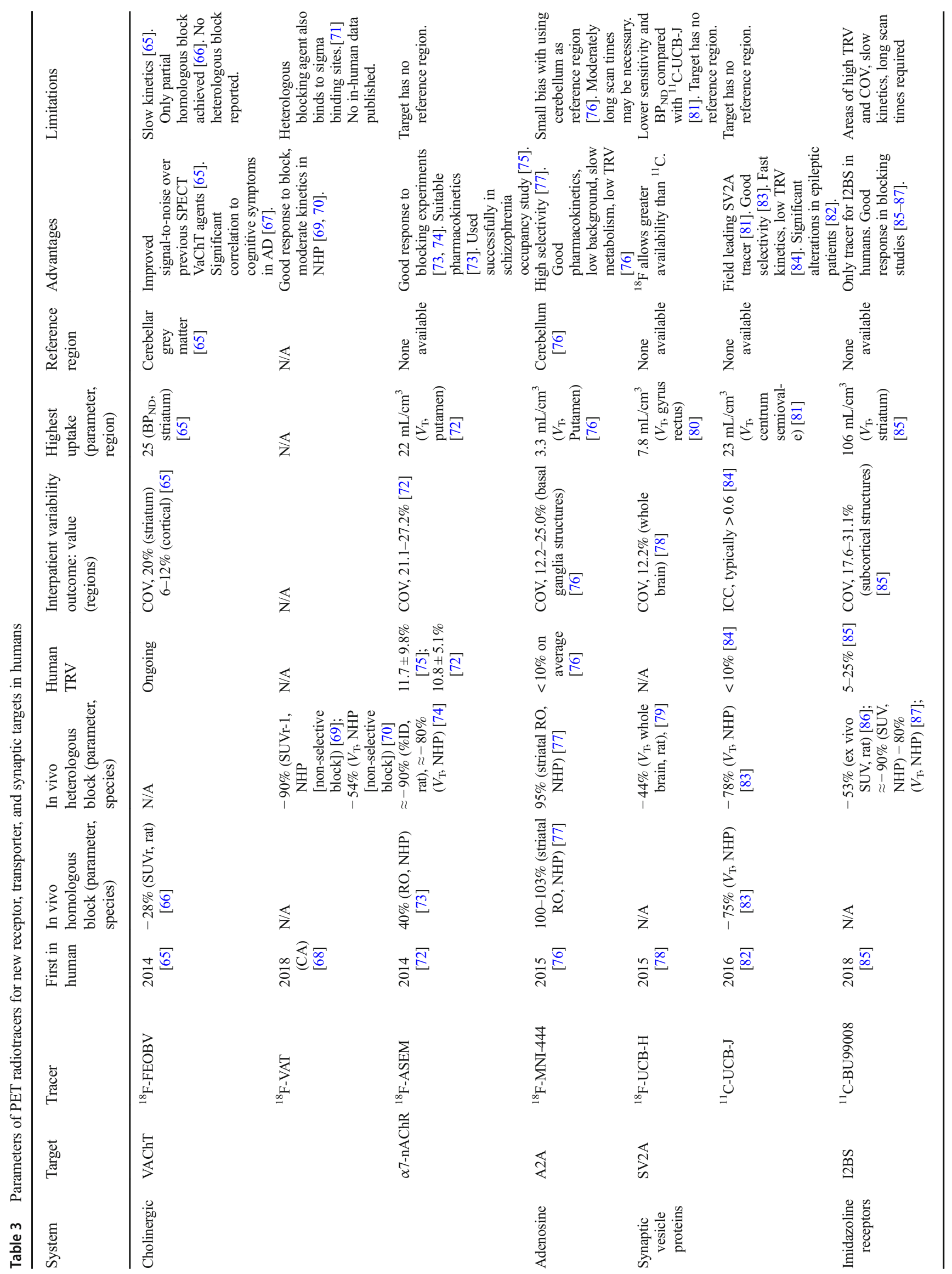




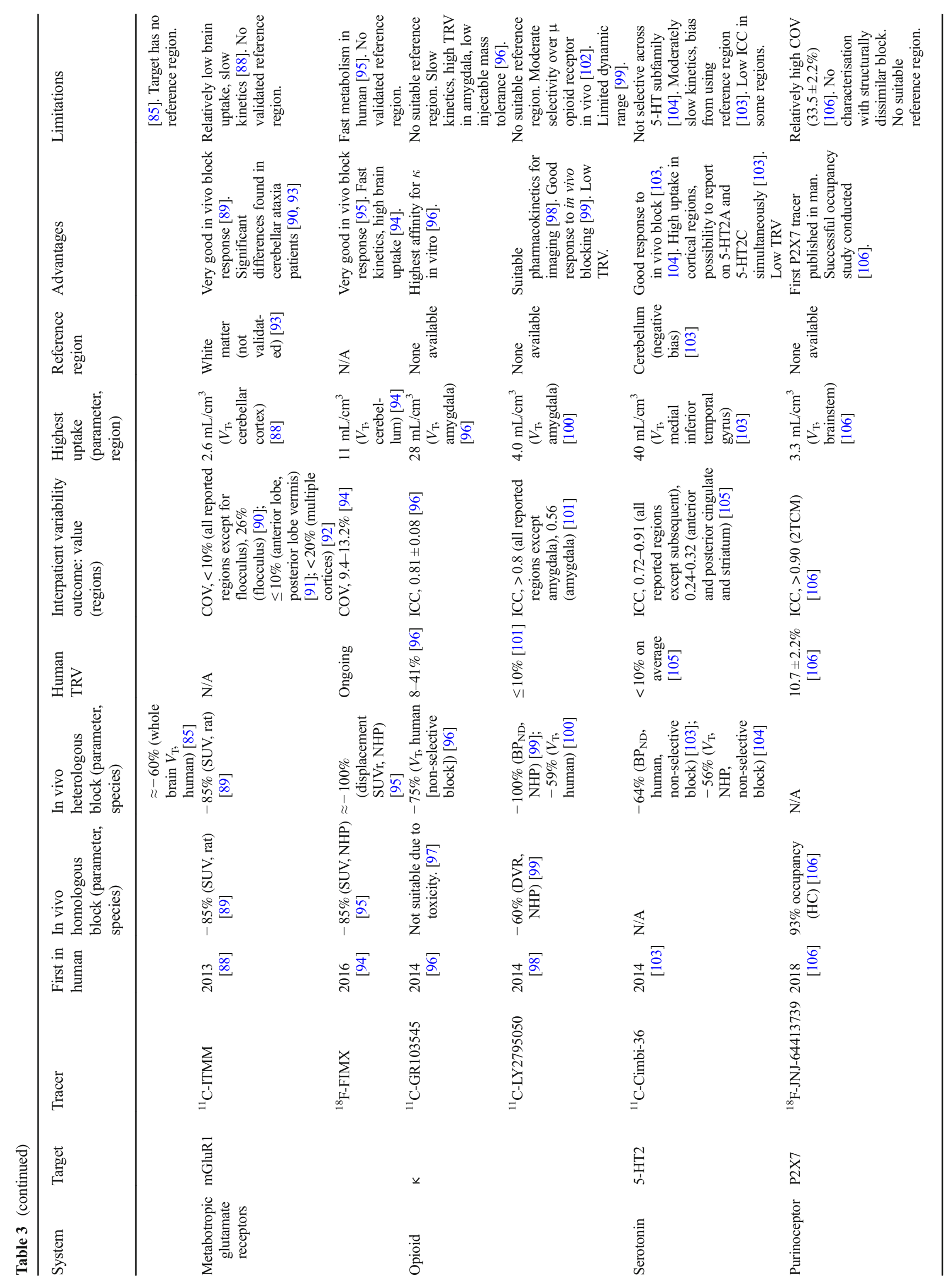




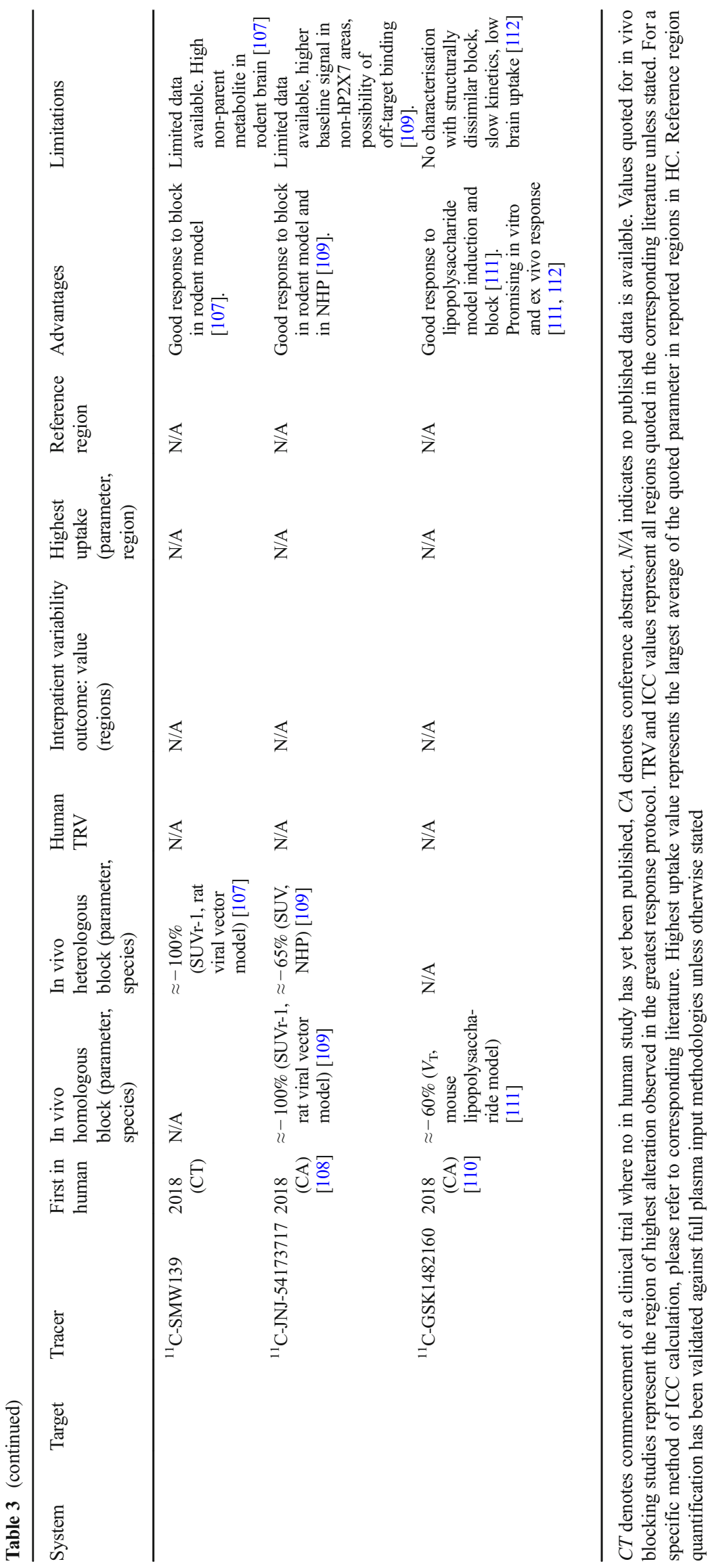


from high levels of background non-specific binding in human and therefore have a low dynamic range for receptor occupancy studies. As such, studies investigating alterations in $\mathrm{A}_{2 \mathrm{~A}}$ availability in the striatum, where $\mathrm{A}_{2 \mathrm{~A}}$ is highest, have shown significant alterations [210]. However, studies interested in other regions of the brain are likely to be severely impaired due to the low specific signal to background ratio. The recent development of ${ }^{18} \mathrm{~F}$ MNI-444 represents a welcome development with the potential to allow improved characterisation of this interesting target across brain regions.

\section{Selectivity data of ${ }^{18} \mathrm{~F}-\mathrm{MNI}-444$}

Blocking experiments in NHP with two $\mathrm{A}_{2 \mathrm{~A}}$ antagonists, preladenant (structurally similar to $\left.{ }^{18} \mathrm{~F}-\mathrm{MNI}-444\right)$ and tozadenant (structurally dissimilar to ${ }^{18} \mathrm{~F}-\mathrm{MNI}-444$ ), showed a dose-responsive decrease in SUV, with TAC in striatal regions similar to that of the cerebellum at maximum dose for both blocking agents $(\mathrm{RO} \approx 100 \%)$ [77]. This represents approximately full blockade of specific signal in these regions providing strong evidence of high $\mathrm{A}_{2 \mathrm{~A}}$ selectivity. Preladenant was treated as a homologous block due to the high structural similarity to ${ }^{18} \mathrm{~F}-\mathrm{MNI}-444$.

\section{Pharmacokinetic properties of ${ }^{18} \mathrm{~F}-\mathrm{MNI}-444$}

In both NHP and human brains, ${ }^{18} \mathrm{~F}-\mathrm{MNI}-444$ distribution is heterogeneous and matched that of known $\mathrm{A}_{2 \mathrm{~A}}$ receptor distribution [76,77], with high retention in the striatum and fast washout in the cerebellum, where the concentration of $\mathrm{A}_{2 \mathrm{~A}}$ is very low [211]. A limitation is the relatively slow kinetics which may require long scan durations. In blocking studies, a small $(<15 \%)$, non-dose-responsive decrease in cerebellar activity was observed, making this a non-perfect reference region. However, comparison between arterial input function and reference region analysis methods showed a high correlation, indicating cerebellum may be able to be used as a reference region in both human and NHP, with minimal error [76, 77]. Utilising this method, high intrapatient repeatability was observed [76].

\section{Conclusions and outstanding issues for ${ }^{18} \mathrm{~F}-\mathrm{MNI}-444$}

There are currently no published results in patients with ${ }^{18} \mathrm{~F}$ MNI-444. However, it appears superior for imaging $A_{2 A}$ in the CNS to the other evaluated tracers, with a robust selectivity profile and suitable pharmacokinetics for imaging $\mathrm{A}_{2 \mathrm{~A}}$. Further studies with ${ }^{18} \mathrm{~F}$-MNI-444 are currently underway and will help determine its full potential.

\section{Synaptic vesicle glycoprotein}

The emergence and now widespread use of effective antiepilepsy medications, such as Brivaracetam [81], which modulate the function of the synaptic vesicle glycoprotein 2A (SV2A) protein, identified this protein as an interesting target. The ubiquitous expression of SV2A in synaptic terminals throughout the brain also brings additional interest as a marker for synaptic density. As such, although this protein is of primary interest to epilepsy, it may also be of use in neurodegenerative diseases where synaptic loss is associated with cognitive impairment $[212,213]$ and other diseases, such as schizophrenia and depression, where regional synaptic alterations have been implicated [214, 215].

The recent emergence of successful radiotracers for SV2A occurred with the publication of ${ }^{11} \mathrm{C}-\mathrm{UCB}-\mathrm{J}$ and ${ }^{18} \mathrm{~F}-\mathrm{UCB}-\mathrm{H}$ in 2014 [216].

\section{Selectivity data for SV2A tracers}

Both ${ }^{18} \mathrm{~F}-\mathrm{UCB}-\mathrm{H}$ and ${ }^{11} \mathrm{C}-\mathrm{UCB}-\mathrm{J}$ show a substantial reduction in $V_{\mathrm{T}}$ upon heterologous block experiments in rat and NHP, respectively, with similar reduction observed with homologous blocking of ${ }^{11} \mathrm{C}-\mathrm{UCB}-\mathrm{J}$ (Table 3). Additionally, screening of 'cold' UCB-H and UCB-J showed no activity $(<50 \%$ effect or inhibition at $10 \mu \mathrm{M})$ across a wide range of brain receptors, transporters, enzymes, and ion channels in vitro $[79,83]$. This data supports a high degree of SV2Aspecific binding and large dynamic range for both ${ }^{18} \mathrm{~F}-\mathrm{UCB}-\mathrm{H}$ and ${ }^{11} \mathrm{C}-\mathrm{UCB}-\mathrm{J}$ in vivo.

\section{Pharmacokinetic profile of SV2A tracers}

Due to the near-ubiquitous nature of SV2A across the brain, no suitable reference region is clearly established, although the centrum semiovale is being evaluated as a pseudo-reference region [217]. Both ${ }^{11} \mathrm{C}-\mathrm{UCB}-\mathrm{J}$ and ${ }^{18} \mathrm{~F}$ $\mathrm{UCB}-\mathrm{H}$ have fast kinetics. However, ${ }^{11} \mathrm{C}-\mathrm{UCB}-\mathrm{J}$ has a higher dynamic range and significantly higher $\mathrm{BP}_{\mathrm{ND}}$ in NHPs and human and has calculated target density $\left(B_{\max }\right)$ and $K_{\mathrm{d}}$ closely matching that of ex vivo data $[81,82]$. As such, ${ }^{11} \mathrm{C}$-UCB-J has been pursued as the lead tracer in this series and showed high stability of $V_{\mathrm{T}}$ in HC test-retest scans, although ICC values were low indicating high interpatient variability (Table 3) [84].

\section{Conclusions and outstanding issues for SV2A tracers}

Of the two tracers, ${ }^{11} \mathrm{C}-\mathrm{UCB}-\mathrm{J}$ appears to be the superior SV2A tracer, with higher affinity in vivo. However, for distribution purposes, the longer half-life of ${ }^{18} \mathrm{~F}$ will make ${ }^{18} \mathrm{~F}$-UCB-H the option available to sites without an on-site 
cyclotron. One disease state imaging proof of concept study with the SV2A tracers has been carried out. Patients with medically refractory temporal lobe epilepsy showed higher levels of ${ }^{11} \mathrm{C}$-UCB-J asymmetry $(>50 \%)$ in the hippocampus compared with that usually observed for ${ }^{18} \mathrm{~F}-\mathrm{FDG}(<20 \%)$, with controls showing little asymmetry [82]. Direct head-to-head studies on larger cohorts are required; however, this is a very promising initial study into the use of ${ }^{11} \mathrm{C}$-UCB-J in epilepsy. Multiple investigations are ongoing into other diseases using SV2A $B_{\max }$ as an index for synaptic density. While a decrease in ${ }^{11} \mathrm{C}-\mathrm{UCB}$ $\mathrm{J}$ signal may represent a loss in synaptic density, it is important to remember that alterations in synaptic vesicle concentration or SV2A regulation or availability may also cause alterations in signal without necessarily correlating to synaptic density and will need to be explored.

Nevertheless, SV2A imaging is one of the most exciting new areas for CNS imaging with scope in many disease states. Clinical trials are currently active in $\mathrm{AD}$ and addiction (clinicaltials.gov, accessed 07 November 2018) as well as schizophrenia [218].

\section{Imidazoline 2 binding site}

Imidazoline 2 subtype binding site (I2BS) is distributed across the brain and has been studied in relation to multiple disease states. I2BS has been implicated in rodent models of depression $[219,220]$, as well as post-mortem reports of significant alteration in $\mathrm{AD}$, heroin addicts, and suicide victims, compared with HC [221-223]. However, the use of nonselective drugs and tracers (such as clonidine and idazoxan) were used for these studies. A post-mortem study on PD and HD tissue with a selective I2BS agonist, ${ }^{3} \mathrm{H}-2$-BFI, found significant increase and decrease in receptor density, respectively [224].

Elucidation of the biology behind these alterations of the I2BS remains an unmet challenge. The development and translation into man of the first I2BS-specific PET tracer ${ }^{11} \mathrm{C}$-BU99008 this year may provide a powerful tool in drug development and studies of this target in neuropsychiatric disorders.

\section{Selectivity data for ${ }^{11}$ C-BU99008}

Ex vivo and in vivo studies with, structurally dissimilar, I2BS selective ligand BU224 showed large decrease in SUV of ${ }^{3} \mathrm{H}$-BU99008 in rats and ${ }^{11} \mathrm{C}$-BU99008 in NHP $[86,87]$. The spatial colocalisation and reported affinity of imidazoline ligands for MAO identify this as a potential high-risk site for off-target binding [225]. No significant alteration was observed in NHP when treated with MAO-A and MAO-B ligands, suggesting off-target binding to MAO is negligible [87]. The majority of signal in NHP appears to be due to specific binding to I2BS.

\section{Pharmacokinetic profile of ${ }^{11} \mathrm{C}-\mathrm{BU} 99008$}

Distribution of ${ }^{11} \mathrm{C}-\mathrm{BU} 99008$ within the brain followed similar patterns throughout species with basal ganglia structures $>$ cortex $>$ cerebellum, in line with I2BS expression [85]. The kinetics of the tracer are relatively slow, requiring long scan durations in humans, with greater implications to image quality for a ${ }^{11} \mathrm{C}$-labelled tracer due to the shorter half-life. Partial blockade with non-selective I2BS in humans reduced SUV across all brain regions showing lack of available reference region [85].

Test-retest variability in humans showed some discord with variation ranging from 5 to $25 \%$ across regions with higher variations found in high uptake regions [85]. The authors postulated the slow kinetics of ${ }^{11} \mathrm{C}$-BU99008 and, therefore, high $\mathrm{V}_{\mathrm{T}}$ could be a contributing factor. Another possible factor could be the relatively low and highly variable molar activity used (quoted as $35.3 \pm 17.5 \mathrm{GBq} /$ $\mu \mathrm{mol})$, with test scans having over twice the injected mass on average than re-test $(3.8 \pm 3.2 \mu \mathrm{g}$ and $1.8 \pm 1.1 \mu \mathrm{g}$, respectively) [85]. A study in rats investigated the effect of ${ }^{11} \mathrm{C}$-BU99008 molar activity, finding significant increase $(+28 \%)$ in hypothalamus SUV area under curve integrals using ultra-high molar activity ${ }^{11} \mathrm{C}$-BU 99008 (>5000 GBq/ $/ \mathrm{mol}$ ) in comparison with standard molar

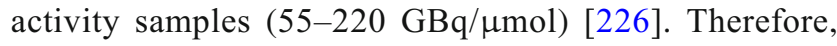
the high variability test-retest, and higher average uptake in the retest scans, may be due in part to the molar activity of the radiotracer range used. It should be noted that the method used to produce ultra-high molar activity ${ }^{11} \mathrm{C}$ BU99008 had an order of magnitude lower radiochemical yield than conventional methods.

\section{Conclusions and outstanding issues for I2BS imaging}

${ }^{11} \mathrm{C}$-BU99008 appears to be a selective tracer for I2BS with appropriate properties for imaging in vivo. However, further studies on the dynamics of the tracer, the biology of the target, and relevance in disease states are required. Factors which may improve the reproducibility of $V_{\mathrm{T}}$ measurements include higher (and more consistent) molar activity of ${ }^{11} \mathrm{C}$-BU99008, a tracer with faster kinetics, or a ${ }^{18} \mathrm{~F}$-labelled tracer. 


\section{Metabotropic glutamate receptor 1}

As the major neurotransmitter at excitatory synapses within the brain, glutamate and glutamate receptors are of high interest across many neuropsychiatric fields. The metabotropic subclass of glutamate receptors is further categorised into 8 known receptor targets (mGluR1-8). Of these, mGluR5 has multiple tracers reported in the literature prior to the scope of this review [227]; mGluR1 has 2 reported successful tracers translated into man $\left({ }^{11} \mathrm{C}\right.$-ITMM and ${ }^{18} \mathrm{~F}$-FIMX, discussed herein), but the other 6 subtypes lack tracers for human use to date.

Post-mortem expression of mGluR1 has been reported to be significantly altered in DLB $(+61 \%)$ [228] and schizophrenic hippocampus $(-33 \%)$ [229], as well as multiple mutations to the mGluR1-encoding gene found regularly in schizophrenia [230, 231]. Negative allosteric modulators of mGluR1 have received recent interest as therapeutics showing efficacy in pre-clinical in vivo models including addiction [232], epilepsy [233], neuropathic pain [234], depression [235], and PD [236].

\section{Selectivity data for mGluR1 tracers}

${ }^{11} \mathrm{C}$-ITMM and ${ }^{18} \mathrm{~F}$-FIMX are the two PET tracers successfully translated into humans for mGluR1 and are structurally related. Pre-clinical characterisation provides strong evidence of selectivity for both tracers, with large decrease in signal and removal of brain heterogeneity upon both heterologous (JNJ-16259685 [237]) and homologous blocking protocols [89, 95]. Additional characterisation of ${ }^{11} \mathrm{C}$-ITMM in mGluR1 KO mice showed substantial decrease in uptake compared with wild-type, although only whole-brain data of knockouts, rather than individual regions, were reported [89]. No decrease in uptake of ${ }^{18} \mathrm{~F}$ FIMX upon administration of mGluR5 selective ligands was observed, showing a lack of specific binding to this site [95].

The robust pre-clinical characterisation of ${ }^{11} \mathrm{C}$-ITMM and ${ }^{18}$ F-FIMX shows a high level of selectivity for mGluR1 in vivo and gives confidence in these tracers for subsequent studies.

\section{Pharmacokinetic profile of mGluR1 tracers}

Both ${ }^{11} \mathrm{C}$-ITMM and ${ }^{18}$ F-FIMX show brain distribution in humans concordant with mGluR1 expression; however, pharmacokinetic profiles of the tracers differ substantially. ${ }^{11} \mathrm{C}$-ITMM has relatively slow kinetics, requiring long scan times, relatively low brain uptake, and slow metabolism [88]. In contrast, ${ }^{18}$ F-FIMX has higher brain uptake, fast kinetics, and much faster decrease in plasma parent fraction [94]. Currently, neither tracer has published TRV, although for ${ }^{18}$ F-FIMX, it has been outlined as an outcome of a current clinical trial (clinicaltrials.gov, trial identifier: NCT02230592). The pons and the medulla are areas of low mGluR1 expression and have been proposed for use in reference region models [93], although no reference region has been validated in humans to date.

An ultra-high molar activity study with ${ }^{11} \mathrm{C}$-ITMM in rodents saw a significant increase in SUV and $V_{\mathrm{T}}$ compared with standard molar activity, highlighting molar activity as a potential risk for introducing variability [238]. A study investigating the relationship of ${ }^{11} \mathrm{C}$-ITMM $V_{\mathrm{T}}$ with age and gender reported increases in $V_{\mathrm{T}}$ in older controls [92]. However, due to significantly higher molar activity of tracer in the older population (average increase of $50 \%$ over young controls, $P<0.01)$ and significantly lower injected activity, the $V_{\mathrm{T}}$ alterations quoted in the paper could be influenced by the lower injected dose of ITMM in older $\mathrm{HC}$, in line with the pre-clinical work.

\section{Conclusions and outstanding issues for mGluR1 tracers}

${ }^{11} \mathrm{C}$-ITMM and ${ }^{18} \mathrm{~F}$-FIMX have shown excellent performance in pre-clinical characterisation studies for imaging of mGluR1. The higher uptake, faster kinetics, and longer halflife of ${ }^{18}$ F-FIMX suggest it will provide higher quality images and better quantification of mGluR1 in patients over ${ }^{11} \mathrm{C}$ ITMM, although further studies are required to verify this. Significant alterations of ${ }^{11} \mathrm{C}$-ITMM in ultra-high molar activity rodent studies highlight molar activity as a potential confound in clinical studies.

So far, ${ }^{11} \mathrm{C}$-ITMM has shown promise for cerebellar ataxia, where it has been shown to have a larger dynamic range than MRI methods and potentially more sensitive than ${ }^{18} \mathrm{~F}-\mathrm{FDG}$ $[90,93]$. However, no other disease states have been investigated with either tracer. Given the current interest in the glutamatergic system, studies are expected to emerge on a variety of disease states over the next few years.

\section{K opioid receptor}

In the brain, there are four subtypes of opioid receptors (OR), $\mu, \delta, \kappa$, and opioid-like receptor (OLR-1). Nonselective opioid PET tracers have been known and used in man for many years. However, for use in disease models and receptor occupancy studies, subtype selective tracers are required. For $\mu$-OR, selective tracers have been wellcharacterised, with ${ }^{11} \mathrm{C}$-carfentanil commonly used 
clinically [239]. Additionally, $\delta$-OR and OLR-1 selective tracers have been translated into humans, prior to the scope of this review [240, 241].

$\kappa$-ORs are the most abundant in the human brain [242] and have been linked to multiple disease states, including depression, stress, addiction, and pain response, as well as $\mathrm{AD}$ [243-247]. ${ }^{11} \mathrm{C}-\mathrm{GR} 103545$ and ${ }^{11} \mathrm{C}-\mathrm{L} Y 2795050$ have recently been translated into man with the aim of selectively imaging $\kappa$-OR.

\section{Selectivity data for $k$-OR tracers}

Both ${ }^{11} \mathrm{C}-\mathrm{GR} 103545$ and ${ }^{11} \mathrm{C}-\mathrm{LY} 2795050$ showed promising in vitro selectivity over $\mu$ - and $\delta$-OR $[99,248]$. As an agonist tracer for $\kappa$-OR, ${ }^{11} \mathrm{C}$-GR103545 is expected to have low dose tolerance before negative pharmacological effects are observed. As such, self-blocking protocols are very limited, with changes in $V_{\mathrm{T}}$ values obtained in NHP too low for an accurate Lassen plot to be constructed [97]. Brain distribution of ${ }^{11} \mathrm{C}$-GR 103545 was reported to align with expected $\kappa$-OR density in NHP [96]. Blocking with naltrexone showed substantial decreases in $V_{\mathrm{T}}$ in human studies; however, naltrexone is known to bind to $\kappa^{-}, \mu$, and $\delta$-OR [99, 249].

${ }^{11} \mathrm{C}$-LY2795050 is an antagonist tracer for $\kappa$-OR. In vivo blocking studies showed good response to both homologous block and heterologous block, with the non-selective opioid ligand naloxone reducing $\mathrm{BP}_{\mathrm{ND}}$ to approximately 0 in NHP, showing approximately all specific binding signal is opioidrelated [99]. Further studies in NHP were conducted where non-radioactive LY2795050 was used to block the signal of ${ }^{11} \mathrm{C}$-LY2795050 and $\mu$-OR tracer ${ }^{11} \mathrm{C}$-carfentanil to determine the selectivity of LY2795050 for $\kappa$-OR over $\mu$-OR. The in vivo results showed 7.6 fold selectivity for $\kappa$-OR over $\mu$ OR, much lower than the reported in vitro selectivity of 36 fold [102].

\section{Pharmacokinetic profile of $k$-OR tracers}

In humans, the kinetics of ${ }^{11} \mathrm{C}$-GR 103545 are slow, leading to complications in the calculation of kinetics and outcome parameters, compounded by the use of ${ }^{11} \mathrm{C}$. This will most likely be a substantial factor in the moderate-high degree of variability observed, with TRV on average $41 \%$ for the highest uptake region [96].

For ${ }^{11} \mathrm{C}$-LY2795050, the in-human pharmacokinetic properties observed are good. It had relatively high initial brain uptake and fast kinetics suitable for accurate kinetic modelling, although no reference region is available in humans [98]. Occupancy studies largely removed regional uptake differences showing almost full occupancy of receptor [98], and the test-retest repeatability was good [101].

\section{Conclusions and outstanding issues for $k$-OR tracers}

${ }^{11} \mathrm{C}-\mathrm{GR} 103545$ suffers from a number of drawbacks including lack of in vivo selectivity studies, due to target related toxicity and poor pharmacokinetics in humans. The binding affinity of ${ }^{11} \mathrm{C}-\mathrm{GR} 103545$ determined in vitro was very high, with a $K_{\mathrm{i}}$ of $0.02 \mathrm{nM}$ [248]. As discussed by the authors of this work, a lower affinity derivative may have faster kinetics and be more suitable for imaging in vivo, highlighting that too high affinity can hinder kinetic analysis.

The moderate selectivity of ${ }^{11} \mathrm{C}$-LY2795050 for $\kappa$-OR over $\mu$-OR in vivo is a manageable limitation of this tracer. In vivo, the vast majority of signal is expected to arise from $\kappa$-OR due to the moderate selectivity and higher natural abundance of $\kappa$-OR, especially in regions of high $\kappa$-OR to $\mu$-OR density. ${ }^{11} \mathrm{C}$-LY2795050 appears the more promising of the two tracers due to its larger dynamic range of occupancy reporting and lower variability. However, experiments must be carefully designed in order to reduce, or control for, potential perturbation of signal by $\mu$-OR alterations. There is therefore a scope for more selective tracers to make an impact on this field.

\section{Serotonin $5-\mathrm{HT}_{2} \mathrm{R}$}

The serotonergic system is one of the major signalling pathways in the brain and as such is relevant to a broad range of disease states [250]. PET tracers have been evaluated in humans from four of the seven serotonin receptor sub-families $\left(5-\mathrm{HT}_{1 \mathrm{~A}}, 5-\mathrm{HT}_{1 \mathrm{~B}}, 5-\mathrm{HT}_{2 \mathrm{~A}}, 5-\mathrm{HT}_{4}\right.$, and 5$\mathrm{HT}_{6}$ ) as well as the serotonin transporter (SERT) [251].

Imaging of the $5-\mathrm{HT}_{2 \mathrm{~A}} \mathrm{R}$ subtype is well established through antagonist tracers such as ${ }^{18} \mathrm{~F}$-seperone and ${ }^{18} \mathrm{~F}$ altanserine, with differences in receptor density identified in patients with obsessive-compulsive disorder [252], Tourette's syndrome [253], schizophrenia [254], and AD [255]. However, while able to report on receptor density, 5$\mathrm{HT}_{2 \mathrm{~A}}$ antagonist tracers are unable to distinguish between the high- and low-affinity states of $5-\mathrm{HT}_{2 \mathrm{~A}}$ and are relatively insensitive to endogenous neurotransmitter concentration $[256,257]$. As such abnormalities related to the 5$\mathrm{HT}_{2 \mathrm{~A}}$ high/low-affinity ratio or serotonin levels are unable to be identified using these tracers. The recent development and translation of ${ }^{11} \mathrm{C}$-Cimbi-36 represent the only clinical 5- $\mathrm{HT}_{2} \mathrm{R}$ agonist tested in man and with it the possibility of imaging high-affinity $5-\mathrm{HT}_{2 \mathrm{~A}}$ receptor. 


\section{Selectivity data for ${ }^{11} \mathrm{C}$-Cimbi-36}

In vitro characterisation showed high binding affinity to all three 5- $\mathrm{HT}_{2} \mathrm{R}$ subtypes (A-C) [258]. In NHP, selective blocking of 5-HT $2 \mathrm{C}$ was achieved with SB 242084 and showed approximately $100 \%$ decrease in $\mathrm{BP}_{\mathrm{ND}}$ in areas of high $5-\mathrm{HT}_{2 \mathrm{C}} \mathrm{R}$ density such as the choroid plexus [104]. In both human and NHP blocking, studies with $5-\mathrm{HT}_{2} \mathrm{R}$ antagonist ketanserin (non-selective between $5-\mathrm{HT}_{2}$ subcategories A-C) showed significant reduction across the brain (Table 3) [103, 104]. Pre-clinical studies have shown a significant response to pharmacologically increased and decreased levels of serotonin in vivo in NHP and rodents respectively showing the potential sensitivity of ${ }^{11} \mathrm{C}$ Cimbi-36 to endogenous neurotransmitter concentration $[257,259]$.

\section{Pharmacokinetic profile of ${ }^{11} \mathrm{C}$-Cimbi-36}

In humans, the uptake of ${ }^{11} \mathrm{C}$-Cimbi-36 was relatively high in cortical regions although the kinetics were moderately slow. Metabolism of the tracer was relatively fast; however, the reported metabolites were more polar than ${ }^{11} \mathrm{C}$-Cimbi-36 and are not likely to cross the BBB. The lack of signal alteration upon blocking in the cerebellum highlights this as a suitable reference region, although a consistent negative bias was found when using this, and the human test-retest showed very low variability across brain regions [104].

\section{Conclusions and outstanding issues for ${ }^{11} \mathrm{C}-\mathrm{Cimbi}-36$}

${ }^{11} \mathrm{C}-\mathrm{C}$ imbi-36 is the first 5- $\mathrm{HT}_{2} \mathrm{R}$ agonist PET tracer translated into man with pharmacokinetics acceptable for in-human imaging. While it appears not to be selective for $5-\mathrm{HT}_{2} \mathrm{R}$ subtypes, the distribution of these within the brain is substantially different. $5-\mathrm{HT}_{2 \mathrm{~B}} \mathrm{R}$ is expressed in low concentrations in the human brain and is therefore unlikely to significantly contribute to observed signal [260]. For $5-\mathrm{HT}_{2 \mathrm{~A}} \mathrm{R}$ and $5-\mathrm{HT}_{2 \mathrm{C}} \mathrm{R}$, regional distribution differences may allow selective determination of subtype signal due to some areas of high $5-\mathrm{HT}_{2 \mathrm{~A}} \mathrm{R}$ being almost devoid of $5-\mathrm{HT}_{2 \mathrm{C}} \mathrm{R}$ and vice-versa (i.e. cortical regions and choroid plexus, respectively). Therefore, in these regions, ketanserin can be treated as a pseudo-selective block in HC. However, caution must be expressed when interpreting results from regions of subtype colocalisation or disease states.

Further studies comparing agonist and antagonist tracers will hopefully provide a more comprehensive report on the role the $5-\mathrm{HT}_{2}$ receptor plays in neuropsychiatric disorders.

\section{P2X7}

The role inflammation plays in the initiation, progression, and symptoms of neuropsychiatric conditions is currently a key research question in medicine. However, imaging inflammation is not straight forward. Pro-inflammatory cells such as M1-activated microglia are upregulated at sites of inflammation and provide a range of possible targets [261]. One of the most successful strategies to date is tracers for translocator protein (TSPO) which is upregulated on activated microglia [262]. The most well-known is ${ }^{11} \mathrm{C}$-PBR28. While multiple studies have shown promising results, there are various confounds with TSPO imaging (e.g. reviewed in Marques et al. [263]). An in-depth discussion is beyond the scope of this review; however, some of the major drawbacks include common TSPO polymorphisms giving rise to distinct high/low-affinity binding groups, low concentration of TSPO even in neurodegenerative disease states, and poor selectivity between pro-inflammatory M1 microglia and antiinflammatory M2 microglia [262]. These confounds have given rise to the emergence of other targets for inflammation, both receptor and enzymatic.

One such target is ionotropic purinoceptor P2X7. In vitro and in vivo work has shown upregulation of $\mathrm{P} 2 \mathrm{X} 7$ in activated microglia, with P2X7 agonists increasing and antagonists decreasing the release of pro-inflammatory markers, in models of inflammation $[262,264,265]$. These results have led to the proposition that $\mathrm{P} 2 \mathrm{X} 7$ may be a selective marker for the proinflammatory M1 subpopulation of microglia, over the antiinflammatory M2 subpopulation [262, 266]. However, currently, there is little evidence to support the lack of expression of $\mathrm{P} 2 \mathrm{X} 7$ on the M2 subpopulation, with multiple studies contradicting this hypothesis $[267,268]$. Nevertheless, P2X7 remains a target of interest both for microglial imaging and for therapeutic indications.

PET tracers for P2X7 are under current clinical evaluation, representing the first in vivo $\mathrm{P} 2 \mathrm{X} 7$ evaluation in human. One tracer, ${ }^{18} \mathrm{~F}-\mathrm{JNJ}-64413739$, has initial human data published in peer-review. In-human work is currently being carried out on other tracers including ${ }^{11} \mathrm{C}-J \mathrm{NJ}-54173717\left({ }^{11} \mathrm{C}-J \mathrm{NJ} 717\right)$ and ${ }^{11} \mathrm{C}$-GSK1482160, which have human data presented at conference $[108,110]$, and ${ }^{11} \mathrm{C}-\mathrm{SMW} 139$, which is currently being evaluated in PD patients (www.clinicaltrialsregister.eu, EudraCT Number: 2018-000405-23).

\section{Selectivity data for P2X7 tracers}

Pre-clinical selectivity data on the current $\mathrm{P} 2 \mathrm{X} 7$ tracers is limited. No small animal selectivity studies are published for ${ }^{18} \mathrm{~F}-J \mathrm{NJ}-64413739$; however, slides on pre-clinical data 
are available online (www.nas.edu). While the data available appears promising, in-depth review of this must wait until peer-review publications are available.

${ }^{11} \mathrm{C}$-JNJ-54173717 and ${ }^{11} \mathrm{C}$-SMW139 have both been characterised with a viral vector model which causes expression of human $\mathrm{P} 2 \mathrm{X} 7$ in one brain hemisphere of rats, with control viral vector injected into the other. Both tracers showed increased uptake in the hemisphere with human P2X7 expressing viral vector and homogeneity upon blocking with P2X7 antagonists [107, 109]. For ${ }^{11} \mathrm{C}$ JNJ-54173717, the block compound was structurally similar whereas for ${ }^{11} \mathrm{C}$-SMW139, this was structurally dissimilar. Further studies in NHP with ${ }^{11} \mathrm{C}-\mathrm{JNJ}-54173717$ showed a substantial decrease in observed SUV upon self-block and blocking with chemically distinct P2X7 antagonist (JNJ-42253432) [109].

${ }^{11} \mathrm{C}-$ GSK1482160 has been characterised in a lipopolysaccharide model of inflammation where $V_{\mathrm{T}}$ was significantly increased upon treatment, with $97 \%$ of the increased signal displaced in lipopolysaccharide and homologous block-treated animals [111]. The in vivo selectivity profile for ${ }^{11} \mathrm{C}$-GSK1482160 is currently lacking heterologous $\mathrm{P} 2 \mathrm{X} 7$ blocking data. In vitro response to $\mathrm{P} 2 \mathrm{X} 7$ expressing cells and correlation to expression of $\mathrm{P} 2 \mathrm{X} 7$ and activated microglia in an ex vivo multiple sclerosis rodent model both increase confidence in selectivity [111, 112], but are not in themselves proof of $\mathrm{P} 2 \mathrm{X} 7$ binding in vivo.

\section{Pharmacokinetic profile of $\mathrm{P} 2 \mathrm{X7}$ tracers}

${ }^{18}$ F-JNJ-64413739, ${ }^{11}$ C-JNJ-54173717, and ${ }^{11} \mathrm{C}-\mathrm{SMW} 139$ appear to have relatively fast kinetics and high brain uptake suitable for imaging in the species investigated [106, 107, 109]. ${ }^{11} \mathrm{C}-\mathrm{GSK} 1482160$, however, has slow kinetics in rodent and NHP making accurate quantification more difficult. In rodents, ${ }^{11} \mathrm{C}-\mathrm{SMW} 139$ suffered from radiometabolites within the brain as well as limited dynamic range. Twenty-one percent of the brain radioactivity was observed as metabolites at $15 \mathrm{~min}$, increasing to $34 \%$ by $45 \mathrm{~min}$ [107]. The presence of radiometabolites in the brain may be detrimental to the accurate quantification of P2X7 in human studies. ${ }^{11} \mathrm{C}$-JNJ-54173717 studies found no evidence of radiometabolites in rodent brain; however, upon self-blocking in NHP, an increase in SUV towards the end of the scan was observed, possibly indicative of brain penetrant metabolites, although this increase was not present in other protocols [109].

Human pharmacokinetics of ${ }^{18}$ F-JNJ-64413739 showed moderate TRV and high ICC suitable for PET imaging studies, although high COV indicates intrapatient variability may be high [106]. No data is available for metabolites of ${ }^{18} \mathrm{~F}-\mathrm{JNJ}$ 64413739 .

\section{Conclusions and outstanding issues for $\mathrm{P} 2 \mathrm{X7}$ tracers}

The rapid translation of $\mathrm{P} 2 \mathrm{X} 7$ tracers into humans signifies both academic and commercial interest in the area. Publication of pre-clinical and clinical data on these recently developed tracers will allow comparison and critical analysis and allow advancement of the quickly progressing P2X7 imaging field. For ${ }^{18}$ F-JNJ-64413739 and ${ }^{11}$ C-GSK1482160, the lack of published, heterologous blocking studies is a limitation in confidence going forward. Additionally, brain penetrant metabolites may be a constraint to one or multiple of the discussed tracers.

\section{Enzymatic targets}

Dysfunction of enzymes within the CNS may substantially perturb neurochemical balance in neuropsychiatric and neurological disorders. From a therapeutic perspective, modulating enzymatic targets may allow more physiological modulation of neurotransmitter systems than alternatives such as receptor antagonists, with potentially lower risk of side effects and drug tolerance issues [269], making PET tracers for enzymatic targets highly desirable in drug development programmes. Table 4 outlines the recent tracers translated into man for enzymatic targets within the CNS.

\section{Cyclooxygenase-1}

The inhibition of cyclooxygenase-1 (COX-1) and COX-2 enzymes underlies the anti-inflammatory response caused by a number of non-steroidal anti-inflammatory drugs, such as aspirin and ibuprofen [270]. They are present in the human brain in activated microglia and are, therefore, targets for inflammation imaging. No PET tracer has shown promise for COX-2 in human CNS to date. However, a very recent candidate for imaging COX-1 has emerged in ${ }^{11} \mathrm{C}-\mathrm{PS} 13$, which was the most promising candidate of a series of COX-1 tracers evaluated pre-clinically.

\section{Selectivity data for ${ }^{11}$ C-PS13}

Self-block and blocking with Me-KTP-ME (prodrug selective for COX-1 over COX-2) in NHP both showed similar decreases in $V_{\mathrm{T}}(\approx-55 \%)$, compared with baseline scans [114]. A negative control blocking study with a COX-2 
selective compound (MC1) showed no significant alterations in uptake. Additionally, in vitro screening found $K_{\mathrm{i}}$ constants of $>10 \mu \mathrm{M}$ for a wide range of human recombinant receptors, indicating potential selectivity against those tested [114]. To date, no in-human data has been published in peer-reviewed journals; however, initial scans are currently being carried out in a clinical trial (www.clinicaltrial.gov, trial identifier: NCT03324646). Some of the early scan data has been presented at the Society of Biological Psychiatry conference (2018) [113].

\section{Pharmacokinetic profile of ${ }^{11} \mathrm{C}-\mathrm{PS} 13$}

In NHP, ${ }^{11} \mathrm{C}-\mathrm{PS} 13$ had the highest brain uptake and $V_{\mathrm{T}}$ values of the series tested, as well as suitable kinetic profile, although there appears to be no suitable reference region [114]. The proportion of non-specific binding in the NHP brain is relatively high and free fraction in plasma low, reducing the dynamic range of the tracer. Early data presented on human brain distribution appears similar to that observed in NHP, although more comprehensive analysis will have to wait until peerreviewed publication [113].

\section{Conclusions and outstanding issues for ${ }^{11}$ C-PS13}

The most apparent disadvantage of ${ }^{11} \mathrm{C}-\mathrm{PS} 13$ is the high proportion of non-specific binding in the NHP brain. This is most likely related to the relatively high lipophilicity of ${ }^{11} \mathrm{C}-\mathrm{PS} 13$ $(\log \mathrm{D}=4.3)$. Therefore, future tracers may reduce this with less lipophilic derivatives. However, the data presented so far, while limited, appears promising and may mark the first successful ligand for COX translated into humans.

\section{Mitochondrial complex 1}

Mitochondria play a crucial role as the major producers of adenosine triphosphate, ATP, in eukaryote cells. The largest of the proteins in this process is mitochondrial complex 1 . Dysfunction in mitochondrial complex 1 has been linked to multiple disease states including PD, Leigh syndrome, and encephalopathy [271, 272]. Although other mitochondrial complex 1 tracers exist, such as ${ }^{18} \mathrm{~F}$-Flurpiridaz used in cardiac imaging [273], only ${ }^{18} \mathrm{~F}-\mathrm{BCPP}-\mathrm{EF}$ has been successfully used for imaging of mitochondrial complex 1 in the brain.

\section{Selectivity data for ${ }^{18}$ F-BCPP-EF}

Early pre-clinical characterisation of ${ }^{18} \mathrm{~F}$-BCPP-EF showed moderate response upon dosing with selective mitochondrial complex 1 inhibitor, rotenone, in both rodents and NHP.
However, due to the cardiac toxicity of rotenone, only very low doses were administered in vivo [116]. In vitro studies on rat brain slices allowed higher doses of rotenone and signal intensity of ${ }^{18} \mathrm{~F}$-BCPP-EF was decreased by $96 \%$ upon maximum block, implying a larger dynamic range and greater selectivity than shown in vivo [118]. The moderate reduction of $V_{\mathrm{T}}$ in NHP upon blocking with rotenone may allow the estimation of $V_{\mathrm{ND}}$ and occupancy using a Lassen plot analysis, therefore giving greater information on dynamic range in vivo.

\section{Pharmacokinetic profile of ${ }^{18} \mathrm{~F}$-BCPP-EF}

High uptake and fast kinetics were observed in rat and NHP brain. Due to the ubiquitous nature of mitochondrial complex 1 , no reference region is available for this target. Implementation of ${ }^{18} \mathrm{~F}$-BCPP-EF for use in humans has recently been undertaken and $8 \mathrm{HC}$ scanned. Initial data presented at conference showed high brain uptake with $V_{\mathrm{T}}$ values around 30 in the striatum [115].

\section{Conclusions and outstanding issues for ${ }^{18} \mathrm{~F}-\mathrm{BCPP}-\mathrm{EF}$}

${ }^{18} \mathrm{~F}-\mathrm{BCPP}-\mathrm{EF}$ is the first tracer to measure the availability of any mitochondrial complex within the CNS and may also have potential as a reporter for mitochondrial density. Since its discovery, multiple preclinical studies have used ${ }^{18} \mathrm{~F}$ BCPP-EF and shown significant alterations in mitochondrial complex 1 availability in models of ischemic injury and PD $[119,121]$, as well as showing negative correlations with age and amyloid load in NHP [120]. However, no in-human patient data are currently available. The toxicity of mitochondrial complex 1 inhibitors is a drawback of the field, as full in vivo blockade is unfeasible.

\section{Histone deacetylase}

The histone deacetylase (HDAC) family of enzymes are transcription regulators and frequently implicated in epigenetic mechanisms, biomedical processes which alter gene expression as a result of environmental interactions with an individual's genome [124]. They have been implicated in multiple disease states both in the periphery and CNS, including AD, HD, cancers, and immune disorders, amongst others [274]. For imaging of HDACs in humans, multiple PET tracers have been developed; however, most are unsuitable for CNS imaging due to poor brain penetration or the presence of brain penetrating metabolites [275]. ${ }^{11} \mathrm{C}$-Martinostat is the only HDAC tracer evaluated in humans suitable for imaging HDAC within the CNS. 


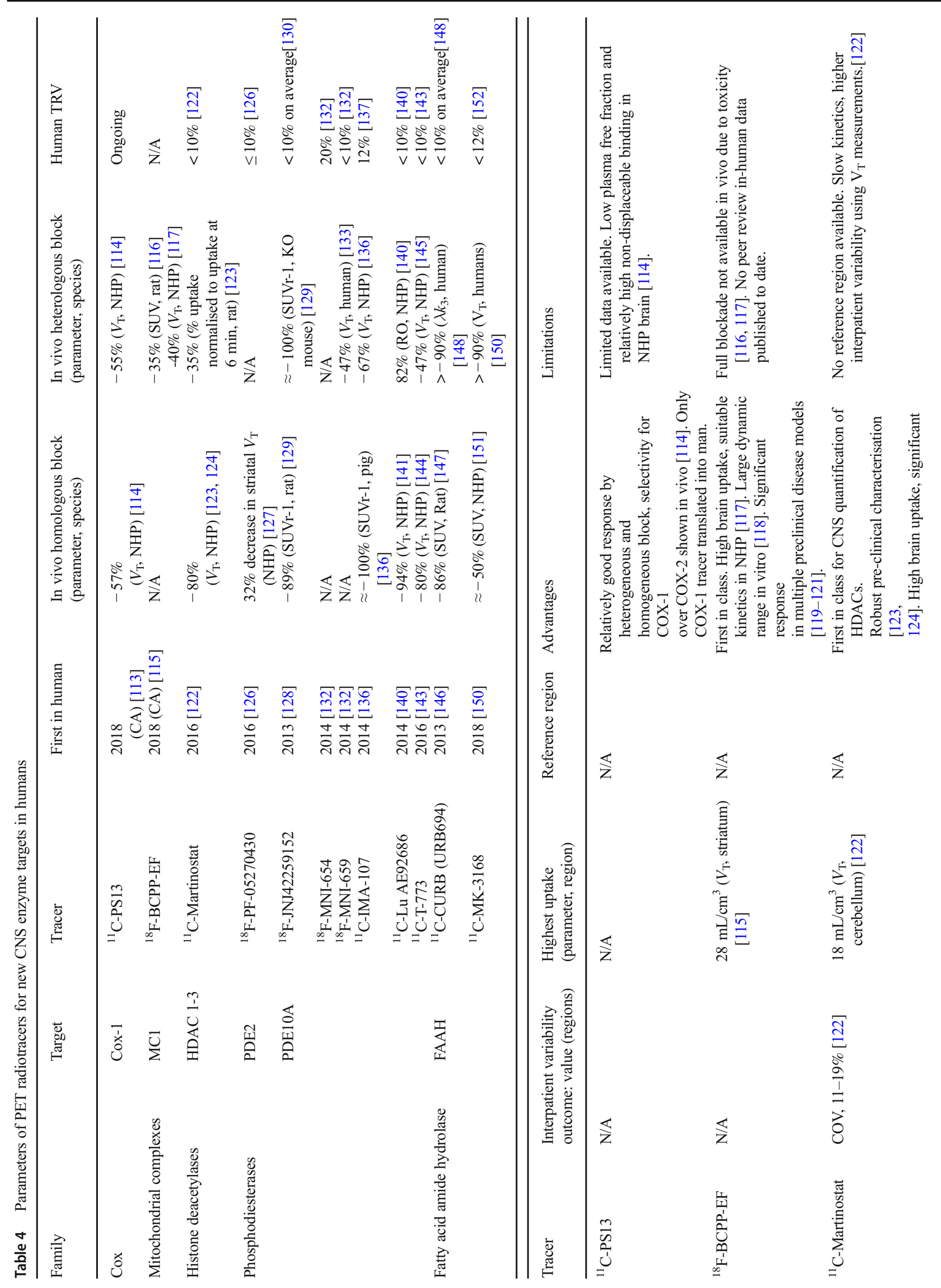




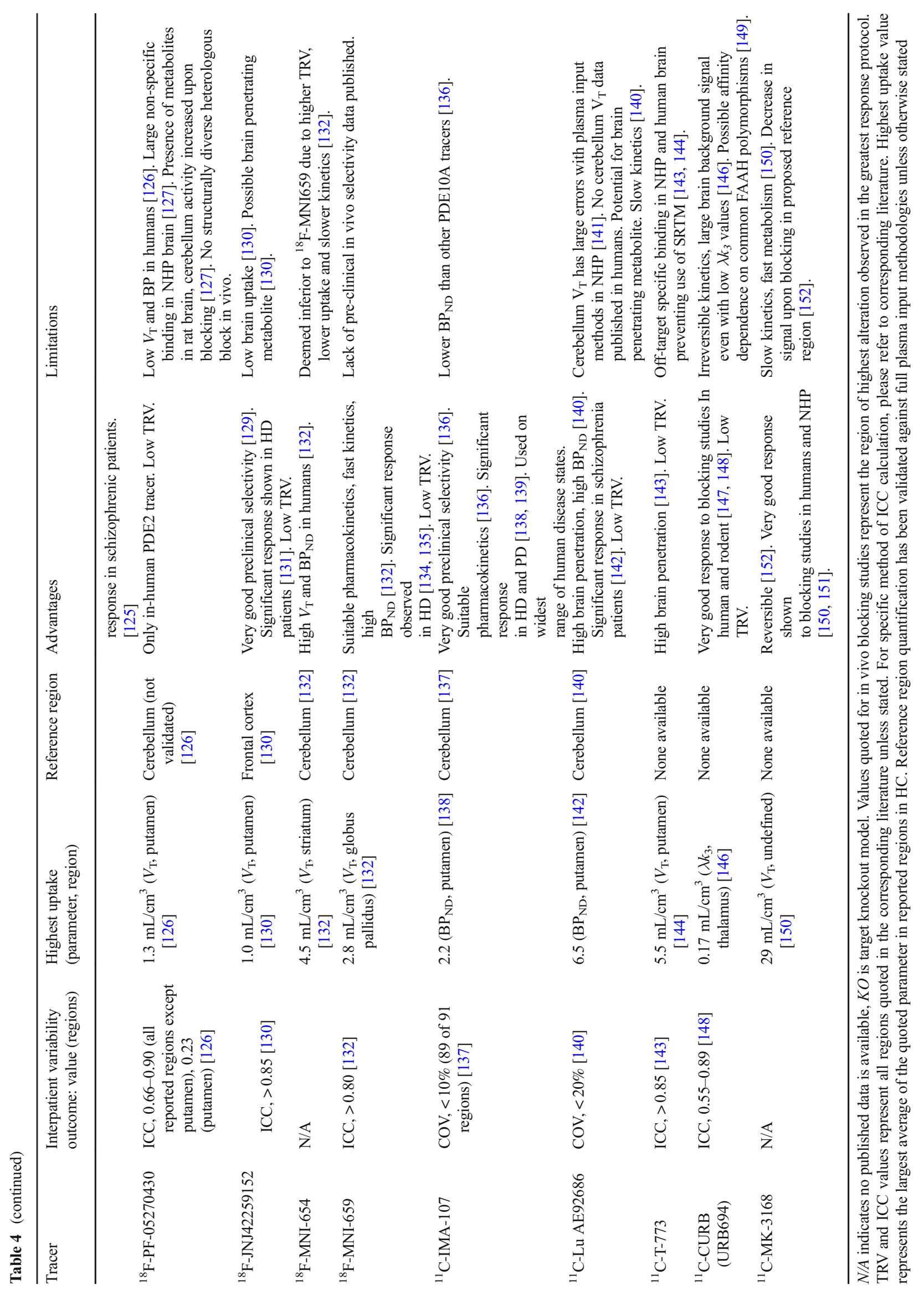




\section{Selectivity data for ${ }^{11} \mathrm{C}-$ Martinostat}

${ }^{11} \mathrm{C}$-Martinostat is reported to bind with high affinity to HDAC 1, 2, and 3 and to a lesser extent 6 , from in vitro assays. In vivo self-block of ${ }^{11} \mathrm{C}$-Martinostat largely reduced $V_{\mathrm{T}}$ in NHP (Table 4), showing high level of specific binding in this species $[123,124]$. In rodents, similar decreases in ' $\%$ whole brain uptake normalised to uptake at 6 min' was observed for both self-blocking at $2 \mathrm{mg} / \mathrm{kg}$ and pre-treatment of CN54, a structurally dissimilar HDAC inhibitor [123]. In vitro screening revealed that at $50 \mathrm{nM}$ of Martinostat resulted in $24 \%$ inhibition of dopamine transporter, highlighting this as a potential off-target binding site. However, additional studies using dopamine transporter tracer ${ }^{11} \mathrm{C}-\beta-\mathrm{CFT}$ showed no alteration of signal upon dosing with Martinostat $(1 \mathrm{mg} / \mathrm{kg})$ showing that Martinostat does not compete to measurable quantities with ${ }^{11} \mathrm{C}-\beta$-CFT in vivo [123].

\section{Pharmacokinetic profile of ${ }^{11} \mathrm{C}$-Martinostat}

${ }^{11} \mathrm{C}$-Martinostat has been shown in all investigated species to have high brain uptake, but slow kinetics [122-124]. Upon self-blocking protocol in NHP, ${ }^{11} \mathrm{C}$-Martinostat was decreased in all brain regions, highlighting the lack of reference region available [123]. In HC, intrapatient reproducibility via testretest was high and the interpatient variability was moderately high for $V_{\mathrm{T}}$ measurements. Interpatient variability was improved using $\mathrm{SUV}_{60-90}$ as an outcome parameter; however, to be applied to patient populations would require validation against arterial input methods. In a comparison with ${ }^{11} \mathrm{C}$ Martinostat uptake in schizophrenic and schizoaffective cohorts compared with HC, SUVR was used as an outcome parameter. The activity in each region was referenced to the activity in the whole brain. This method showed significant alterations in schizophrenic patients in multiple regions; however, the use of SUVR in this way requires validation in patient populations with arterial input functions, as highlighted by the authors [125].

\section{Conclusions and outstanding issues for ${ }^{11}$ C-Martinostat}

${ }^{11} \mathrm{C}$-Martinostat represents the first HDAC tracer to be useable for brain imaging in humans. The pre-clinical selectivity data for this compound appears robust, with good response to blocking protocols. The slow kinetics of the tracer is a disadvantage; however, for the purposes of determining brain penetration and occupancy of HDAC-targeted drugs, this tracer appears suitable. From the two published in-human studies, two different outcome parameters were proposed in $\mathrm{SUV}_{60-90}$ and SUVR (using the whole brain uptake as a reference region). Both of these methods would require further validation in patient populations. Standardisation of outcome parameter in future studies would allow direct comparison between results.

\section{Phosphodiesterase}

Cyclic nucleotide phosphodiesterases (PDE) are intracellular enzymes which inactivate the secondary messenger molecules cyclic adenosine monophosphate (cAMP) and/or cyclic guanosine monophosphate (cGMP). Dysfunction of PDEs can impact multiple cell processes regulated by these messengers, including proliferation, metabolism, inflammation, and apoptosis [276]. As such, PDEs are of interest in many disease states, including schizophrenia, depression, and degenerative diseases [276, 277]. Of the 11 currently known PDE subtypes, pre-clinical PET tracers have been reported for PDE2, 4, 5, 7, and 10. Of these, tracers for PDE2, 4, and 10 have been assessed in man, with PDE4 tracers well-characterised prior to the scope of this review [278].

\section{PDE2A}

PDE2A is one of three isoforms of PDE2 and is highly expressed in limbic structures and basal ganglia of the brain and is concentrated in glutamate synapses [127]. Pre-clinical data has shown links to synaptic plasticity and cognition with PDE2A inhibitors having being investigated predominantly as treatments for schizophrenia and migraine, but they are also of interest in degenerative diseases [279-281]. ${ }^{18}$ F-PF-05270430 is the only PDE2A-specific tracer, thus far, to be translated into man.

\section{Selectivity data for ${ }^{18}$ F-PF-05270430}

In NHP, brain distribution concordant with PDE2A expression was found, and occupancy studies in NHP with PDE2A inhibitor PF-05180999 showed a decrease in $V_{\mathrm{T}}$ of $32 \%$ and a maximum $\mathrm{BP}_{\mathrm{ND}}$ reduction of $72 \%$, in high-binding regions (Table 4) [127]. However, in lower uptake regions (including the cerebellum as the reference region), $V_{\mathrm{T}}$ increased upon blocking, with no hypothesis from the authors discussed [127]. Due to high structural similarities, PF-05180999 would be expected to act as a homologous block. In vitro screening of PF-05270430 indicates selectivity over other PDE and CNS targets; however, no heterologous blocking studies have been reported with structurally diverse PDE2A ligands in vivo, reducing confidence in selectivity.

\section{Pharmacokinetic profile of ${ }^{18} \mathrm{~F}$-PF-05270430}

Pre-clinical characterisation ${ }^{18}$ F-PF-05270430 showed high uptake, fast kinetics, and low TRV in NHP [127]. In rodents, 
low levels of non-parent brain metabolites (5-7\%) were observed indicating potential for BBB penetrant metabolites in clinic [127]. The occupancy and decrease in $V_{\mathrm{T}}$ reported indicate that the $V_{\mathrm{T}}$ signal is predominantly non-displaceable binding, restricting its dynamic range. Moreover, the metabolism of ${ }^{18} \mathrm{~F}-\mathrm{PF}-05270430$ varied substantially between NHP subjects. The percentage of ${ }^{18} \mathrm{~F}-\mathrm{PF}-05270430$ in plasma was very variable, ranging from approximately 10 to $45 \%$ across the three NHP subjects at 120 min post-injection in baseline scans. The percentage of ${ }^{18} \mathrm{~F}-\mathrm{PF}-05270430$ in plasma for intra-animal metabolism rate remained constant under testretest conditions and upon blocking [127].

In the only published human data on ${ }^{18} \mathrm{~F}-\mathrm{PF}-05270430$, similar brain distribution to pre-clinical studies was observed, suggesting binding to PDE2 and low test-retest variability across brain regions reported [126]. For this study, the cerebellum was used as a reference region, although additional studies are required to validate this. Both $V_{\mathrm{T}}$ and $\mathrm{BP}_{\mathrm{ND}}$ were low, decreasing dynamic range and reducing signal-to-noise ratios [126].

\section{Conclusions and outstanding issues for ${ }^{18}$ F-PF-05270430}

From the data presented to date, ${ }^{18} \mathrm{~F}-\mathrm{PF}-05270430$ may be adequate for some applications; however, it appears nonoptimal for imaging PDE2A in humans and is lacking critical selectivity data. Therefore, while ${ }^{18} \mathrm{~F}-\mathrm{PF}-05270430$ may represent the first PDE2A tracer to be translated into humans, there is the need to develop new, more specific tracers in this field.

\section{PDE10A}

PDE10A is a dual substrate PDE, degrading both cAMP and cGMP. It is localised primarily in medium spiny neuron cells of the striatum and other basal ganglia structures, with negligible levels in other brain regions [276]. The last 5 years have seen the emergence of multiple tracers for PDE10A successfully translated into humans. The first, ${ }^{18} \mathrm{~F}-\mathrm{JNJ} 42259152$, was published in humans in 2013 [128], with four more the subsequent year, ${ }^{18} \mathrm{~F}$-MNI-654, ${ }^{18} \mathrm{~F}$-MNI-659,,${ }^{11} \mathrm{C}$-IMA107, ${ }^{11} \mathrm{C}$ Lu AE92686, and lastly ${ }^{11} \mathrm{C}-\mathrm{T}-773$ in 2016 [132, 136, 140, 143]. Since publication, these tracers have been used for the study of PDE10A in HD, PD, and schizophrenia [131, 138, 282].

\section{Selectivity data for PDE10A ligands}

The selectivity data for the in-human tracers of PDE10A (Table 4) generally show a high degree of selectivity across tracers, with the exception of ${ }^{18} \mathrm{~F}-\mathrm{MNI}-654$, for which no data are available, and ${ }^{11} \mathrm{C}-\mathrm{T}-773$ which shows substantial off-target, specific binding. Two blocking studies have been published with ${ }^{11} \mathrm{C}-\mathrm{T}-773$ in NHPs, both using female rhesus monkeys. The first used structurally dissimilar, PDE10A selective, MP-10 which showed a moderate decrease in striatal region $V_{\mathrm{T}}$ (caudate $-36 \%$, putamen $-47 \%$ ), indicating binding to PDE10A in these regions, with little effect on other regions investigated including the cerebellum [145]. The second used a structurally related drug candidate (TAK-063) which showed large decreases in $V_{\mathrm{T}}$ across the whole brain (approximately $75 \%$ on average) [144]. The large reduction of $V_{\mathrm{T}}$ in areas of negligible PDE10A concentration with TAK063 that showed no response when blocked with PDE10A selective compound MP-10 strongly indicates that ${ }^{11} \mathrm{C}-\mathrm{T}-773$ has substantial off-target specific binding to the unknown site(s) across these regions. There is therefore no reference region for this tracer and interpretation of results is complicated by potential alteration in off-target site expression/ availability.

${ }^{18} \mathrm{~F}$-JNJ42259152 is a structural derivative of selective PDE10A ligand MP-10; studies using this inhibitor are expected to act as a self-block. In the mouse KO model used for ${ }^{18} \mathrm{~F}-J \mathrm{NJ} 42259152$ characterisation, homogenous brain distribution was observed, giving confidence of a high level of selectivity in the mouse. All other tracers are structurally dissimilar to MP-10 and utilised this compound in selectivity studies across a number of species, showing promising results (Table 4). For ${ }^{11} \mathrm{C}$-IMA107, structurally related compound IMA102 was used assumed to act as a self-block.

\section{Pharmacokinetic profile of PDE10A tracers}

Kinetic profiles of the PDE10A PET tracers were generally reported to be suitable for PET imaging in human. ${ }^{18} \mathrm{~F}$ JNJ42259152 showed similar brain distribution as preclinical models; however, $V_{\mathrm{T}}$ and $\mathrm{BP}_{\mathrm{ND}}$ values were globally low with $\max V_{\mathrm{T}}$ approximately 1.5 in the putamen and $<1$ for other regions [130]. Contrasting to the other PDE10A tracers, the frontal cortex was used as a reference region due to consistently showing the lowest uptake across brain regions. For all remaining tracers, the cerebellum was validated as an appropriate reference region (Table 4), with the exception of ${ }^{11} \mathrm{C}-\mathrm{T}-773$ for which no reference region is available.

${ }^{18} \mathrm{~F}-\mathrm{MNI}-654$ displayed slower kinetics, higher variability, and lower uptake than ${ }^{18} \mathrm{~F}-\mathrm{MNI}-659$ and was therefore deemed an inferior PDE10A tracer [132]. All other reported tracers showed low to moderate inter- and intrapatient variability where reported (Table 4).

From preclinical characterisation, two tracers have evidence of brain penetrant radiometabolites. ${ }^{18} \mathrm{~F}-J \mathrm{NJ} 42259152$ showed high quantities of radiometabolite in brain tissue of rats $(53 \%$ of cerebellum activity, $60 \mathrm{~min}$ ), which could make quantification of this tracer difficult. However, the identified 
metabolite is not expected to bind to PDE10A and authors of human studies claim this does not impact the quantification of PDE10A with ${ }^{18}$ F-JNJ42259152 [130]. ${ }^{11}$ C-Lu AE92686 underwent fast metabolism in NHP, with slow increase in cerebellum $V_{\mathrm{T}}$ observed throughout the scan, indicating a brain-penetrating metabolite may be present in small quantities [141]. The cerebellum $V_{\mathrm{T}}$ increase over time has not yet been reported in human, preventing the assessment of the possibility of brain-penetrating metabolite accumulation.

Research in $\mathrm{HC}$ with ${ }^{18} \mathrm{~F}-\mathrm{MNI}-695$ have investigated mapping PDE10A, showing a significant negative correlation of striatal $\mathrm{BP}_{\mathrm{ND}}$ with age, as well as increased $\mathrm{BP}_{\mathrm{ND}}$ in women over men $[135,283]$. ${ }^{18}$ F-MNI-659 has also been successfully applied to receptor occupancy studies [133, 135].

\section{Disease state imaging with PDE10A tracers}

The first investigation into PDE10A in human disease was a pilot study with ${ }^{18}$ F-JNJ42259152. Significant decrease in $\mathrm{BP}_{\mathrm{ND}}$ (alongside MRI volume) was observed in the putamen and caudate nucleus of HD patients compared with controls [131]. No significant correlation with disease severity was observed, although due to the small sample size $(n=5)$, this is unsurprising. $\mathrm{BP}_{\mathrm{ND}}$ images published did, however, hint at a trend towards significance.

In $\mathrm{HD},{ }^{18} \mathrm{~F}-\mathrm{MNI}-659 \mathrm{BP}_{\mathrm{ND}}$ of the basal ganglia structures was around $50 \%$ of $\mathrm{HC}$ and showed a strong inverse correlation to both genetic burden (burden of pathology) and clinical disease rating (motor subscale score) [134]. Additionally, while both studies had small cohorts, and further studies are required, these results imply PDE10A is a major feature in HD pathology. They also support the applicability of ${ }^{18} \mathrm{~F}-\mathrm{MNI}-$ 659 for PDE10A imaging in HD.

In a cohort of 12 early premanifest HD patients, predicted several years until onset, ${ }^{11} \mathrm{C}$-IMA107 $\mathrm{BP}_{\mathrm{ND}}$ was significantly decreased in multiple areas, with the largest in the sensorimotor striatum ( $-33.0 \%$ caudate, $-30.5 \%$ putamen) as well as substantial increase in motor thalamic nuclei $(+34.5 \%)$ compared with HC [139]. Significant correlations between ratios of motor thalamic nuclei $\mathrm{BP}_{\mathrm{ND}} /$ striatal $\mathrm{BP}_{\mathrm{ND}}$ compared with predicted disease onset [139]. The authors claim this to be the strongest correlation with risk of symptomatic HD conversion of any technique, and the earliest in vivo pathophysiological mechanism identified. No comment was published on correlation directly between striatal $\mathrm{BP}_{\mathrm{ND}}$ and risk of symptomatic $\mathrm{HD}$ conversion. The motor thalamic nucleus has $\mathrm{BP}_{\mathrm{ND}}$ values substantially lower than close proximity structures of the basal ganglia. As a region, this may, therefore, be susceptible to partial volume correction errors and show substantial differences dependent on the analysis method used. Nevertheless, this study correlates well with that published for ${ }^{18} \mathrm{~F}-\mathrm{MNI}$ 659 , discussed above, with PDE10A emerging as a potential therapeutic target and ${ }^{11} \mathrm{C}$-IMA107 as a suitable tool for tracking it in clinical trials. Longitudinal studies will, however, be required to assess the predictive power of PDE10A imaging in symptomatic conversion.

In $24 \mathrm{PD}$ patients, a significant reduction in ${ }^{11} \mathrm{C}$-IMA107 $\mathrm{BP}_{\mathrm{ND}}$ was found in multiple basal ganglia regions, with the largest decreases observed in caudate $(-28.4 \%)$ and putamen $(-25.5 \%)$ compared with that in HC [138]. Significant inverse correlations were found between ${ }^{11} \mathrm{C}$-IMA107 $\mathrm{BP}_{\mathrm{ND}}$, compared with disease duration and severity of motor symptoms [138]. As the only published PET study of PDE10A in PD patients, this work provides substantial justification for further investigations into the role of PDE10A in PD.

In a study investigating the role of PDE10A in schizophrenia, ${ }^{11} \mathrm{C}$-IMA107 showed no significant difference between patients and $\mathrm{HC}$ in any brain region, with all average differences within the variability of the tracer from previous testretest data [282]. In contrast, ${ }^{11} \mathrm{C}$-Lu AE92686 showed significantly lower $\mathrm{BP}_{\mathrm{ND}}$ in the putamen and caudate nucleus compared with that in $\mathrm{HC}$, but no correlation to symptoms was found [142].

\section{Conclusions and outstanding issues for PDE10A tracers}

Multiple tracers appear suitable for imaging PDE10A in humans; therefore, the selection of lead tracer to use in studies is not straightforward.

No head-to-head studies have been carried out on the tracers in humans (except MNI-654 and MNI-659), so conclusions on the applicability of tracers are subjective. However, comparison of the $\mathrm{HC}$ data collected so far allows forerunners for clinical imaging purposes to be identified. Due to its slow kinetics and high variability, ${ }^{18} \mathrm{~F}-\mathrm{MNI}-654$ appears unsuitable for clinical imaging. ${ }^{11} \mathrm{C}-\mathrm{T}-773$ has the highest quoted $V_{\mathrm{T}}$ in $\mathrm{HC}$, fastest kinetics, and low test-retest variability. However, the presence of an unknown off-target binding site, and the unsuitability of the cerebellum as a reference region, may restrict use in preference of other available tracers. ${ }^{11} \mathrm{C}$-Lu AE92686 also shows high brain uptake and low variability in high PDE10A regions. The kinetics of ${ }^{11} \mathrm{C}$ $\mathrm{Lu}$ AE92686 are slower than ideal and the indication of a possible brain-penetrating metabolite, confounding cerebel$\operatorname{lum} V_{\mathrm{T}}$, is the drawback of this tracer. Of the remaining tracers, ${ }^{18} \mathrm{~F}-J N J 42259152,{ }^{18} \mathrm{~F}-\mathrm{MNI}-659$, and ${ }^{11} \mathrm{C}$-IMA107 all have appropriate kinetics for clinical imaging, have suitable testretest, and have successfully been applied for disease state imaging. Of the three, ${ }^{18} \mathrm{~F}-\mathrm{MNI}-659$ has the highest $V_{\mathrm{T}}$ and $\mathrm{BP}_{\mathrm{ND}}$ values; however, it currently has no self-bock in vivo data available. ${ }^{18} \mathrm{~F}-J \mathrm{NJ} 42259152$ and ${ }^{11} \mathrm{C}$-IMA107 both have convincing selectivity data from in vivo pre-clinical studies. The low brain uptake of ${ }^{18} \mathrm{~F}$-JNJ42259152 results in low $V_{\mathrm{T}}$ values, potentially complicating quantification, although $\mathrm{BP}_{\mathrm{ND}}$ values remain moderately high. The reverse is the case 
with ${ }^{11} \mathrm{C}$-IMA107 which shows moderate $V_{\mathrm{T}}$ values but the lowest $\mathrm{BP}_{\mathrm{ND}}$ values of the in-human tracers discussed. None of the in-human tracers is without flaws; however, multiple tracers appear suitable for clinical studies, with the current forerunners being ${ }^{18} \mathrm{~F}$-JNJ42259152, ${ }^{11} \mathrm{C}$-IMA107, and ${ }^{18} \mathrm{~F}$ MNI-659.

\section{FAAH}

Fatty acid amide hydrolase (FAAH) breaks down fatty acid ethanolamide signalling molecules across the brain. These molecules act on a variety of receptors, including cannabinoid and vanilloid (TRPV1) receptors. Inhibition of FAAH increases endogenous levels of fatty acid ethanolamide, increasing the activity of associated receptors, potentially without the observed side effects of direct agonists [269]. Clinical trials have been instigated to examine FAAH inhibitors as potential therapeutics for pain, addiction, and Tourette syndrome (www.clinicaltrials.gov). Two FAAH tracers have been translated clinically to aid in studies of this enzyme, one which binds irreversibly, ${ }^{11} \mathrm{C}-\mathrm{CURB}$, and one reversibly, ${ }^{11} \mathrm{C}-\mathrm{MK}-3168$.

\section{Selectivity data for FAAH tracers}

Both FAAH tracers showed promising pre-clinical blocking profiles in pre-clinical models and humans. Ex vivo data from rats showed ${ }^{11} \mathrm{C}$-CURB had regional heterogeneity in accordance with the known distribution of FAAH with high uptake in the cerebral cortex, cerebellum, and hippocampus, compared with that in the hypothalamus [147]. A high degree of specific binding was found in the regions investigated upon blocking with cold reference compound (also known as URB694) and the highly structurally related compound URB597 [147]. In humans, studies with the structurally dissimilar and selective FAAH inhibitor PF-04457845 showed an excellent response, decreasing the outcome parameter, $\lambda k_{3}$ (see further explanation below), by over $90 \%$ and removing heterogeneity of this parameter across the brain, giving further evidence to the selectivity of the tracer [148].

${ }^{11} \mathrm{C}-\mathrm{MK}-3168$ is the other FAAH tracer to be evaluated in humans and binds reversibly. Pre-clinical data show good brain uptake and response to blocking with a compound of the same series, as well as high occupancy with the structurally dissimilar FAAH inhibitor JNJ-42165279 [150, 151]. Additionally, an occupancy study in humans, with JNJ42165279, showed high FAAH occupancy, correlating with dose, and decreased the $V_{\mathrm{T}}$ of ${ }^{11} \mathrm{C}-\mathrm{MK}-3168$ by over $90 \%$ in multiple brain regions [150].

\section{Pharmacokinetic profile of FAAH tracers}

Both tracers showed high brain uptake and distributions in line with FAAH distribution and similar TRV. With the different binding pharmacokinetics, analysis methods and outcome parameters for the two tracers are substantially different. Modelling of ${ }^{11} \mathrm{C}$-CURB revealed an irreversible two-tissue compartment model (2-TCMi) gave the most accurate fit, giving the outcome parameter of scans as $\lambda k_{3}$ [146]. Here, $k_{3}$ is the rate constant into the irreversibly bound compartment and $\lambda$ is $K_{1} / k_{2}$, equivalent to the equilibrium distribution volume of the ligand in the free and non-specifically bound compartment. ${ }^{11} \mathrm{C}-\mathrm{MK}-3168$ has the more intuitive outcome parameter of $V_{\mathrm{T}}$ measurements, but suffers from slow kinetics at baseline and rapid metabolism in humans $(<5 \%$ parent after $30 \mathrm{~min})$, with no published data on the nature of the metabolites. However, from the occupancy data reported, this does not appear to cause issue. Originally, white matter was proposed as a reference tissue for ${ }^{11} \mathrm{C}-\mathrm{MK}-3168$ but a decrease in white matter signal was associated with blocking $(<15 \%)$ and poorer repeatability reported [152]. Additionally, no reference tissue method was used in the subsequent clinical trial employing ${ }^{11} \mathrm{C}-\mathrm{MK}-3168$ [150]. These observations suggest that white matter is not a suitable reference tissue for ${ }^{11} \mathrm{C}-\mathrm{MK}-3168$.

The binding of ${ }^{11} \mathrm{C}$-CURB has been found to be linked to variation in a common nucleotide polymorphism on the FAAH gene (C385A, associated with increased risk of addiction); the $\lambda k_{3}$ of ${ }^{11} \mathrm{C}$-CURB was found to be significantly lower $(-23 \%)$ in those with the A allele $(\mathrm{A} / \mathrm{C}+\mathrm{A} / \mathrm{A})$ than those with the $\mathrm{C} / \mathrm{C}$ alleles [149]. While the authors suggest the change may represent a decrease in $B_{\max }$, the possibility of decreased ${ }^{11} \mathrm{C}$-CURB binding affinity has not been ruled out, especially as the polymorphism alters a nucleotide close to the catalytic site [149]. Either way, controlling for this polymorphism in further studies employing ${ }^{11} \mathrm{C}$-CURB will be necessary. A further study by the group investigated the effect of cannabis and found significantly lower $\left(-14 \%{ }^{11} \mathrm{C}-\mathrm{CURB}\right.$ $\lambda k_{3}$ values) in cannabis users vs $\mathrm{HC}$, and a negative correlation with clinical impulsiveness scale assessments [284]. In both reported studies, one subject with the A/A polymorphism was included and had the lowest $\lambda k_{3}$ value from each cohort, implying an A-allele dose-response may be present. For ${ }^{11} \mathrm{C}$ MK-3168, no work has been published on the effect of C385A polymorphisms on binding properties.

\section{Conclusions and outstanding issues for FAAH tracers}

These two tracers represent the first successful strategies to image FAAH in humans, proving feasibility of PET studies for this target. While the kinetics of ${ }^{11} \mathrm{C}-\mathrm{MK}-3168$ are relatively slow, reversible tracers are preferred as quantification is 
easier and outcome parameters are more intuitive than their irreversible counterparts, such as for ${ }^{11} \mathrm{C}$-CURB. Nevertheless, both tracers have shown repeatability of their outcome parameters in humans and appear suitable for occupancy studies. The effects of the C385A polymorphism are a complicating factor for ${ }^{11} \mathrm{C}$-CURB studies; however, characterisation of the polymorphism impact will now be expected for all FAAH tracers.

\section{Overall limitations and future directions}

Substantial progress has been made in multiple areas; however, many important targets have no suitable tracers in human. Misfolded proteins, such as $\alpha$-synuclein which generates high interest in PD research and transactive response DNA-binding protein (TDP-43), emerging as a key molecular target in amyotrophic lateral sclerosis (ALS) and frontotemporal dementia [285], have proven to be difficult targets for radioligand development. Glutamate is the major excitatory neurotransmitter within the CNS, yet despite some success in the development of metabotropic glutamate receptor PET ligands, there are no useful radioligands for the major inotropic glutamate receptors, including direct targeting of AMPA, or any NMDA or kainate subtypes. Likewise, for $\gamma$ aminobutyric acid (GABA), the most widely distributed inhibitory neurotransmitter in the CNS [286], the majority of subunits of $\mathrm{GABA}_{\mathrm{A}} \mathrm{R}$ (the major type found in the CNS) are lacking selective PET tracers, with none available for $\mathrm{GABA}_{\mathrm{B}} \mathrm{R}$ or $\mathrm{GABA}_{\mathrm{C}} \mathrm{R}$.

Tracers able to image different aspects of targets are also desirable. Investigating the downstream effects of drugs on other CNS systems, by imaging of targets other than those directly bound by the drug, is becoming increasingly important to unpick the complex cascade processes within the brain [287]. The availability of PET tracers responsive to the receptor occupancy of endogenous neurotransmitters allows these effects to be explored, as has been the case for dopamine [288, 289]. Recent developments have provided evidence for the feasibility of imaging endogenous opioids [290], acetylcholine [291], and 5-HT [292] and this is an area that has the potential of expanding into other neurotransmitter systems. Allosteric modulators are an area of high interest in drug development programmes, with candidates binding away from the active site of the target. These in themselves provide distinct binding sites for PET tracers, enabling characterisation of target and allosteric ligand binding.

The development of PET tracers for new targets is challenging, with intensive screening processes required in development phases. Drug development campaigns in industry generate large compound libraries with associated screening data not available in the literature. These data provide important information on selectivity for PET tracer development programmes. Thus, one strategy to aid efficient PET tracer development could be precompetitive partnering with industry and academia to share data to identify and characterise the best tracers. This, in turn, could provide valuable new PET tools for industry to use in development and clinical trial programmes

\section{Overall conclusions}

Our review identified 40 new tracers across 16 different CNS targets available for imaging in humans. The high number of CNS PET tracers for tau, P2X7, and PDE10A translated into humans within this timeframe shows the impetus for developing imaging tools to explore new targets in vivo. The selectivity and pharmacokinetic data we have summarised allow tracers to be compared and informed choices on which tracer to be selected for future studies made, as well as identifying information that needs to be determined to fully characterise some tracers. Many of the discussed tracers have the potential to make substantial contribution to the characterisation of diseases and drug development programmes, with some already having multiple in-human results published.

There are also, however, a number of recurrent issues that emerge throughout the review.

\section{Lack of pre-clinical in vivo blocking studies}

Of the 40 tracers discussed, less than half have robust preclinical blocking studies published (defined as analogous and heterologous block in vivo corresponding to high $\mathrm{RO}$ ). In vitro selectivity profiles, while useful for screening, are insufficient to prove in vivo selectivity but are repeatedly quoted as proof of tracer selectivity. Multiple tracers discussed have been used in clinical studies where the validity of findings may therefore be compromised due to the lack of characterisation, as seen in the tau imaging field.

\section{High and consistent molar activity}

It is well known that 'low' molar activity will cause occupation of the target site due to self-block, effecting outcome parameters. However, the quantity of injected mass that would cause a non-negligible self-block is dependent on multiple factors including the target density and affinity of tracer for the target and is often not well characterised in humans. Therefore, the validity of results from studies using poor molar activity, or significantly different injected masses between groups, may be questioned, reducing confidence in results. 


\section{Characterisation of off-target sites}

Multiple tracers discussed have evidence of off-target binding sites. For some, such as ${ }^{11} \mathrm{C}$-LY2795050 and ${ }^{11} \mathrm{C}$-Cimbi-36, off-target sites are known and characterised, allowing assessment of when this limitation will and will not impede study outcomes. For others, however, the off-target site(s) are unknown, preventing informed decisions on potential outcome parameter impact, raising concerns on biological outcomes, and ultimately reducing tracer usefulness.

Addressing these issues will increase the chances of developing useful PET tracers for the CNS and help prevent latestage issues arising. Notwithstanding these issues, the large number of tracers for new CNS targets identified in this review indicates there is considerable potential to advance understanding of brain function across disorders and informs the development of new therapies.

Funding information This work was funded by Medical Research Council-UK (no. MC-A656-5QD30), Maudsley Charity (no. 666), Brain and Behavior Research Foundation, and Wellcome Trust (no. 094849/Z/10/Z) grants to Dr Howes and the National Institute for Health Research (NIHR) Biomedical Research Centre at South London and Maudsley NHS Foundation Trust and King's College London.

\section{Compliance with ethical standards}

Disclaimer The views expressed are those of the author(s) and not necessarily those of the NHS, the NIHR, or the UK Government Department of Health.

Conflict of interest Stuart McCluskey, Christophe Plisson Eugenii Rabiner are full-time employees of Invicro LLC. Oliver Howes has received investigator-initiated research funding from and/or participated in advisory/speaker meetings organised by Angellini, Astra-Zeneca, Autifony, Biogen, BMS, Eli Lilly, Heptares, Jansenn, Lundbeck, Lyden-Delta, Otsuka, Servier, Sunovion, Rand, Recordati, and Roche.

Open Access This article is distributed under the terms of the Creative Commons Attribution 4.0 International License (http:// creativecommons.org/licenses/by/4.0/), which permits unrestricted use, distribution, and reproduction in any medium, provided you give appropriate credit to the original author(s) and the source, provide a link to the Creative Commons license, and indicate if changes were made.

\section{References}

1. Lopez AD, Murray CCJL. The global burden of disease, 1990 2020. Nat Med. 1998;4:1241-3.

2. Vigo D, Thornicroft G, Atun R. Estimating the true global burden of mental illness. Lancet Psychiatry. 2016;3:171-8.

3. Pangalos MN, Schechter LE, Hurko O. Drug development for CNS disorders: strategies for balancing risk and reducing attrition. Nat Rev Drug Discov. 2007;6:521-32.

4. Kim E, Howes OD, Turkheimer FE, Kim B-H, Jeong JM, Kim JW, et al. The relationship between antipsychotic D2 occupancy and change in frontal metabolism and working memory. Psychopharmacology. 2013;227:221-9.

5. Long NJ, Wong WT. The chemistry of molecular imaging. 2015.

6. Shivamurthy VKN, Tahari AK, Marcus C, Subramaniam RM. Brain FDG PET and the diagnosis of dementia. Am J Roentgenol. 2015;204:W76-85.

7. Schöll M, Damián A, Engler H. Fluorodeoxyglucose PET in neurology and psychiatry. PET Clin. 2014;9:371-90.

8. Kumakura Y, Cumming P. PET studies of cerebral levodopa metabolism: a review of clinical findings and modeling approaches. Neurosci. 2009;15:635-50.

9. Quigley H, Colloby SJ, O’Brien JT. PET imaging of brain amyloid in dementia: a review. Int J Geriatr Psychiatry. 2011;26:991-9.

10. Cerami C, Iaccarino L, Perani D. Molecular imaging of neuroinflammation in neurodegenerative dementias: the role of in vivo PET imaging. Int J Mol Sci. 2017;18.

11. Pike VW. Considerations in the development of reversibly binding PET radioligands for brain imaging. Curr Med Chem. 2016;23: 1818-69.

12. Adenot M, Lahana R. Blood-brain barrier permeation models: discriminating between potential CNS and non-CNS drugs including P-glycoprotein substrates. 2004;

13. Hitchcock SA. Structural modifications that alter the Pglycoprotein efflux properties of compounds. J Med Chem. 2012;55:4877-95.

14. Desai PV, Sawada GA, Watson IA, Raub TJ. Integration of in silico and in vitro tools for scaffold optimization during drug discovery: predicting P-glycoprotein efflux. Mol Pharm. 2013;10: 1249-61.

15. Rankovic Z. CNS drug design: balancing physicochemical properties for optimal brain exposure. J Med Chem. 2015;58:2584 608.

16. Innis RB, Cunningham VJ, Delforge J, Fujita M, Gjedde A, Gunn $\mathrm{RN}$, et al. Consensus nomenclature for in vivo imaging of reversibly binding radioligands. J Cereb Blood Flow Metab. 2007;27: 1533-9.

17. Van de Bittner GC, Ricq EL, Hooker JM. A philosophy for CNS radiotracer design. Acc Chem Res. 2014;47:3127-34.

18. Zimmer L, Luxen A. PET radiotracers for molecular imaging in the brain: past, present and future. Neuroimage. 2012;61:363-70.

19. Jones T, Rabiner EA. The development, past achievements, and future directions of brain PET. J Cereb Blood Flow Metab. 2012;32:1426-54.

20. Cunningham VJ, Rabiner EA, Slifstein M, Laruelle M, Gunn RN. Measuring drug occupancy in the absence of a reference region: the Lassen plot re-visited. J Cereb Blood Flow Metab. 2010;30: 46-50.

21. Chien DT, Bahri S, Szardenings AK, Walsh JC, Mu F, Su M-Y, et al. Early clinical PET imaging results with the novel PHF-tau radioligand [F-18]-T807. J Alzheimers Dis. 2013;34:457-68.

22. Hostetler ED, Walji AM, Zeng Z, Miller P, Bennacef I, Salinas C, et al. Preclinical characterization of $18 \mathrm{~F}-\mathrm{MK}-6240$, a promising PET tracer for in vivo quantification of human neurofibrillary tangles. J Nucl Med. 2016;57:1599-606.

23. Devous MD, Joshi AD, Navitsky M, Southekal S, Pontecorvo MJ, Shen $\mathrm{H}$, et al. Test-retest reproducibility for the tau PET imaging agent flortaucipir F 18. J Nucl Med. 2017;59(6):937-43 jnumed.117.200691.

24. Wooten DW, Guehl NJ, Verwer EE, Shoup TM, Yokell DL, Zubcevik N, et al. Pharmacokinetic evaluation of the tau PET radiotracer 18F-T807 (18F-AV-1451) in human subjects. J Nucl Med. 2017;58:484-91.

25. Johnson KA, Schultz A, Betensky RA, Becker JA, Sepulcre J, Rentz D, et al. Tau positron emission tomographic imaging in aging and early Alzheimer disease. Ann Neurol. 2016;79:110-9. 
26. Zhang W, Arteaga J, Cashion DK, Chen G, Gangadharmath U, Gomez LF, et al. A highly selective and specific PET tracer for imaging of tau pathologies. J Alzheimers Dis. 2012;31:601-12.

27. Schonhaut DR, McMillan CT, Spina S, Dickerson BC, Siderowf A, Devous MD, et al. ${ }^{18} \mathrm{~F}$-flortaucipir tau positron emission tomography distinguishes established progressive supranuclear palsy from controls and Parkinson disease: a multicenter study. Ann Neurol. 2017;82:622-34.

28. Smith R, Schöll M, Londos E, Ohlsson T, Hansson O. 18F-AV1451 in Parkinson's disease with and without dementia and in dementia with Lewy bodies. Sci Rep. 2018;8:4717.

29. Schöll M, Lockhart SN, Schonhaut DR, O’Neil JP, Janabi M, Ossenkoppele R, et al. PET imaging of tau deposition in the aging human brain. Neuron. 2016;89:971-82.

30. Ossenkoppele R, Schonhaut DR, Schöll M, Lockhart SN, Ayakta N, Baker SL, et al. Tau PET patterns mirror clinical and neuroanatomical variability in Alzheimer's disease. Brain. 2016;139: 1551-67.

31. Cho H, Choi JY, Hwang MS, Lee JH, Kim YJ, Lee HM, et al. Tau PET in Alzheimer disease and mild cognitive impairment. Neurology. 2016;87:375-83.

32. Bejanin A, Schonhaut DR, La Joie R, Kramer JH, Baker SL, Sosa $\mathrm{N}$, et al. Tau pathology and neurodegeneration contribute to cognitive impairment in Alzheimer's disease. Brain. 2017;140:3286300.

33. Marquié M, Normandin MD, Meltzer AC, Siao Tick Chong M, Andrea NV, Antón-Fernández A, et al. Pathological correlations of [F-18]-AV-1451 imaging in non-alzheimer tauopathies. Ann Neurol. 2017;81:117-28.

34. Choi JY, Cho H, Ahn SJ, Lee JH, Ryu YH, Lee MS, et al. Offtarget $18 \mathrm{~F}-\mathrm{AV}-1451$ binding in the basal ganglia correlates with age-related iron accumulation. J Nucl Med. 2018;59:117-20.

35. Vermeiren C, Motte P, Viot D, Mairet-Coello G, Courade J-P, Citron $\mathrm{M}$, et al. The tau positron-emission tomography tracer AV-1451 binds with similar affinities to tau fibrils and monoamine oxidases. Mov Disord. 2018;33:273-81.

36. Smith R, Schöll M, Honer M, Nilsson CF, Englund E, Hansson O. Tau neuropathology correlates with FDG-PET, but not AV-1451PET, in progressive supranuclear palsy. Acta Neuropathol. 2017;133:149-51.

37. Lowe VJ, Curran G, Fang P, Liesinger AM, Josephs KA, Parisi JE, et al. An autoradiographic evaluation of AV-1451 Tau PET in dementia. Acta Neuropathol Commun. 2016;4:58.

38. Sander K, Lashley T, Gami P, Gendron T, Lythgoe MF, Rohrer JD, et al. Characterization of tau positron emission tomography tracer [18F]AV-1451 binding to postmortem tissue in Alzheimer's disease, primary tauopathies, and other dementias. Alzheimers Dement. 2016;12:1116-24.

39. Villemagne VL, Furumoto S, Fodero-Tavoletti MT, Mulligan RS, Hodges J, Harada R, et al. In vivo evaluation of a novel tau imaging tracer for Alzheimer's disease. Eur J Nucl Med Mol Imaging. 2014;41:816-26.

40. Choi Y, Ha S, Lee Y-S, Kim YK, Lee DS, Kim DJ. Development of tau PET imaging ligands and their utility in preclinical and clinical studies. Nucl Med Mol Imaging (2010). 2018;52:24-30.

41. Fodero-Tavoletti MT, Okamura N, Furumoto S, Mulligan RS, Connor AR, McLean CA, et al. 18F-THK523: a novel in vivo tau imaging ligand for Alzheimer's disease. Brain. 2011;134: 1089-100.

42. Li Y, Tsui W, Rusinek H, Butler T, Mosconi L, Pirraglia E, et al. Cortical laminar binding of PET amyloid and tau tracers in Alzheimer disease. J Nucl Med. 2015;56:270-3.

43. Ishiki A, Okamura N, Furukawa K, Furumoto S, Harada R, Tomita N, et al. Longitudinal assessment of tau pathology in patients with Alzheimer's disease using [18F]THK-5117 positron emission tomography. Ginsberg SD, editor. PLoS One. 2015;10: e0140311.

44. Okamura N, Furumoto S, Harada R, Tago T, Yoshikawa T, Fodero-Tavoletti M, et al. Novel 18F-labeled arylquinoline derivatives for noninvasive imaging of tau pathology in Alzheimer disease. J Nucl Med. 2013;54:1420-7.

45. Jonasson M, Wall A, Chiotis K, Saint-Aubert L, Wilking H, Sprycha M, et al. Tracer kinetic analysis of (S)-18F-THK5117 as a PET tracer for assessing tau pathology. J Nucl Med. 2016;57:574-81.

46. Chiotis K, Saint-Aubert L, Savitcheva I, Jelic V, Andersen P, Jonasson M, et al. Imaging in-vivo tau pathology in Alzheimer's disease with THK5317 PET in a multimodal paradigm. Eur J Nucl Med Mol Imaging. 2016;43:1686-99.

47. Harada R, Okamura N, Furumoto S, Furukawa K, Ishiki A, Tomita N, et al. 18F-THK5351: a novel PET radiotracer for imaging neurofibrillary pathology in Alzheimer disease. J Nucl Med. 2016;57:208-14.

48. Ng KP, Pascoal TA, Mathotaarachchi S, Therriault J, Kang MS, Shin M, et al. Monoamine oxidase B inhibitor, selegiline, reduces 18F-THK5351 uptake in the human brain. Alzheimers Res Ther. 2017:9:25.

49. Sone D, Imabayashi E, Maikusa N, Okamura N, Furumoto S, Kudo Y, et al. Regional tau deposition and subregion atrophy of medial temporal structures in early Alzheimer's disease: a combined positron emission tomography/magnetic resonance imaging study. Alzheimer's Dement (Amsterdam, Netherlands). 2017;9: 35-40.

50. Betthauser TJ, Lao PJ, Murali D, Barnhart TE, Furumoto S, Okamura N, et al. In vivo comparison of tau radioligands ${ }^{18} \mathrm{~F}$ THK-5351 and ${ }^{18}$ F-THK-5317. J Nucl Med. 2017;58:996-1002.

51. Kikuchi A, Okamura N, Hasegawa T, Harada R, Watanuki S, Funaki Y, et al. In vivo visualization of tau deposits in corticobasal syndrome by 18F-THK5351 PET. Neurology. 2016;87:2309-16.

52. Brendel M, Schönecker S, Höglinger G, Lindner S, Havla J, Blautzik J, et al. [18F]-THK5351 PET correlates with topology and symptom severity in progressive supranuclear palsy. Front Aging Neurosci. 2017;9:440.

53. Yokoi T, Watanabe H, Yamaguchi H, Bagarinao E, Masuda M, Imai $\mathrm{K}$, et al. Involvement of the precuneus/posterior cingulate cortex is significant for the development of Alzheimer's disease: a PET (THK5351, PiB) and resting fMRI study. Front Aging Neurosci. 2018;10:304.

54. Harada R, Ishiki A, Kai H, Sato N, Furukawa K, Furumoto S, et al. Correlations of ${ }^{18}$ F-THK5351 PET with post-mortem burden of tau and astrogliosis in Alzheimer's disease. J Nucl Med. 2017;59(4):671-4 jnumed.117.197426.

55. Betthauser TJ, Cody KA, Zammit MD, Murali D, Converse AK, Barnhart TE, et al. In vivo characterization and quantification of neurofibrillary tau PET radioligand [ ${ }^{18}$ F]MK-6240 in humans from Alzheimer's disease dementia to young controls. J Nucl Med. 2018;60(1):93-9 jnumed.118.209650.

56. Walji AM, Hostetler ED, Selnick H, Zeng Z, Miller P, Bennacef I, et al. Discovery of 6-(Fluoro- ${ }^{18} F$ )-3-(1 $H$-pyrrolo[2,3- $c$ ]pyridin-1-yl)isoquinolin-5-amine ([ $\left.\left.{ }^{18} \mathrm{~F}\right]-\mathrm{MK}-6240\right)$ : a positron emission tomography (PET) imaging agent for quantification of neurofibrillary tangles (NFTs). J Med Chem. 2016;59:4778-89.

57. Pascoal TA, Shin M, Kang MS, Chamoun M, Chartrand D, Mathotaarachchi S, et al. In vivo quantification of neurofibrillary tangles with [18F]MK-6240. Alzheimers Res Ther. 2018;10:74.

58. Wong DF, Comley R, Kuwabara H, Rosenberg PB, Resnick SM, Ostrowitzki S, et al. First in-human PET study of 3 novel tau radiopharmaceuticals: [ ${ }^{11}$ C]RO6924963, [ ${ }^{11}$ C]RO6931643, and [ ${ }^{18}$ F]RO6958948. J Nucl Med. 2018;59(12):1869-76 jnumed.118.209916. 
59. Kuwabara H, Comley RA, Borroni E, Honer M, Kitzmiller K, Roberts J, et al. Evaluation of 18F-RO-948 (18F-RO6958948) for quantitative assessment of tau accumulation in the human brain with positron emission tomography. J Nucl Med. 2018;59(12): 1877-84 jnumed.118.214437.

60. Jennings D. Evaluation of [18F]MNI-815 as a potential PET radioligand for imaging tau protein in the brain of patients with tauopathies [Internet]. [cited 2018 Jun 5].

61. Bohorquez SS, Barret O, Tamagnan G, Alagille D, Marik J, Ayalon G, et al. Evaluation of tau burden in a cross-sectional cohort of alzheimer's disease subjects using [18F]GTP1 (Genentech tau probe 1). Alzheimers Dement. 2016;12:P1172.

62. Shimada H, Kitamura S, ONO M, Kimura Y, Ichise M, Takahata $\mathrm{K}$, et al. First-in-human pet study with $18 \mathrm{~F}-\mathrm{AM}-\mathrm{PBB} 3$ and $18 \mathrm{~F}$ PM-PBB3. Alzheimers Dement. 2017;13:P1104.

63. Kim JS. Evaluation of [18F]PI-2620 as a potential positron emission computed tomography radioligand for imaging tau protein in the brain [Internet]. [cited 2018 Jun 5].

64. Mueller A, Kroth H, Berndt M, Capotosti F, Molette J, Schieferstein $\mathrm{H}$, et al. Characterization of the novel PET tracer PI-2620 for the assessment of tau pathology in Alzheimer's disease and other tauopathies. J Nucl Med. 2017;58:847.

65. Petrou M, Frey KA, Kilbourn MR, Scott PJH, Raffel DM, Bohnen NI, et al. In vivo imaging of human cholinergic nerve terminals with (-)-5-(18)F-fluoroethoxybenzovesamicol: biodistribution, dosimetry, and tracer kinetic analyses. J Nucl Med. 2014;55: 396-404.

66. Kilbourn MR, Hockley B, Lee L, Sherman P, Quesada C, Frey $\mathrm{KA}$, et al. Positron emission tomography imaging of (2R,3R)-5$[(18) F]$ fluoroethoxybenzovesamicol in rat and monkey brain: a radioligand for the vesicular acetylcholine transporter. Nucl Med Biol. 2009;36:489-93.

67. Aghourian M, Legault-Denis C, Soucy J-P, Rosa-Neto P, Gauthier S, Kostikov A, et al. Quantification of brain cholinergic denervation in Alzheimer's disease using PET imaging with [18F]FEOBV. Mol Psychiatry. 2017;22:1531-8.

68. Laforest R, Lui H, HUssain J, Cummings K, Perlmutter J, Tu Z. Radiation dosimetry on 18F-VAT in human. J Nucl Med. 2018;59: 1002.

69. Tu Z, Zhang X, Jin H, Yue X, Padakanti PK, Yu L, et al. Synthesis and biological characterization of a promising F-18 PET tracer for vesicular acetylcholine transporter. Bioorg Med Chem. 2015;23: 4699-709.

70. Jin H, Yue X, Liu H, Han J, Flores H, Su Y, et al. Kinetic modeling of $\left[{ }^{18}\right.$ F]VAT, a novel radioligand for positron emission tomography imaging vesicular acetylcholine transporter in non-human primate brain. J Neurochem. 2018;144:791-804.

71. Ogawa K, Shiba K. In vivo and in vitro characteristics of radiolabeled vesamicol analogs as the vesicular acetylcholine transporter imaging agents. Contrast Media Mol Imaging. 2018;2018:1-14.

72. Wong DF, Kuwabara H, Pomper M, Holt DP, Brasic JR, George $\mathrm{N}$, et al. Human brain imaging of $\alpha 7 \mathrm{nAChR}$ with [(18)F]ASEM: a new PET radiotracer for neuropsychiatry and determination of drug occupancy. Mol Imaging Biol. 2014;16:730-8.

73. Hillmer AT, Li S, Zheng M-Q, Scheunemann M, Lin S, Nabulsi N, et al. PET imaging of $\alpha 7$ nicotinic acetylcholine receptors: a comparative study of [18F]ASEM and [18F]DBT-10 in nonhuman primates, and further evaluation of [18F]ASEM in humans. Eur J Nucl Med Mol Imaging. 2017;44:1042-50.

74. Gao Y, Kellar KJ, Yasuda RP, Tran T, Xiao Y, Dannals RF, et al. Derivatives of dibenzothiophene for positron emission tomography imaging of $\alpha 7$-nicotinic acetylcholine receptors. J Med Chem. 2013;56:7574-89.

75. Wong DF, Kuwabara H, Horti AG, Roberts JM, Nandi A, Cascella $\mathrm{N}$, et al. Brain PET imaging of $\alpha 7$-nAChR with [18F]ASEM: reproducibility, occupancy, receptor density, and changes in schizophrenia. Int J Neuropsychopharmacol. 2018;21(7):656-67.

76. Barret O, Hannestad J, Vala C, Alagille D, Tavares A, Laruelle M, et al. Characterization in humans of $18 \mathrm{~F}-\mathrm{MNI}-444$, a PET radiotracer for brain adenosine 2A receptors. J Nucl Med. 2015;56: 586-91.

77. Barret O, Hannestad J, Alagille D, Vala C, Tavares A, Papin C, et al. Adenosine $2 \mathrm{~A}$ receptor occupancy by tozadenant and preladenant in rhesus monkeys. J Nucl Med. 2014;55:1712-8.

78. Bretin F, Bahri MA, Bernard C, Warnock G, Aerts J, Mestdagh N, et al. Biodistribution and radiation dosimetry for the novel SV2A radiotracer [18F]UCB-H: first-in-human study. Mol Imaging Biol. 2015;17:557-64.

79. Warnock GI, Aerts J, Bahri MA, Bretin F, Lemaire C, Giacomelli F, et al. Evaluation of $18 \mathrm{~F}-\mathrm{UCB}-\mathrm{H}$ as a novel PET tracer for synaptic vesicle protein 2A in the brain. J Nucl Med. 2014;55: 1336-41.

80. Bahri MA, Plenevaux A, Aerts J, Bastin C, Becker G, Mercier J, et al. Measuring brain synaptic vesicle protein $2 \mathrm{~A}$ with positron emission tomography and [18F]UCB-H. Alzheimer's Dement (New York, N Y). 2017;3:481-6.

81. Mercier J, Provins L, Valade A. Discovery and development of SV2A PET tracers: potential for imaging synaptic density and clinical applications. Drug Discov Today Technol. 2017;25:4552.

82. Finnema SJ, Nabulsi NB, Eid T, Detyniecki K, Lin S-F, Chen M$\mathrm{K}$, et al. Imaging synaptic density in the living human brain. Sci Transl Med. 2016;8:348ra96.

83. Nabulsi NB, Mercier J, Holden D, Carre S, Najafzadeh S, Vandergeten M-C, et al. Synthesis and preclinical evaluation of $11 \mathrm{C}-\mathrm{UCB}-\mathrm{J}$ as a PET tracer for imaging the synaptic vesicle glycoprotein 2A in the brain. J Nucl Med. 2016;57:777-84.

84. Finnema SJ, Nabulsi NB, Mercier J, Lin S, Chen M-K, Matuskey $\mathrm{D}$, et al. Kinetic evaluation and test-retest reproducibility of [ ${ }^{11}$ C]UCB-J, a novel radioligand for positron emission tomography imaging of synaptic vesicle glycoprotein $2 \mathrm{~A}$ in humans. J Cereb Blood Flow Metab. 2017;38(11):2041-52 0271678X1772494.

85. Tyacke RJ, Myers JFM, Venkataraman A, Mick I, Turton S, Passchier J, et al. Evaluation of ${ }^{11} \mathrm{C}$-BU99008, a positron emission tomography ligand for the Imidazoline ${ }_{2}$ binding site in human brain. J Nucl Med. 2018;59(10):1597-602 jnumed.118.208009.

86. Tyacke RJ, Fisher A, Robinson ESJ, Grundt P, Turner EM, Husbands SM, et al. Evaluation and initial in vitro and ex vivo characterization of the potential positron emission tomography ligand, BU99008 (2-(4,5-Dihydro-1H-imidazol-2-yl)-1- methyl1H-indole), for the imidazoline2 binding site. Synapse. 2012;66: 542-51.

87. Parker CA, Nabulsi N, Holden D, Lin SF, Cass T, Labaree D, et al. Evaluation of 11C-BU99008, a PET ligand for the imidazoline2 binding sites in rhesus brain. J Nucl Med. 2014;55:838-44.

88. Toyohara J, Sakata M, Oda K, Ishii K, Ito K, Hiura M, et al. Initial human PET studies of metabotropic glutamate receptor type 1 ligand 11C-ITMM. J Nucl Med. 2013;54:1302-7.

89. Fujinaga M, Yamasaki T, Yui J, Hatori A, Xie L, Kawamura K, et al. Synthesis and evaluation of novel radioligands for positron emission tomography imaging of metabotropic glutamate receptor subtype 1 (mGluR1) in rodent brain. J Med Chem. 2012;55:234252.

90. Ishibashi K, Miura Y, Ishikawa K, Ishii K, Ishiwata K. Decreased metabotropic glutamate receptor type 1 availability in a patient with spinocerebellar ataxia type 6: a 11C-ITMM PET study. J Neurol Sci. 2015;355:202-5.

91. Ishibashi K, Miura Y, Ishikawa K, Zhang M-R, Toyohara J, Ishiwata $\mathrm{K}$, et al. Relationship between type 1 metabotropic 
glutamate receptors and cerebellar ataxia. J Neurol. 2016;263: 2179-87.

92. Sakata M, Toyohara J, Ishibashi K, Wagatsuma K, Ishii K, Zhang $\mathrm{M}-\mathrm{R}$, et al. Age and gender effects of 11C-ITMM binding to metabotropic glutamate receptor type 1 in healthy human participants. Neurobiol Aging. 2017;55:72-7.

93. Ishibashi K, Miura Y, Toyohara J, Ishii K, Ishiwata K. Comparison of imaging using $11 \mathrm{C}$-ITMM and $18 \mathrm{~F}$-FDG for the detection of cerebellar ataxia. J Neurol Sci. 2017;375:97-102.

94. Zanotti-Fregonara P, Xu R, Zoghbi SS, Liow J-S, Fujita M, Veronese M, et al. The PET radioligand 18F-FIMX images and quantifies metabotropic glutamate receptor 1 in proportion to the regional density of its gene transcript in human brain. J Nucl Med. 2016;57:242-7.

95. Xu R, Zanotti-Fregonara P, Zoghbi SS, Gladding RL, Woock AE, Innis RB, et al. Synthesis and evaluation in monkey of [(18)F]4fluoro-N-methyl-N-(4-(6-(methylamino)pyrimidin-4-yl)thiazol-2yl)benzamide ([(18)F]FIMX): a promising radioligand for PET imaging of brain metabotropic glutamate receptor 1 (mGluR1). J Med Chem. 2013;56:9146-55.

96. Naganawa M, Jacobsen LK, Zheng M-Q, Lin S-F, Banerjee A, Byon W, et al. Evaluation of the agonist PET radioligand $\left[{ }^{11} \mathrm{C}\right] \mathrm{GR} 103545$ to image kappa opioid receptor in humans: kinetic model selection, test-retest reproducibility and receptor occupancy by the antagonist PF-04455242. Neuroimage. 2014;99:6979.

97. Tomasi G, Nabulsi N, Zheng M-Q, Weinzimmer D, Ropchan J, Blumberg L, et al. Determination of in vivo Bmax and $\mathrm{Kd}$ for [11C]GR103545, an agonist PET tracer for kappa opioid receptors: a study in nonhuman primates. J Nucl Med. 2013;54:600.

98. Naganawa M, Zheng M-Q, Nabulsi N, Tomasi G, Henry S, Lin SF, et al. Kinetic modeling of (11)C-LY2795050, a novel antagonist radiotracer for PET imaging of the kappa opioid receptor in humans. J Cereb Blood Flow Metab. 2014;34:1818-25.

99. Zheng M-Q, Nabulsi N, Kim SJ, Tomasi G, Lin S-F, Mitch C, et al. Synthesis and evaluation of 11C-LY2795050 as a K-opioid receptor antagonist radiotracer for PET imaging. J Nucl Med. 2013;54:455-63.

100. Naganawa M, Dickinson GL, Zheng M-Q, Henry S, Vandenhende F, Witcher J, et al. Receptor occupancy of the K-opioid antagonist LY2456302 measured with positron emission tomography and the novel radiotracer 11C-LY2795050. J Pharmacol Exp Ther. 2016;356:260-6.

101. Naganawa M, Zheng M-Q, Henry S, Nabulsi N, Lin S-F, Ropchan $\mathrm{J}$, et al. Test-retest reproducibility of binding parameters in humans with 11C-LY2795050, an antagonist PET radiotracer for the $\mathrm{K}$ opioid receptor. J Nucl Med. 2015;56:243-8.

102. Kim SJ, Zheng M-Q, Nabulsi N, Labaree D, Ropchan J, Najafzadeh S, et al. Determination of the in vivo selectivity of a new K-opioid receptor antagonist PET tracer 11C-LY2795050 in the rhesus monkey. J Nucl Med. 2013;54:1668-74.

103. Ettrup A, da Cunha-Bang S, McMahon B, Lehel S, Dyssegaard A, Skibsted AW, et al. Serotonin $2 \mathrm{~A}$ receptor agonist binding in the human brain with [ $\left.{ }^{11} \mathrm{C}\right]$ Cimbi-36. J Cereb Blood Flow Metab. 2014;34:1188-96.

104. Finnema SJ, Stepanov V, Ettrup A, Nakao R, Amini N, Svedberg $\mathrm{M}$, et al. Characterization of [11C]Cimbi-36 as an agonist PET radioligand for the 5-HT2A and 5-HT2C receptors in the nonhuman primate brain. Neuroimage. 2014;84:342-53.

105. Ettrup A, Svarer C, McMahon B, da Cunha-Bang S, Lehel S, Møller K, et al. Serotonin 2A receptor agonist binding in the human brain with [11C]Cimbi-36: Test-retest reproducibility and head-to-head comparison with the antagonist [18F]altanserin. Neuroimage. 2016;130:167-74.

106. Koole M, Schmidt M, Hijzen A, Ravenstijn P, Vandermeulen C, Van Weehaeghe D, et al. 18F-JNJ-64413739, a novel PET ligand for the P2X7 ion channel: radiation dosimetry, kinetic modeling, test-retest variability and occupancy of the $\mathrm{P} 2 \mathrm{X} 7$ antagonist JNJ54175446. J Nucl Med. 2018;60(5):683-90 jnumed.118.216747.

107. Janssen B, Vugts DJ, Wilkinson SM, Ory D, Chalon S, Hoozemans JJM, et al. Identification of the allosteric P2X7 receptor antagonist [11C]SMW139 as a PET tracer of microglial activation. Sci Rep. 2018;8:6580.

108. Van Weehaeghe D. TSPO versus P2X7 as target for neuroinflammation - an in vitro and in vivo study. Eur Conf Clin Neuroimaging. 2018;OC21.

109. Ory D, Celen S, Gijsbers R, Van C, Haute D, Postnov A, et al. Preclinical evaluation of a $\mathrm{P} 2 \mathrm{X} 7$ receptor selective radiotracer: positron emission tomography studies in a rat model with local overexpression of the human P2X7 receptor and in non-human primates. J Nucl Med. 2016;57(9):1436-41.

110. Green M, Hutchins G, Fletcher J, Territo W, Polson H, Trussell H, et al. Distribution of the P2X7-receptor-targeted [11C]GSK1482160 radiopharmaceutical in normal human subjects. J Nucl Med. 2018;59:1009.

111. Territo PR, Meyer JA, Peters JS, Riley AA, McCarthy BP, Gao M, et al. Characterization of ${ }^{11} \mathrm{C}$-GSK1482160 for targeting the P2X7 receptor as a biomarker for neuroinflammation. J Nucl Med. 2017;58:458-65.

112. Han J, Liu H, Liu C, Jin H, Perlmutter JS, Egan TM, et al. Pharmacologic characterizations of a $\mathrm{P} 2 \mathrm{X} 7$ receptor-specific radioligand, [11C]GSK1482160 for neuroinflammatory response. Nucl Med Commun. 2017;38:372-82.

113. Henry K, Kim M-J, Shrestha S, Cortes M, Singh P, Morse C, et al. S173. evaluation of a potent and selective PET radioligand to image COX-1 in human and nonhuman primates. Biol Psychiatry. 2018;83:S415.

114. Singh P, Shrestha S, Cortes-Salva MY, Jenko KJ, Zoghbi SS, Morse CL, et al. 3-Substituted 1,5-Diaryl-1 $H$-1,2,4-triazoles as prospective PET radioligands for imaging brain COX-1 in monkey. Part 1: synthesis and pharmacology. ACS Chem Neurosci. 2018; acschemneuro.8b00102.

115. Mansur A, Comley R, Lewis Y, Middleton L, Huiban M, Guo Q, et al. Imaging of mitochondrial complex 1 with $18 \mathrm{~F}-\mathrm{BCPP}-\mathrm{EF}$ in the healthy human brain. J Nucl Med. 2018;59:1709.

116. Tsukada H, Nishiyama S, Fukumoto D, Kanazawa M, Harada N. Novel PET probes 18F-BCPP-EF and 18F-BCPP-BF for mitochondrial complex I: a PET study in comparison with 18F-BMS747158-02 in rat brain. J Nucl Med. 2014;55:473-80.

117. Tsukada H, Ohba H, Kanazawa M, Kakiuchi T, Harada N. Evaluation of 18F-BCPP-EF for mitochondrial complex 1 imaging in the brain of conscious monkeys using PET. Eur J Nucl Med Mol Imaging. 2014;41:755-63.

118. Harada N, Nishiyama S, Kanazawa M, Tsukada H. Development of novel PET probes, [ $\left.{ }^{18} \mathrm{~F}\right] \mathrm{BCPP}-\mathrm{EF},\left[{ }^{18} \mathrm{~F}\right] \mathrm{BCPP}-\mathrm{BF}$, and [ ${ }^{11}$ C]BCPP-EM for mitochondrial complex 1 imaging in the living brain. J Label Compd Radiopharm. 2013;56:553-61.

119. Fukuta T, Asai T, Ishii T, Koide H, Kiyokawa C, Hashimoto M, et al. Non-invasive evaluation of neuroprotective drug candidates for cerebral infarction by PET imaging of mitochondrial complexI activity. Sci Rep. 2016;6:30127.

120. Tsukada H, Nishiyama S, Ohba H, Kanazawa M, Kakiuchi T, Harada N. Comparing amyloid- $\beta$ deposition, neuroinflammation, glucose metabolism, and mitochondrial complex I activity in brain: a PET study in aged monkeys. Eur J Nucl Med Mol Imaging. 2014;41:2127-36.

121. Tsukada H, Kanazawa M, Ohba H, Nishiyama S, Harada N, Kakiuchi T. PET imaging of mitochondrial complex I with 18FBCPP-EF in the brains of MPTP-treated monkeys. J Nucl Med. 2016;57:950-3. 
122. Wey H-Y, Gilbert TM, Zürcher NR, She A, Bhanot A, Taillon BD, et al. Insights into neuroepigenetics through human histone deacetylase PET imaging. Sci Transl Med. 2016;8:351ra106.

123. Wang C, Schroeder FA, Wey H-Y, Borra R, Wagner FF, Reis S, et al. In vivo imaging of histone deacetylases (HDACs) in the central nervous system and major peripheral organs. J Med Chem. 2014;57:7999-8009.

124. Wey H-Y, Wang C, Schroeder FA, Logan J, Price JC, Hooker JM. Kinetic analysis and quantification of $\left[{ }^{11} \mathrm{C}\right]$ Martinostat for in vivo HDAC imaging of the brain. ACS Chem Neurosci. 2015;6:70815.

125. Gilbert TM, Zürcher NR, Wu CJ, Bhanot A, Hightower BG, Kim $\mathrm{M}$, et al. PET neuroimaging reveals histone deacetylase dysregulation in schizophrenia. J Clin Invest. 2019;129:364-72.

126. Naganawa M, Waterhouse RN, Nabulsi N, Lin S-F, Labaree D, Ropchan J, et al. First-in-human assessment of the novel PDE2A PET radiotracer 18F-PF-05270430. J Nucl Med. 2016;57:138895.

127. Chen L, Nabulsi N, Naganawa M, Zasadny K, Skaddan MB, Zhang L, et al. Preclinical evaluation of 18F-PF-05270430, a novel PET radioligand for the phosphodiesterase 2A Enzyme. J Nucl Med. 2016;57:1448-53.

128. Van Laere K, Ahmad RU, Hudyana H, Celen S, Dubois K, Schmidt ME, et al. Human biodistribution and dosimetry of 18F-JNJ42259152, a radioligand for phosphodiesterase 10A imaging. Eur J Nucl Med Mol Imaging. 2013;40:254-61.

129. Celen S, Koole M, Ooms M, De Angelis M, Sannen I, Cornelis J, et al. Preclinical evaluation of [18F]JNJ42259152 as a PET tracer for PDE10A. Neuroimage. 2013;82:13-22.

130. Van Laere K, Ahmad RU, Hudyana H, Dubois K, Schmidt ME, Celen S, et al. Quantification of 18F-JNJ-42259152, a novel phosphodiesterase 10A PET tracer: kinetic modeling and test-retest study in human brain. J Nucl Med. 2013;54:1285-93.

131. Ahmad R, Bourgeois S, Postnov A, Schmidt ME, Bormans G, Van Laere K, et al. PET imaging shows loss of striatal PDE10A in patients with Huntington disease. Neurology. 2014;82:279-81.

132. Barret O, Thomae D, Tavares A, Alagille D, Papin C, Waterhouse $\mathrm{R}$, et al. In vivo assessment and dosimetry of 2 novel PDE10A PET radiotracers in humans: 18F-MNI-659 and 18F-MNI-654. J Nucl Med. 2014;55:1297-304.

133. Delnomdedieu M, Forsberg A, Ogden A, Fazio P, Yu C-R, Stenkrona $\mathrm{P}$, et al. In vivo measurement of PDE10A enzyme occupancy by positron emission tomography (PET) following single oral dose administration of PF-02545920 in healthy male subjects. Neuropharmacology. 2017;117:171-81.

134. Russell DS, Barret O, Jennings DL, Friedman JH, Tamagnan GD, Thomae D, et al. The phosphodiesterase 10 positron emission tomography tracer, $\left[{ }^{18} \mathrm{~F}\right] \mathrm{MNI}-659$, as a novel biomarker for early huntington disease. JAMA Neurol. 2014;71:1520.

135. Russell DS, Jennings DL, Barret O, Tamagnan GD, Carroll VM, Caillé F, et al. Change in PDE10 across early Huntington disease assessed by [18F]MNI-659 and PET imaging. Neurology. 2016;86:748-54

136. Plisson C, Weinzimmer D, Jakobsen S, Natesan S, Salinas C, Lin S-F, et al. Phosphodiesterase 10A PET radioligand development program: from pig to human. J Nucl Med. 2014;55:595-601.

137. Searle G, Reis Marques T, Plisson C, Natesan S, Howes O, Tzortzi A, et al. Kinetic analysis of [11C]-IMA107, a novel PET radiotracer for PDE10A. J Nucl Med. 2014;55:204.

138. Niccolini F, Foltynie T, Reis Marques T, Muhlert N, Tziortzi AC, Searle GE, et al. Loss of phosphodiesterase 10A expression is associated with progression and severity in Parkinson's disease. Brain. 2015;138:3003-15.

139. Niccolini F, Haider S, Reis Marques T, Muhlert N, Tziortzi AC, Searle GE, et al. Altered PDE10A expression detectable early before symptomatic onset in Huntington's disease. Brain. 2015;138:3016-29.

140. Kehler J, Kilburn JP, Estrada S, Christensen SR, Wall A, Thibblin A, et al. Discovery and development of 11C-Lu AE92686 as a radioligand for PET imaging of phosphodiesterase 10A in the brain. J Nucl Med. 2014;55:1513-8.

141. Yang K-C, Stepanov V, Amini N, Martinsson S, Takano A, Nielsen J, et al. Characterization of [11C]Lu AE92686 as a PET radioligand for phosphodiesterase $10 \mathrm{~A}$ in the nonhuman primate brain. Eur J Nucl Med Mol Imaging. 2017;44:308-20.

142. Bodén R, Persson J, Wall A, Lubberink M, Ekselius L, Larsson E$\mathrm{M}$, et al. Striatal phosphodiesterase 10A and medial prefrontal cortical thickness in patients with schizophrenia: a PET and MRI study. Transl Psychiatry. 2017;7:e1050.

143. Takano A, Stenkrona P, Stepanov V, Amini N, Martinsson S, Tsai $\mathrm{M}$, et al. A human [11C]T-773 PET study of PDE10A binding after oral administration of TAK-063, a PDE10A inhibitor. Neuroimage. 2016;141:10-7.

144. Takano A, Stepanov V, Nakao R, Amini N, Gulyás B, Kimura H, et al. Brain PET measurement of PDE10A occupancy by TAK063, a new PDE10A inhibitor, using [ $\left.{ }^{11} \mathrm{C}\right] \mathrm{T}-773$ in nonhuman primates. Synapse. 2016;70:253-63.

145. Takano A, Stepanov V, Gulyás B, Nakao R, Amini N, Miura S, et al. Evaluation of a novel PDE10APET radioligand, [ $\left.{ }^{11} \mathrm{C}\right] \mathrm{T}-$ 773 , in nonhuman primates: brain and whole body PET and brain autoradiography. Synapse. 2015;69:345-55.

146. Rusjan PM, Wilson AA, Mizrahi R, Boileau I, Chavez SE, Lobaugh NJ, et al. Mapping human brain fatty acid amide hydrolase activity with PET. J Cereb Blood Flow Metab. 2013;33:40714.

147. Wilson AA, Garcia A, Parkes J, Houle S, Tong J, Vasdev N. [11C]CURB: evaluation of a novel radiotracer for imaging fatty acid amide hydrolase by positron emission tomography. Nucl Med Biol. 2011;38:247-53.

148. Boileau I, Rusjan PM, Williams B, Mansouri E, Mizrahi R, De Luca V, et al. Blocking of fatty acid amide hydrolase activity with PF-04457845 in human brain: a positron emission tomography study with the novel radioligand [(11)C]CURB. J Cereb Blood Flow Metab. 2015;35:1827-35.

149. Boileau I, Tyndale RF, Williams B, Mansouri E, Westwood DJ, Le Foll B, et al. The fatty acid amide hydrolase $\mathrm{C} 385 \mathrm{~A}$ variant affects brain binding of the positron emission tomography tracer [11C]CURB. J Cereb Blood Flow Metab. 2015;35:1237-40.

150. Postnov A, Schmidt ME, Pemberton DJ, de Hoon J, van Hecken A, van den Boer M, et al. Fatty acid amide hydrolase inhibition by JNJ-42165279: a multiple-ascending dose and a positron emission tomography study in healthy volunteers. Clin Transl Sci. 2018;11(4):397-404.

151. Liu P, Hamill TG, Chioda M, Chobanian H, Fung S, Guo Y, et al. Discovery of MK-3168: a PET tracer for imaging brain fatty acid amide hydrolase. ACS Med Chem Lett. 2013;4:509-13.

152. Joshi A, Li W, Sanabria S, Holahan M, Purcell M, Declercq R, et al. Translational studies with [11C]MK-3168, a PET tracer for fatty acid amide hydrolase (FAAH). J Nucl Med. 2012;53:397.

153. Coenen HH, Gee AD, Adam M, Antoni G, Cutler CS, Fujibayashi $\mathrm{Y}$, et al. Open letter to journal editors on: International Consensus Radiochemistry Nomenclature Guidelines. Ann Nucl Med. 2018;32:236-8.

154. Jack CR, Knopman DS, Jagust WJ, Petersen RC, Weiner MW, Aisen PS, et al. Tracking pathophysiological processes in Alzheimer's disease: an updated hypothetical model of dynamic biomarkers. Lancet Neurol. 2013;12:207-16.

155. Goedert M. Alpha-synuclein and neurodegenerative diseases. Nat Rev Neurosci. 2001;2:492-501. 
156. Dimou E, Booij J, Rodrigues M, Prosch H, Attems J, Knoll P, et al. Amyloid PET and MRI in Alzheimer's disease and mild cognitive impairment. Curr Alzheimer Res. 2009;6:312-9.

157. Braak H, Braak E, Bohl J, Reintjes R. Age, neurofibrillary changes, a beta-amyloid and the onset of Alzheimer's disease. Neurosci Lett. 1996;210:87-90.

158. Quiroz YT, Sperling RA, Norton DJ, Baena A, ArboledaVelasquez JF, Cosio D, et al. Association between amyloid and tau accumulation in young adults with autosomal dominant Alzheimer disease. JAMA Neurol. 2018;75(5):548-56.

159. Maruyama M, Shimada H, Suhara T, Shinotoh H, Ji B, Maeda J, et al. Imaging of tau pathology in a tauopathy mouse model and in Alzheimer patients compared to normal controls. Neuron. 2013;79:1094-108.

160. Shin J, Lee S-Y, Kim S-H, Kim Y-B, Cho S-J. Multitracer PET imaging of amyloid plaques and neurofibrillary tangles in Alzheimer's disease. Neuroimage. 2008;43:236-44.

161. Hashimoto H, Kawamura K, Igarashi N, Takei M, Fujishiro T, Aihara Y, et al. Radiosynthesis, photoisomerization, biodistribution, and metabolite analysis of 11C-PBB3 as a clinically useful PET probe for imaging of tau pathology. J Nucl Med. 2014;55:1532-8.

162. Kimura $Y$, Ichise $M$, Ito $H$, Shimada H, Ikoma $Y$, Seki $C$, et al. PET quantification of tau pathology in human brain with 11CPBB3. J Nucl Med. 2015;56:1359-65.

163. Saint-Aubert L, Lemoine L, Chiotis K, Leuzy A, RodriguezVieitez E, Nordberg A. Tau PET imaging: present and future directions. Mol Neurodegener. 2017;12:19.

164. Cho H, Choi JY, Hwang MS, Kim YJ, Lee HM, Lee HS, et al. In vivo cortical spreading pattern of tau and amyloid in the Alzheimer disease spectrum. Ann Neurol. 2016;80:247-58.

165. Honer M, Gobbi L, Knust H, Kuwabara H, Muri D, Koerner M, et al. Preclinical evaluation of 18F-RO6958948, 11CRO6931643, and 11C-RO6924963 as novel PET radiotracers for imaging tau aggregates in Alzheimer disease. J Nucl Med. 2018;59:675-81.

166. Xia C-F, Arteaga J, Chen G, Gangadharmath U, Gomez LF, Kasi D, et al. [18F]T807, a novel tau positron emission tomography imaging agent for Alzheimer's disease. Alzheimers Dement. 2013;9:666-76

167. Fowler JS, Volkow ND, Wang G-J, Pappas N, Logan J, Macgregor $\mathrm{R}$, et al. Neuropharmacological actions of cigarette smoke. J Addict Dis. 1998;17:23-34.

168. Fowler JS, Volkow ND, Wang GJ, Logan J, Pappas N, Shea C, et al. Age-related increases in brain monoamine oxidase B in living healthy human subjects. Neurobiol Aging. 18:431-5.

169. Mueller A, Kroth H, Berndt M, Capotosti F, Molette J, Schieferstein H, et al. First-in-human pet study with 18F-AMPBB3 and 18F-PM-PBB3. J Nucl Med. 2017;58:847.

170. Li C, Götz J. Tau-based therapies in neurodegeneration: opportunities and challenges. Nat Rev Drug Discov. 2017;16:863-83.

171. King A. The search for better animal models of Alzheimer's disease. Nature. 2018;559:S13-5.

172. Imming P, Sinning C, Meyer A. Drugs, their targets and the nature and number of drug targets. Nat Rev Drug Discov. 2006;5:82134.

173. Dupont A-C, Largeau B, Guilloteau D, Santiago Ribeiro MJ, Arlicot N. The Place of PET to assess new therapeutic effectiveness in neurodegenerative diseases. Contrast Media Mol Imaging. 2018;2018:1-15.

174. Roy R, Niccolini F, Pagano G, Politis M. Cholinergic imaging in dementia spectrum disorders. Eur J Nucl Med Mol Imaging. 2016;43:1376-86.

175. Raina P, Santaguida P, Ismaila A, Patterson C, Cowan D, Levine $\mathrm{M}$, et al. Effectiveness of cholinesterase inhibitors and memantine for treating dementia: evidence review for a clinical Practice guideline. Ann Intern Med. 2008;148:379.

176. Müller MLTM, Bohnen NI. Cholinergic dysfunction in Parkinson's disease. Curr Neurol Neurosci Rep. 2013;13:377.

177. Schmitz TW, Nathan Spreng R, Weiner MW, Aisen P, Petersen R, Jack CR, et al. Basal forebrain degeneration precedes and predicts the cortical spread of Alzheimer's pathology. Nat Commun. 2016;7:13249.

178. Butler T, Harvey P, Deshpande A, Tanzi E, Li Y, Tsui W, et al. Basal forebrain septal nuclei are enlarged in healthy subjects prior to the development of Alzheimer's disease. Neurobiol Aging. 2018;65:201-5.

179. Bohnen NI, Grothe MJ, Ray NJ, Müller MLTM, Teipel SJ. Recent advances in cholinergic imaging and cognitive decline - revisiting the cholinergic hypothesis of dementia. Curr Geriatr Reports. 2018;7:1-11.

180. Kuhl DE, Koeppe RA, Fessler JA, Minoshima S, Ackermann RJ, Carey JE, et al. In vivo mapping of cholinergic neurons in the human brain using SPECT and IBVM. J Nucl Med. 1994;35: 405-10.

181. Mazère J, Lamare F, Allard M, Fernandez P, Mayo W. 123IIodobenzovesamicol SPECT imaging of cholinergic systems in dementia with Lewy bodies. J Nucl Med. 2017;58:123-8.

182. Freedman R, Hall M, Adler LE, Leonard S. Evidence in postmortem brain tissue for decreased numbers of hippocampal nicotinic receptors in schizophrenia. Biol Psychiatry. 1995;38:22-33.

183. Guan ZZ, Zhang X, Blennow K, Nordberg A. Decreased protein level of nicotinic receptor alpha7 subunit in the frontal cortex from schizophrenic brain. Neuroreport. 1999;10:1779-82.

184. Marutle A, Zhang X, Court J, Piggott M, Johnson M, Perry R, et al. Laminar distribution of nicotinic receptor subtypes in cortical regions in schizophrenia. J Chem Neuroanat. 2001;22:115-26.

185. Verbois SL, Sullivan PG, Scheff SW, Pauly JR. Traumatic brain injury reduces hippocampal $\alpha 7$ Nicotinic cholinergic receptor binding. J Neurotrauma. 2000;17:1001-11.

186. Verbois SL, Scheff SW, Pauly JR. Time-dependent changes in rat brain cholinergic receptor expression after experimental brain injury. J Neurotrauma. 2002;19:1569-85.

187. Thomsen MS, Weyn A, Mikkelsen JD. Hippocampal $\alpha 7$ nicotinic acetylcholine receptor levels in patients with schizophrenia, bipolar disorder, or major depressive disorder. Bipolar Disord. 2011;13:701-7.

188. Ishikawa M, Sakata M, Toyohara J, Oda K, Ishii K, Wu J, et al Occupancy of $\alpha 7$ nicotinic acetylcholine receptors in the brain by tropisetron: a positron emission tomography study using [(11)C]CHIBA-1001 in healthy human subjects. Clin Psychopharmacol Neurosci. 2011;9:111-6.

189. Horti AG. Development of [(18)F]ASEM, a specific radiotracer for quantification of the $\alpha 7-\mathrm{nAChR}$ with positron-emission tomography. Biochem Pharmacol. 2015;97:566-75.

190. Gundlach AL, Largent BL, Snyder SH. Autoradiographic localization of sigma receptor binding sites in guinea pig and rat central nervous system with (+)3H-3-(3-hydroxyphenyl)-N-(1propyl)piperidine. J Neurosci. 1986;6:1757-70.

191. Horti AG, Gao Y, Kuwabara H, Wang Y, Abazyan S, Yasuda RP, et al. 18F-ASEM, a radiolabeled antagonist for imaging the 7nicotinic acetylcholine receptor with PET. J Nucl Med. 2014;55: $672-7$.

192. Villar-Menendez I. Reduced striatal adenosine A2A receptor levels define a molecular subgroup in schizophrenia. J Psychiatr Res. 2014;51:49-59.

193. Albasanz JL, Rodríguez A, Ferrer I, Martín M. Adenosine A 2A receptors are up-regulated in Pick's disease frontal cortex. Brain Pathol. 2006;16:249-55

194. Arosio B, Viazzoli C, Mastronardi L, Bilotta C, Vergani C, Bergamaschini L. Adenosine A2A receptor expression in 
peripheral blood mononuclear cells of patients with mild cognitive impairment. J Alzheimers Dis. 2010;20:991-6.

195. Martini C, Tuscano D, Trincavelli ML, Cerrai E, Bianchi M, Ciapparelli A, et al. Upregulation of A2A adenosine receptors in platelets from patients affected by bipolar disorders under treatment with typical antipsychotics. J Psychiatr Res. 2006;40:81-8.

196. Villar-Menéndez I, Blanch M, Tyebji S, Pereira-Veiga T, Albasanz JL, Martín M, et al. Increased 5-methylcytosine and decreased 5hydroxymethylcytosine levels are associated with reduced striatal A2AR levels in Huntington's disease. NeuroMolecular Med. 2013; 15:295-309.

197. Orr AG, Hsiao EC, Wang MM, Ho K, Kim DH, Wang X, et al. Astrocytic adenosine receptor A2A and Gs-coupled signaling regulate memory. Nat Neurosci. 2015;18:423-34.

198. Marcellino D, Roberts DCS, Navarro G, Filip M, Agnati L, Lluís $\mathrm{C}$, et al. Increase in $\mathrm{A} 2 \mathrm{~A}$ receptors in the nucleus accumbens after extended cocaine self-administration and its disappearance after cocaine withdrawal. Brain Res. 2007;1143:208-20.

199. Costa MS, Ardais AP, Fioreze GT, Mioranzza S, Botton PHS, Portela LV, et al. Treadmill running frequency on anxiety and hippocampal adenosine receptors density in adult and middleaged rats. Prog Neuro-Psychopharmacol Biol Psychiatry. 2012;36:198-204.

200. Masuo Y, Ishido M, Morita M, Sawa H, Nagashima K, Niki E. Behavioural characteristics and gene expression in the hyperactive wiggling (Wig) rat. Eur J Neurosci. 2007;25:3659-66.

201. Giraldez L, Zanetti F, Girardi E. Striatum adenosine A2 receptors are modified during seizure: effect of cyclopentyladenosine administration. Neurochem Res. 1999;24:1217-23.

202. Bruzzese L, Rostain J-C, Née L, Condo J, Mottola G, Adjriou N, et al. Effect of hyperoxic and hyperbaric conditions on the adenosinergic pathway and CD26 expression in rat. J Appl Physiol. 2015;119:140-7.

203. Liu Y, Zou H, Zhao P, Sun B, Wang J, Kong Q, et al. Activation of the adenosine $\mathrm{A} 2 \mathrm{~A}$ receptor attenuates experimental autoimmune encephalomyelitis and is associated with increased intracellular calcium levels. Neuroscience. 2016;330:150-61.

204. Tomiyama M, Kimura T, Maeda T, Tanaka H, Kannari K, Baba M. Upregulation of striatal adenosine A2A receptor mRNA in 6hydroxydopamine-lesioned rats intermittently treated with LDOPA. Synapse. 2004;52:218-22.

205. Quiroz C, Pearson V, Gulyani S, Allen R, Earley C, Ferré S. Upregulation of striatal adenosine $\mathrm{A} 2 \mathrm{~A}$ receptors with iron deficiency in rats: Effects on locomotion and cortico-striatal neurotransmission. Exp Neurol. 2010;224:292-8.

206. Laurent C, Burnouf S, Ferry B, Batalha VL, Coelho JE, Baqi Y, et al. A2A adenosine receptor deletion is protective in a mouse model of tauopathy. Mol Psychiatry. 2016;21:97-107.

207. van Waarde A, Dierckx RAJO, Zhou X, Khanapur S, Tsukada H, Ishiwata $\mathrm{K}$, et al. Potential therapeutic applications of adenosine $\mathrm{A}$ ${ }_{2 \mathrm{~A}}$ receptor ligands and opportunities for $\mathrm{A}_{2 \mathrm{~A}}$ receptor imaging. Med Res Rev. 2018;38:5-56.

208. Cheffer A, Castillo ARG, Corrêa-Velloso J, Gonçalves MCB, Naaldijk Y, Nascimento IC, et al. Purinergic system in psychiatric diseases. Mol Psychiatry. 2018;23:94-106.

209. Moresco RM, Todde S, Belloli S, Simonelli P, Panzacchi A, Rigamonti $\mathrm{M}$, et al. In vivo imaging of adenosine A2A receptors in rat and primate brain using [11C]SCH442416. Eur J Nucl Med Mol Imaging. 2005;32:405-13.

210. Mishina M, Ishiwata K, Naganawa M, Kimura Y, Kitamura S, Suzuki M, et al. Adenosine A2A receptors measured with [11C]TMSX PET in the striata of Parkinson's disease patients. Linden R, editor. PLoS One. 2011;6:e17338.

211. Sihver W, Schulze A, Wutz W, Stüsgen S, Olsson RA, Bier D, et al. Autoradiographic comparison of in vitro binding characteristics of various tritiated adenosine $\mathrm{A} 2 \mathrm{~A}$ receptor ligands in rat, mouse and pig brain and first ex vivo results. Eur J Pharmacol. 2009;616:107-14.

212. Terry RD, Masliah E, Salmon DP, Butters N, DeTeresa R, Hill R, et al. Physical basis of cognitive alterations in alzheimer's disease: Synapse loss is the major correlate of cognitive impairment. Ann Neurol. 1991;30:572-80.

213. Robinson JL, Molina-Porcel L, Corrada MM, Raible K, Lee EB Lee VM-Y, et al. Perforant path synaptic loss correlates with cognitive impairment and Alzheimer's disease in the oldest-old. Brain. 2014;137:2578-87.

214. Glantz LA, Lewis DA. Decreased dendritic spine density on prefrontal cortical pyramidal neurons in schizophrenia. Arch Gen Psychiatry. 2000;57:65-73.

215. Kang HJ, Voleti B, Hajszan T, Rajkowska G, Stockmeier CA, Licznerski P, et al. Decreased expression of synapse-related genes and loss of synapses in major depressive disorder. Nat Med. 2012;18:1413-7.

216. Mercier J, Archen L, Bollu V, Carré S, Evrard Y, Jnoff E, et al. Discovery of heterocyclic nonacetamide synaptic vesicle protein 2A (SV2A) ligands with single-digit nanomolar potency: opening avenues towards the first SV2A positron emission tomography (PET) ligands. ChemMedChem. 2014;9:693-8.

217. Koole M, van Aalst J, Devrome M, Mertens N, Serdons K, Lacroix B, et al. Quantifying SV2A density and drug occupancy in the human brain using [11C]UCB-J PET imaging and subcortical white matter as reference tissue. Eur J Nucl Med Mol Imaging. 2018;46(2):396-406 1-11.

218. Radhakrishnan R, Skosnik P, Finnema S, Rotolo R, ForseliusBielen K, Creatura G, et al. In-vivo evidence of decreased synaptic density in schizophrenia: a [11C]UCB-J PET imaging study. Biol Psychiatry. 2017;81:S389.

219. Zhu H, Paul IA, McNamara M, Redmond A, Nowak G, Piletz JE. Chronic imipramine treatment upregulates IR2-imidazoline receptive sites in rat brain. Neurochem Int. 1997;30:101-7.

220. Nutt DJ, French N, Handley S, Hudson A, Husbands S, Jackson $\mathrm{H}$, et al. Functional studies of specific imidazoline-2 receptor ligands. Ann N Y Acad Sci. 1995;763:125-39.

221. García-Sevilla JA, Escribá PV, Walzer C, Bouras C, Guimón J. Imidazoline receptor proteins in brains of patients with Alzheimer's disease. Neurosci Lett. 1998;247:95-8.

222. Sastre M, Ventayol P, García-Sevilla JA. Decreased density of I2imidazoline receptors in the postmortem brain of heroin addicts. Neuroreport. 1996;7:509-12.

223. Sastre M, García-Sevilla JA. Densities of I2-imidazoline receptors, $\alpha 2$-adrenoceptors and monoamine oxidase B in brains of suicide victims. Neurochem Int. 1997;30:63-72.

224. Reynolds GP, Boulton RM, Pearson SJ, Hudson AL, Nutt DJ. Imidazoline binding sites in Huntington's and Parkinson's disease putamen. Eur J Pharmacol. 1996;301:R19-21.

225. Bonivento D, Milczek EM, McDonald GR, Binda C, Holt A, Edmondson DE, et al. Potentiation of ligand binding through cooperative effects in monoamine oxidase B. J Biol Chem. 2010;285:36849-56.

226. Kawamura K, Shimoda Y, Yui J, Zhang Y, Yamasaki T, Wakizaka $\mathrm{H}$, et al. A useful PET probe [11C]BU99008 with ultra-high specific radioactivity for small animal PET imaging of I2-imidazoline receptors in the hypothalamus. Nucl Med Biol. 2017;45:1-7.

227. Pillai RLI, Tipre DN. Metabotropic glutamate receptor 5 - a promising target in drug development and neuroimaging. Eur J Nucl Med Mol Imaging. 2016;43:1151-70.

228. Dalfó E, Albasanz JL, Martin M, Ferrer I. Abnormal metabotropic glutamate receptor expression and signaling in the cerebral cortex in diffuse Lewy body disease is associated with irregular alphasynuclein/phospholipase C (PLCbeta1) interactions. Brain Pathol. 2004;14:388-98. 
229. Matosin N, Fernandez-Enright F, Lum JS, Engel M, Andrews JL, Gassen NC, et al. Molecular evidence of synaptic pathology in the CA1 region in schizophrenia. NPJ Schizophr. 2016;2:16022.

230. Ayoub MA, Angelicheva D, Vile D, Chandler D, Morar B, Cavanaugh JA, et al. Deleterious GRM1 mutations in schizophrenia. PLoS One. 2012;7:e32849.

231. Cho HP, Garcia-Barrantes PM, Brogan JT, Hopkins CR, Niswender CM, Rodriguez AL, et al. Chemical modulation of mutant mGlu1 receptors derived from deleterious GRM1 mutations found in schizophrenics. ACS Chem Biol. 2014;9:2334-46.

232. Dravolina OA, Zvartau E, Danysz W, Bespalov AY. mGlu1 receptor as a drug target for treatment of substance use disorders: time to gather stones together? Psychopharmacology. 2017;234:1333-45.

233. Shannon HE, Peters SC, Kingston AE. Anticonvulsant effects of LY456236, a selective mGlu1 receptor antagonist. Neuropharmacology. 2005;49:188-95.

234. Jeffrey M. Schkeryantz JM, Kingston AE, Johnson MP. Prospects for metabotropic glutamate 1 receptor antagonists in the treatment of neuropathic pain. 2007;

235. Belozertseva I, Kos T, Popik P, Danysz W, Bespalov A. Antidepressant-like effects of mGluR1 and mGluR5 antagonists in the rat forced swim and the mouse tail suspension tests. Eur Neuropsychopharmacol. 2007;17:172-9.

236. Ossowska K, Wardas J, Pietraszek M, Konieczny J, Wolfarth S. The striopallidal pathway is involved in antiparkinsonian-like effects of the blockade of group I metabotropic glutamate receptors in rats. Neurosci Lett. 2003;342:21-4.

237. Lavreysen H, Wouters R, Bischoff F, Nóbrega Pereira S, Langlois $\mathrm{X}$, Blokland S, et al. JNJ16259685, a highly potent, selective and systemically active mGlu 1 receptor antagonist. Neuropharmacology. 2004;47:961-72.

238. Yamasaki T, Fujinaga M, Yui J, Wakizaka H, Ohya T, Nengaki N, et al. Improved visualization and specific binding for metabotropic glutamate receptor subtype 1 (mGluR1) using [11C]ITMM with ultra-high specific activity in small-animal PET. PLoS One. 2015;10:e0130006.

239. Ghitza UE. Human brain imaging of opioid receptors. Imaging Hum Brain Heal Dis. 2014 [cited 2018 Jun 18]. p. 81-98.

240. Weerts EM, Kim YK, Wand GS, Dannals RF, Lee JS, Frost JJ, et al. Differences in $\delta$ - and $\mu$-opioid receptor blockade measured by positron emission tomography in naltrexone-treated recently abstinent alcohol-dependent subjects. Neuropsychopharmacology. 2008;33:653-65.

241. Lohith TG, Zoghbi SS, Morse CL, Araneta MF, Barth VN, Goebl $\mathrm{NA}$, et al. Brain and whole-body imaging of nociceptin/orphanin FQ peptide receptor in humans using the PET ligand 11C-NOP1A. J Nucl Med. 2012;53:385-92.

242. Peckys D, Landwehrmeyer G. Expression of mu, kappa, and delta opioid receptor messenger RNA in the human CNS: a 33P in situ hybridization study. Neuroscience. 1999;88:1093-135.

243. Lalanne L, Ayranci G, Kieffer BL, Lutz P-E. The kappa opioid receptor: from addiction to depression, and back. Front psychiatry. 2014;5:170

244. Chavkin C. The therapeutic potential of K-opioids for treatment of pain and addiction. Neuropsychopharmacology. 2011;36:369-70.

245. Land BB, Bruchas MR, Schattauer S, Giardino WJ, Aita M, Messinger D, et al. Activation of the kappa opioid receptor in the dorsal raphe nucleus mediates the aversive effects of stress and reinstates drug seeking. Proc Natl Acad Sci U S A. 2009;106:19168-73.

246. Cai Z, Li S, Pracitto R, Navarro A, Shirali A, Ropchan J, et al. Fluorine-18-labeled antagonist for PET imaging of kappa opioid receptors. ACS Chem Neurosci. 2017;8:12-6.

247. Mathieu-Kia AM, Fan LQ, Kreek MJ, Simon EJ, Hiller JM. Mu-, delta- and kappa-opioid receptor populations are differentially altered in distinct areas of postmortem brains of Alzheimer's disease patients. Brain Res. 2001;893:121-34.

248. Schoultz BW, Hjornevik T, Willoch F, Marton J, Noda A, Murakami Y, et al. Evaluation of the kappa-opioid receptor-selective tracer [11C]GR103545 in awake rhesus macaques. Eur J Nucl Med Mol Imaging. 2010;37:1174-80.

249. Mallik A, Chanda ML, Levitin DJ. Anhedonia to music and muopioids: evidence from the administration of naltrexone. Sci Rep. 2017;7:41952.

250. Wirth A, Holst K, Ponimaskin E. How serotonin receptors regulate morphogenic signalling in neurons. Prog Neurobiol. 2017;151:35-56.

251. Hazari PP, Pandey A, Chaturvedi S, Mishra AK. New trends and current status of positron-emission tomography and singlephoton-emission computerized tomography radioligands for neuronal serotonin receptors and serotonin transporter. Bioconjug Chem. 2017;28:2647-72.

252. Adams KH, Hansen ES, Pinborg LH, Hasselbalch SG, Svarer C, Holm S, et al. Patients with obsessive-compulsive disorder have increased 5-HT2A receptor binding in the caudate nuclei. Int J Neuropsychopharmacol. 2005;8:391-401.

253. Haugbøl S, Pinborg LH, Regeur L, Hansen ES, Bolwig TG, Nielsen FÅ, et al. Cerebral 5-HT2A receptor binding is increased in patients with Tourette's syndrome. Int J Neuropsychopharmacol. 2007;10:245.

254. Erritzoe D, Rasmussen H, Kristiansen KT, Frokjaer VG, Haugbol S, Pinborg L, et al. Cortical and subcortical 5-HT2A receptor binding in neuroleptic-naive first-episode schizophrenic patients. Neuropsychopharmacology. 2008;33:2435-41.

255. Santhosh L, Estok KM, Vogel RS, Tamagnan GD, Baldwin RM, Mitsis EM, et al. Regional distribution and behavioral correlates of 5-HT2A receptors in Alzheimer's disease with [18F]deuteroaltanserin and PET. Psychiatry Res Neuroimaging. 2009; 173:212-7.

256. Song J, Hanniford D, Doucette C, Graham E, Poole MF, Ting A, et al. Development of homogeneous high-affinity agonist binding assays for 5-HT 2 receptor subtypes. Assay Drug Dev Technol. 2005;3:649-59.

257. Yang K-C, Stepanov V, Martinsson S, Ettrup A, Takano A, Knudsen GM, et al. Fenfluramine reduces [11C]Cimbi-36 binding to the 5-HT2A receptor in the nonhuman primate brain. Int J Neuropsychopharmacol. 2017;20:683-91.

258. Ettrup A, Hansen M, Santini MA, Paine J, Gillings N, Palner M, et al. Radiosynthesis and in vivo evaluation of a series of substituted 11C-phenethylamines as 5-HT2A agonist PET tracers. Eur J Nucl Med Mol Imaging. 2011;38:681-93.

259. Jørgensen CV, Jacobsen JP, Caron MG, Klein AB, Knudsen GM, Mikkelsen JD. Cerebral 5-HT2A receptor binding, but not mGluR2, is increased in tryptophan hydroxylase 2 decrease-offunction mice. Neurosci Lett. 2013;555:118-22.

260. Paterson LM, Kornum BR, Nutt DJ, Pike VW, Knudsen GM. 5HT radioligands for human brain imaging with PET and SPECT. Med Res Rev. 2013;33:54-111.

261. Janssen B, Vugts D, Windhorst A, Mach R, Janssen B, Vugts DJ, et al. PET imaging of microglial activation - beyond targeting TSPO. Molecules. 2018;23:607.

262. Tronel C, Largeau B, Santiago Ribeiro MJ, Guilloteau D, Dupont A-C, Arlicot N. Molecular targets for PET imaging of activated microglia: the current situation and future expectations. Int J Mol Sci $2017 ; 18$.

263. Marques TR, Ashok AH, Pillinger T, Veronese M, Turkheimer FE, Dazzan P, et al. Neuroinflammation in schizophrenia: metaanalysis of in vivo microglial imaging studies. Psychol Med. 2018: $1-11$.

264. Apolloni S, Amadio S, Parisi C, Matteucci A, Potenza RL, Armida $\mathrm{M}$, et al. Spinal cord pathology is ameliorated by $\mathrm{P} 2 \mathrm{X} 7$ 
antagonism in a SOD1-mutant mouse model of amyotrophic lateral sclerosis. Dis Model Mech. 2014;7:1101-9.

265. Bhattacharya A. Recent advances in CNS P2X7 physiology and pharmacology: focus on neuropsychiatric disorders. Front Pharmacol. 2018;9:30.

266. Janssen B, Vugts DJ, Funke U, Spaans A, Schuit RC, Kooijman E, et al. Synthesis and initial preclinical evaluation of the $\mathrm{P} 2 \mathrm{X}_{7}$ receptor antagonist [ ${ }^{11} \mathrm{C}$ ]A-740003 as a novel tracer of neuroinflammation. J Label Compd Radiopharm. 2014;57:509-16.

267. Wu C, Zhao Y, Xiao X, Fan Y, Kloc M, Liu W, et al. Graftinfiltrating macrophages adopt an M2 phenotype and are inhibited by purinergic receptor $\mathrm{P} 2 \mathrm{X} 7$ antagonist in chronic rejection. Am J Transplant. 2016;16:2563-73.

268. de Torre-Minguela C, Barberà-Cremades M, Gómez AI, MartínSánchez F, Pelegrín P. Macrophage activation and polarization modify P2X7 receptor secretome influencing the inflammatory process. Sci Rep. 2016;6:22586.

269. Griebel G, Stemmelin J, Lopez-Grancha M, Fauchey V, Slowinski F, Pichat P, et al. The selective reversible FAAH inhibitor, SSR 411298, restores the development of maladaptive behaviors to acute and chronic stress in rodents. Sci Rep. 2018;8:2416.

270. Cryer B, Feldman M. Cyclooxygenase-1 and cyclooxygenase-2 selectivity of widely used nonsteroidal anti-inflammatory drugs. Am J Med. 1998;104:413-21.

271. Shults CW. Mitochondrial dysfunction and possible treatments in Parkinson's disease - a review. Mitochondrion. 2004:4:641-8.

272. Rodenburg RJ. Mitochondrial complex I-linked disease. Biochim Biophys Acta Bioenerg. 1857;2016:938-45.

273. Calnon DA. Will $18 \mathrm{~F}$ flurpiridaz replace 82 rubidium as the most commonly used perfusion tracer for PET myocardial perfusion imaging? J Nucl Cardiol. 2018:1-3.

274. Falkenberg KJ, Johnstone RW. Histone deacetylases and their inhibitors in cancer, neurological diseases and immune disorders. Nat Rev Drug Discov. 2014;13:673-91.

275. Tago T, Toyohara J. Advances in the development of PET ligands targeting histone deacetylases for the assessment of neurodegenerative diseases. Mol A J Synth Chem Nat Prod Chem. 2018;23: E300.

276. Schröder S, Wenzel B, Deuther-Conrad W, Scheunemann M, Brust P. Novel radioligands for cyclic nucleotide phosphodiesterase imaging with positron emission tomography: an update on developments since 2012. Molecules. 2016;21:650.

277. Francis SH, Blount MA, Corbin JD. Mammalian cyclic nucleotide phosphodiesterases: molecular mechanisms and physiological functions. Physiol Rev. 2011;91:651-90.

278. Andrés JI, De Angelis M, Alcázar J, Celen S, Bormans G. Recent advances in positron emission tomography (PET) radiotracers for imaging phosphodiesterases. Curr Top Med Chem. 2012;12: 1224-36.

279. Fernández-Fernández D, Rosenbrock H, Kroker KS. Inhibition of PDE2A, but not PDE9A, modulates presynaptic short-term plasticity measured by paired-pulse facilitation in the CA1 region of the hippocampus. Synapse. 2015;69:484-96.

280. Gomez L, Breitenbucher JG. PDE2 inhibition: potential for the treatment of cognitive disorders. Bioorg Med Chem Lett. 2013;23:6522-7.

281. Abdel-Magid AF, Applicant Y. Potential treatment of cognitive impairment in schizophrenia by phosphodiesterase 2 (PDE2) inhibitors. 2016

282. Marques TR, Natesan S, Niccolini F, Politis M, Gunn RN, Searle GE, et al. Phosphodiesterase 10A in schizophrenia: a PET study using [ ${ }^{11}$ C]IMA107. Am J Psychiatry. 2016;173:714-21.

283. Fazio P, Schain M, Mrzljak L, Amini N, Nag S, Al-Tawil N, et al. Patterns of age related changes for phosphodiesterase type-10A in comparison with dopamine D2/3 receptors and sub-cortical volumes in the human basal ganglia: A PET study with 18F-MNI-659 and $11 \mathrm{C}$-raclopride with correction for partial volume effect. Neuroimage. 2017;152:330-9.

284. Boileau I, Mansouri E, Williams B, Le Foll B, Rusjan P, Mizrahi $\mathrm{R}$, et al. Fatty acid amide hydrolase binding in brain of cannabis users: imaging with the novel radiotracer [11C]CURB. Biol Psychiatry. 2016;80:691-701.

285. Peled S, Sade D, Bram Y, Porat Z, Kreiser T, Mimouni M, et al. Single cell imaging and quantification of TDP-43 and $\alpha$-synuclein intercellular propagation. Sci Rep. 2017;7:544.

286. Nutt D. GABAA receptors: subtypes, regional distribution, and function. J Clin Sleep Med. 2006;2:S7-11.

287. Hargreaves RJ, Rabiner EA. Translational PET imaging research. Neurobiol Dis. 2014;61:32-8.

288. Laruelle M. Imaging synaptic neurotransmission with in vivo binding competition techniques: a critical review. J Cereb Blood Flow Metab. 2000;20:423-51.

289. Egerton A, Mehta MA, Montgomery AJ, Lappin JM, Howes OD, Reeves SJ, et al. The dopaminergic basis of human behaviors: a review of molecular imaging studies. Neurosci Biobehav Rev. 2009;33:1109-32.

290. Colasanti A, Searle GE, Long CJ, Hill SP, Reiley RR, Quelch D, et al. Endogenous opioid release in the human brain reward system induced by acute amphetamine administration. Biol Psychiatry. 2012;72:371-7.

291. Gallezot J-D, Esterlis I, Bois F, Zheng M-Q, Lin S-F, Kloczynski $\mathrm{T}$, et al. Evaluation of the sensitivity of the novel $\alpha 4 \beta 2 *$ nicotinic acetylcholine receptor PET radioligand ${ }^{18} \mathrm{~F}-(-)$-NCFHEB to increases in synaptic acetylcholine levels in rhesus monkeys. Synapse. 2014;68:556-64.

292. Yang K-C, Takano A, Halldin C, Farde L, Finnema SJ. Serotonin concentration enhancers at clinically relevant doses reduce [11C]AZ10419369 binding to the 5-HT1B receptors in the nonhuman primate brain. Transl Psychiatry. 2018;8:132.

Publisher's note Springer Nature remains neutral with regard to jurisdictional claims in published maps and institutional affiliations. 